UC-15

Issued: July 1982

LA- -9343

DE82 021849

\title{
Producticn of Actinide Isotopes in Simulated PWR Fuel and Their Influence on Inherent Neutron Emission
}

\author{
G. E. Bosler* \\ J. R. Phillips \\ W. B. Wilson \\ R. J. LaBauve \\ T. R. England
}

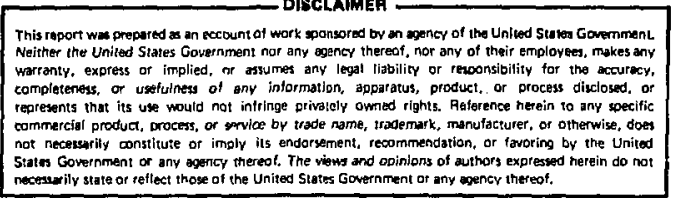

*International Atomic Energy Agency, Box 200, Vienna, AUSTRIA.
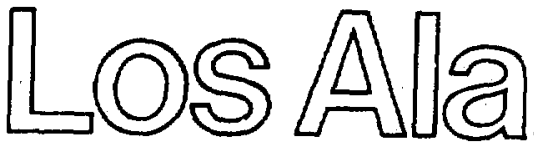

กิก)

Los Alamos National Laboratory Los Alamos, New Mexico 87545 
CONTENTS

ABSTRACT

I. INTRODUCTION . . . . . . . . . . . . . . . . . 1

II. TEST CASES . . . . . . . . . . . . . . . . . . 4 4

A. Calculational Data. . . . . . . . . . . . . 4

B. Detailed Power History vs Constant Power History . . . . 5

c. Sensitivity Studies . . . . . . . . . . . . . 7

III. ACTINIDE ISOTOPE PRODUCTION, DEPLETION, AND DECAY . • • • . 12

A. Uranium Isotopes . . . . . . . . . . . . . . 12

B. Neptuniam Isotopes . . . . . . . . . . . . . . 22

c. Plutonium Isotopes . . . . . . . . . . . . . . 22

D. Americium Isotopes . . . . . . . . . . . . . 41

E. Curium Isotopes . . . . . . . . . . . . . . . 49

IV. DATA ANALYSIS AND POTENTIAL APPLICATIONS . . . . . . . . 59

V. CORRELATIONS . . . . . . . . . . . . . . 75

VI. SOURCES OF NEUTRONS IN IRRADIATED FUEL MATERIAL . . . . . . 83

VII. PARAMETERS AFFECTING NEUTRON SOURCES . . . . . . . . . . 88

VIII. CORRELATION BETWEEN SOURCE NEUTRON RATES AND FISSILE CONTENT • 95

IX. CONCLUSIONS . . . . . . . . . . . . . . . . . . 98

APPENDIX: DEVELOPMENT AND VALIDATION OF CALCULATIONAL TECHNIQUES • . 99

REFERENCES . . . . . . . . . . . . . . . . . . . 108 
PRODUCTION OF ACTINIDE ISOTOPES IN SIMULATED PWR FUEL AND THEIR INFLUENCE ON INHERENT NEUTRON EMISSION

\author{
by
}

G. E. Bosler, J. R. Phillips, W. B. Wilson,

R. J. LaBauve, and T. R. England

\begin{abstract}
This report describes calculations that examine the sensitivity of actinide isotopes to various reactor parameters. The impact of actinide isotope build-up, depletion, and decay on the neutron source rate in a spent-fuel assembly is determined, and correlations between neutron source rates and spent-fuel characteristics such as exposure, fissile content, and plutonium content are established. The application of calculations for evaluating experimental results is discussed.
\end{abstract}

\title{
I. INTRODUCTIION
}

Nondestructive assay (NDA) techniques are being developed to verify characteristics of irradiated fuel assemblies. Measurable, inherent attributes of irradiated fuel assemblies include gamma rays primarily from fission-product isotopes and neutrons associated almost entirely with the decay of actinide isotopes. Although these radiation signals are easily detected, interpreting the acquired data can be difficult.

Detection systems for monitoring irradiated fuel assemblies are simple and basic. Possible complexities in the equipment occur because the measurements must be made underwatex and (for safeguards inspector use) the instruments must be portable. Ion chambers and high-resolution ganma spectrometry (HRGS) are 
generally used for detecting gamma-ray signals. For neutron detection, fission chambers are used. Of these three types of detector systems, only HRGS has resolvable signals that can be related directly to spent-fuel characteristics (in this case, the concentrations of specific fission-product isotopes). The other detectors monitor gross signals, which must be correlated to various irradiated fuel attributes to obtain meaningful information.

In this report, we analyze neutron signals inherent to irradiated fuel assemblies. Passive neutron emission rates from irradiated fuel assemblies have been measured for limited exposures and cooling times. ${ }^{1-3}$ Although these measurements demonstrate feasibility, questions exist about the interpretation of the results. To investigate the applicability of such measurements, we need to understand the neutron emission characteristics of irradiated fuel. Because neutron characteristics depend on the heavy-element actinide inventories, calculations are used to predict the build-up, depletion, and decay of the neutron-producing isotopes and to determine the neutron source rates from these isotopes. The calculational models also are used to determine the sensitivity of the neutron emission rates to parameters of initial ${ }^{235} \mathrm{U}$ enrichment, fuel density, different exposure conditions, power levels, and irradiation histories.

These calculational techniques complement the limited experimental results. They are used to predict trends and parameter sensitivities that should be investigated experimentally to understand fully the effects of various irradiated fuel parameters on the measured neutron signals.

The production and depletion of actinide isotopes were calculated for a typical pressurized-water-reactor (PWR) fuel assembly using core characteristics from the H. B. Robinson-2 (HBR-2) facility (Westinghouse 700-MWe reactor). CINDER 2, an improved version of the single-point depletion code EPRI-CINDER ${ }^{4}$ and associated data library, ${ }^{5}$ performed these calculations. Flux and shielded cross-section data were obtained from the EPRI-CELL code. 6

Neutron signals inherent to irradiated fuel depend on the fuel exposure: ${ }^{\dagger}$ the neutron source rate increases with exposure. To correlate the experimentally obtained neutron count rates with operator-declared exposure values, a

FThe term "exposure" has units of megawatt days (thermal) per metric ton of initial uranium, whereas the term "burnup" has units of atom per cent fission. Al.though these terms generally are used interchangeably, in this report they will be used in their proper context. These quantitieg are discussed in the Appendix. 
power function relation typically has been used: count rate $=\alpha$ * (exposure) $)^{B}$, where $\alpha$ is a scaling factor and $\beta$ ranges between 3 and 4 , depending on the type of fuel assemblies measured. Once a relationship is established for a given fuel type, the neutron count rate can be used to predict the exposures of other fuel assemblies with similar irradiation histories. Results from predicting exposures vary. Generally, the established relationship is valid for a given set of fuel assembly measurements, and exposures of "unknown" assemblies are determined with accuracies of $5 \%$ or better. This technique's main problem is lack of a universal power function relationship that satisfies all fuel types and measurement conditions. Typically, the power function will vary, depending on generic fuel type and possibly on boron in the cooling water. Within a generic reactor fuel, variations also occur as a result of initial ${ }^{235} \mathrm{U}$ enrichment, clad material, proximity of control material, and power level. To establish applicable ranges and sensitivities, we want to identify those parameters having a significant impact on the power function relationship.

In addition to power function correlatiuns between neutron count rate and exposure, methods ${ }^{2}$ have been proposed that use neutron count rates to determine specific information, such as total plutonium and total fissile content in the fuel. These methods use correlations that provide quantitative information about the fuel assembly. Again, as with the power function relationship, these specific correlations have been evaluated calculationally to establish their validity and applicable ranges.

Although our analyses, which determine neutron source rates in irradiated fuel assemblies, predict source rate differences resulting from variations in basic fuel parameters, they do not predict actual detector response. The detector response may not be directly proportional to neutron source rate. Multiplication and self-shielding within the fuel materials and moderation in the water can affect the detector responses. To predict adequately the effects of such parameters on the detector response, transport calculations are required. with a specially adapted version ${ }^{7}$ of the neutron-photon Monte carlo code (MCNP), ${ }^{8}$ the fuel assembly and detector geometry can be modeled exactly. Fuel material specifications and neutron source rates for the transport calculations can be determined from the data assembled for this report. 


\section{TEST CASES}

The calculational model is based on a fuel assembly from the HBR-2 reactor (see the Appendix for details). The HBR-2 fuel is convenient to model for at least three reasons. First, the fuel is from a PWR, which is easier to analyze than other reactor types, such as a boiling-water reactor (BWR). In a PWR, flux gradients and spectral variations are minimal, resulting in uniform burnup in both the radial and axial directions. For BWRs, axial burnup can vary greatly because of control materials and differences in the void fraction from the boiling of water. Simple cell models can adequately analyze PWR, whereas more complicated models are needed to describe BWRs.

Second, destructive analysis data for direct comparisons with calculationally predicted quantities are available. 9 Such comparisons give confidence in the analytical techniques, the results obtained, and the overall ability to predict actual isotopic inventories in spent-fuel assemblies. For the HBR-2 fuel, uranium and plutonium isotopic concentrations were measured. Concentrations of the important neutron-producing curium isotopes were not measured destructively.

Finally, the 15 by 15 array of fuel pins in the HBR-2 assembly is typical of the PWR fuels widely used today. A detailed analysis of this fuel should be applicable to the fuel assemblies at many similar reactor facilities.

A. Calculational Data

The EPRI-CINDER data library, ${ }^{5}$ describing 46 actinide isotopes, contains all pertinent problem-independent data necessary in nuclide-inventory and aggregate-property calculations for many light-water-reactor (LWR) fuel irradiations. These data include four-energy-group abscrption cross sections and branching fractions for multiple paths in radioactive decay and transmutation of fission products. Also included are similar basic nuclear data for actinide nuclides produced by the transmutation of the initially present heavy-metal nuclides and their absorption and decay products. Four-group unshielded actinide cross sections complete the nuclear data library. When using this library, a problem can be completely specified by defining the power history, temporal four-group neutron flux spectrum, and initial nuclide inventory.

Four-group unshielded cross sections in the basic EPRI-CINDER library have been produced from cross-section data in Evaluated Nuclear Data Files (INDF)/ 
B-IV or preliminary ENDE/B- $\mathrm{V}^{10}$ by a representative weighting spectrum. More accurate four-group shielded cross-section data can be entered as problemdependent data to override the basic library data. For calculatjons in this report, four-group cross sections for principal contributing actinides $\left({ }^{234-238} \mathrm{U},{ }^{239-242} \mathrm{Pu}\right)$ were obtained from the EPRI-CELI code ${ }^{6}$ for each time step. In this manner, effects such as initial enrichment, exposure, poisons, water-to-metal ratio, rod pitch, and other heterogeneity considerations can be modeled accurately.

B. Detailed Power History vs Constant Power History

For the reference HBR-2 reactor fuel, Table I compares the destructively analyzed data and calculational results of the Appendix. Both calculational sets in Table I use a detailed power history to represent HBR-2 operating conditions. In the first set, the reported sample power listing is scaled so the calculated burnup (at.o fission) is identical to the value obtained destructively. This calculation represents the best attempt to match the destructive data. The second set of calculational data was selected from our constant power calculations, and no attempt was made to duplicate reported power variations. The first set has smaller errors than the second set when compared to the destructive data. "Eor both sets, the largest disagreements occur for the single uranium $\left({ }^{234} \mathrm{U}\right)$ isotope and two plutonium $\left({ }^{238} \mathrm{Pu}\right.$ and $\left.{ }^{242} \mathrm{Pu}\right)$ isotopes, which have the smallest concentrations. All other discrepancies are within 6.18 .

For our parametric studies, the exposure range of the detailed power history case in Table I extends only to $31.19 \mathrm{GWd} / \mathrm{tU}$. Fuel similar to the HBR-2 fuel has been discharged from PWR facilities with exposures greater than $40 \mathrm{GWd} / \mathrm{tU}$ under the program to improve uranium utilization in power reactors. Therefore, calculational results are needed for exposures higher than those obtained from the detailed power history case. For our studies, irradiations for exposure levels slightly above $50 \mathrm{GWd} / \mathrm{tU}$ are simulated. Such high exposures may become common as utilities increase fuel burnup to maxinize uranium utilization. The exposure range of 30 to $50 \mathrm{GWd} / \mathrm{tU}$ is extremely interesting with respect to the rapid increase in the production of the curium isotopes and their subsequent effects on the neutron source terms.

Because the detailed power history case cannot be used as a reference for high exposures, another case is needed. For convenience, a constant power 
TABIE I

MEASURED AND CALCULATED ISOTOPIC RATIOS FOR A 506.75-DAY COOLING TIME

\begin{tabular}{|c|c|c|c|c|c|}
\hline Quantity & $\begin{array}{l}\text { Destructively } \\
\text { Measureda } \\
\text { Value }\end{array}$ & $\begin{array}{l}\text { Detailed Pow } \\
\text { Calculated } \\
\text { Value }\end{array}$ & $\begin{array}{l}\frac{\text { er History }}{\text { Difference }} \\
(8) \\
\end{array}$ & $\begin{array}{l}\text { Constant Powe } \\
\text { CalculatedC } \\
\text { Value }\end{array}$ & $\begin{array}{c}\text { er History } \\
\begin{array}{c}\text { Difference } \\
(8)\end{array} \\
\end{array}$ \\
\hline $\begin{array}{l}\text { Burnup at.o } \\
\text { Fission }\end{array}$ & 3.221 & 3.221 & +0.00 & 3.234 & +0.40 \\
\hline $\begin{array}{l}\text { Exposure } \\
\text { GWd/tU }\end{array}$ & 30.92 & 31.19 & +0.89 & 31.32 & +1.29 \\
\hline $234 \mathrm{U} / \mathrm{U}$ & 0.00014 & 0.00012 & -12.81 & 0.00012 & -12.81 \\
\hline $235_{U} / U$ & 0.00612 & 0.00588 & -3.84 & 0.00585 & -4.41 \\
\hline${ }^{236} \mathrm{U} / \mathrm{U}$ & 0.00352 & 0.00357 & +1.52 & 0.00357 & +1.52 \\
\hline $238_{\mathrm{U} / \mathrm{U}}$ & 0.99022 & 0.99043 & +0.02 & 0.99047 & +0.03 \\
\hline $238^{\mathrm{Pu} / \mathrm{Pu}}$ & 0.01676 & 0.01452 & $-13 \cdot 35$ & 0.01462 & $-12 \cdot 77$ \\
\hline $239^{\mathrm{Pu} / \mathrm{Pu}}$ & 0.54261 & 0.53966 & -0.54 & 0.53877 & -0.71 \\
\hline $240 \mathrm{Pu} / \mathrm{Pu}$ & 0.25101 & 0.24002 & $-4 \cdot 38$ & 0.24018 & -4.31 \\
\hline $241_{\mathrm{Pu} / \mathrm{Pu}}$ & 0.12998 & 0.13772 & +5.95 & 0.13791 & 6.10 \\
\hline $242 \mathrm{Pu} / \mathrm{Pu}$ & 0.05964 & 0.06807 & +11.41 & 0.06852 & 14.89 \\
\hline${ }^{239} \mathrm{Pu} /{ }^{238} \mathrm{U}$ & 0.00518 & 0.00496 & $-4 \cdot 28$ & 0.00496 & -4.28 \\
\hline $148_{\mathrm{Nd}} / 238_{\mathrm{U}}$ & 0.00057 & 0.00059 & +3.96 & 0.00059 & +3.96 \\
\hline
\end{tabular}


history is more desirable than a detailed power history, provided that the constant power history adequately predicts isotopic build-up and depletion. Table II compares results from the detailed power history case and three constant power histories, each with a different linear power level (watts per unit rod length). Atom density ratios are shown for compaxison with those in Table $I$, and mass ratios are shown because most data analyzed in this report are mass values instead of atom densities. Results are reported for approximately the same burnups. To accomplish this, the total fluence must be the same; that is, cases with lower power levels have longer irradiation periods than do cases with higher power levels.

Table II indicates that a constant power level is adequate for predicting isotopic build-up and depletion, particularly for long-lived isotopes. For short-lived isotopes such as ${ }^{242} \mathrm{Cm}$ (162.9-day half-life), a detailed power history is needed for accurate results. Such detail, however, is unnecessary if the assembly's cooling time is long compared to the half-life of the shortlived isotope.

\section{c. Sensitivity Studies}

A particular actinide isotope $i$ may, in general, be produced as a neutron transmutation reaction product of each $j$ isotope or as a daughter in the radioactive decay of each $k$ radioisotope. In turn, isotope $i$ may be depleted by its own radioactive decay or neutron-induced fission and transmutation. Using some G neutron energy groups to describe the neutron absorption reactions, Eq. (1) gives the build-up and depletion of isotope $i$.

$$
\frac{d N_{i}}{d t}=\sum_{j=1}^{J} N_{j} f_{j i} \sum_{g=1}^{G}\left(\sigma_{a j}^{g}-\sigma_{f j}^{g}\right) \phi_{g}+\sum_{k=1}^{K} N_{k} \lambda_{k} f_{k i}-N_{i} \lambda_{i}-N_{i} \sum_{g=1}^{G} \sigma_{a i}^{g} \phi_{g},
$$

\footnotetext{
where $\quad N_{i}=$ number of isotope $i$ atoms ;

$\mathrm{N}_{j}$ = number of isotope $j$ atoms, which, through neutron transmutation, may become nuclide $i$;

$\mathrm{N}_{k}$ = number of isotore $\mathrm{k}$ atoms, which, through radioactive decay, may produce as a daughter the isotope $i$;
} 
TABLE II

CALCULATED RATIOS AT TIME OF DISCHARGE FROM THE REACTOR

\begin{tabular}{|c|c|c|c|c|c|c|c|c|}
\hline & & & & & nstant Pow & History & & \\
\hline & Detailed & Power History & $\begin{array}{l}\text { Linear Po } \\
(160 \mathrm{~W} / \mathrm{cm}\end{array}$ & ver & $\begin{array}{l}\text { Linear } P_{0} \\
1200 \mathrm{w} / \mathrm{cm} \\
\end{array}$ & rer & $\begin{array}{l}\text { Linear Por } \\
(240 \mathrm{~W} / \mathrm{cm}\end{array}$ & er \\
\hline Quantity & $\begin{array}{l}\text { Atom } \\
\text { Density } \\
\text { Ratio }\end{array}$ & $\begin{array}{l}\text { Mass } \\
\text { Ratio }\end{array}$ & $\begin{array}{l}\text { Aton } \\
\text { Density } \\
\text { Ratio } \\
\end{array}$ & $\begin{array}{l}\text { Mass } \\
\text { Ratio } \\
\end{array}$ & $\begin{array}{l}\text { Atom } \\
\text { Density } \\
\text { Power } \\
\end{array}$ & $\begin{array}{l}\text { Mass } \\
\text { Ratio }\end{array}$ & $\begin{array}{l}\text { Atom } \\
\text { Density } \\
\text { Ratio } \\
\end{array}$ & $\begin{array}{l}\text { Mass } \\
\text { Ratio } \\
\end{array}$ \\
\hline Burnup & & & & & & & & \\
\hline at.z Eission & $3 \cdot 324$ & 3.234 & 3.254 & 3.254 & 3.253 & 3.253 & 3.251 & 3.251 \\
\hline Exposure & & & & & & & & \\
\hline $\mathrm{GWd} / \mathrm{tU}$ & 31.32 & 31.32 & 31.51 & 31.51 & 31.51 & 31.51 & 31.49 & 31.49 \\
\hline${ }^{234} \mathrm{U} / \mathrm{U}$ & 0.00012 & 0.00012 & 0.00012 & 0.00012 & 0.00012 & 0.00012 & 0.00012 & 0.00012 \\
\hline $235 \mathrm{U} / \mathrm{U}$ & 0.00585 & 0.00577 & 0.00579 & 0.00571 & 0.00580 & 0.00573 & 0.00582 & 0.00575 \\
\hline${ }^{236} \mathrm{U} / \mathrm{U}$ & 0.00357 & 0.00354 & 0.00357 & 0.00354 & 0.00357 & 0.00354 & 0.00357 & 0.00354 \\
\hline${ }^{238} \mathrm{v} / \mathrm{U}$ & 0.99047 & 0.99056 & 0.99032 & 0.99062 & 0.99051 & 0.99061 & 0.99049 & 0.99059 \\
\hline $238 \mathrm{Pu} / \mathrm{Pu}$ & 0.01318 & 0.01309 & 0.01330 & 0.01322 & 0.01300 & 0.01292 & 0.01254 & 0.01245 \\
\hline${ }^{239} \mathrm{Pu} / \mathrm{Pu}$ & 0.52981 & 0.52820 & 0.52966 & 0.52804 & 0.52990. & 0.52828 & .0 .53036 & 0.52873 \\
\hline $240 \mathrm{Pu} / \mathrm{Pu}$ & 0.24075 & 0.24102 & 0.23857 & 0.23884 & 0.23834 & 0.23860 & 0.23796 & $0.23 B 23$ \\
\hline${ }^{241} \mathrm{Pu} / \mathrm{Pu}$ & 0.14756 & 0.14834 & 0.14859 & 0.14938 & 0.14896 & 0.14975 & 0.14953 & 0.15032 \\
\hline $242 \mathrm{Pu} / \mathrm{Pu}$ & 0.06868 & 0.06933 & 0.06985 & 0.07052 & 0.06977 & 0.07044 & 0.06959 & 0.07025 \\
\hline${ }^{239}{ }_{\mathrm{Pu} /}{ }^{238_{\mathrm{U}}}$ & 0.00487 & 0.00489 & 0.00487 & 0.00489 & 0.00488 & 0.00490 & 0.00490 & 0.00492 \\
\hline${ }^{148} \mathrm{Na} /{ }^{238} \mathrm{U}$ & 0.00059 & 0.00037 & 0.00060 & 0.00037 & 0.00060 & 0.00037 & 0.00060 & 0.00037 \\
\hline $242 \mathrm{Cm} /{ }^{239} \mathrm{Pu}$ & 0.00319 & 0.00323 & 0.00291 & 0.00295 & 0.00278 & 0.00282 & 0.00255 & 0.00258 \\
\hline${ }^{244} \mathrm{Cr} /{ }^{239} \mathrm{Pu}$ & 0.00713 & $0.0072 B$ & 0.00739 & 0.00754 & 0.00738 & 0.00753 & 0.00735 & 0.00750 \\
\hline
\end{tabular}

avalues differ from those in Table I because Table I data were calculated for a 506.75-day cooling time. 


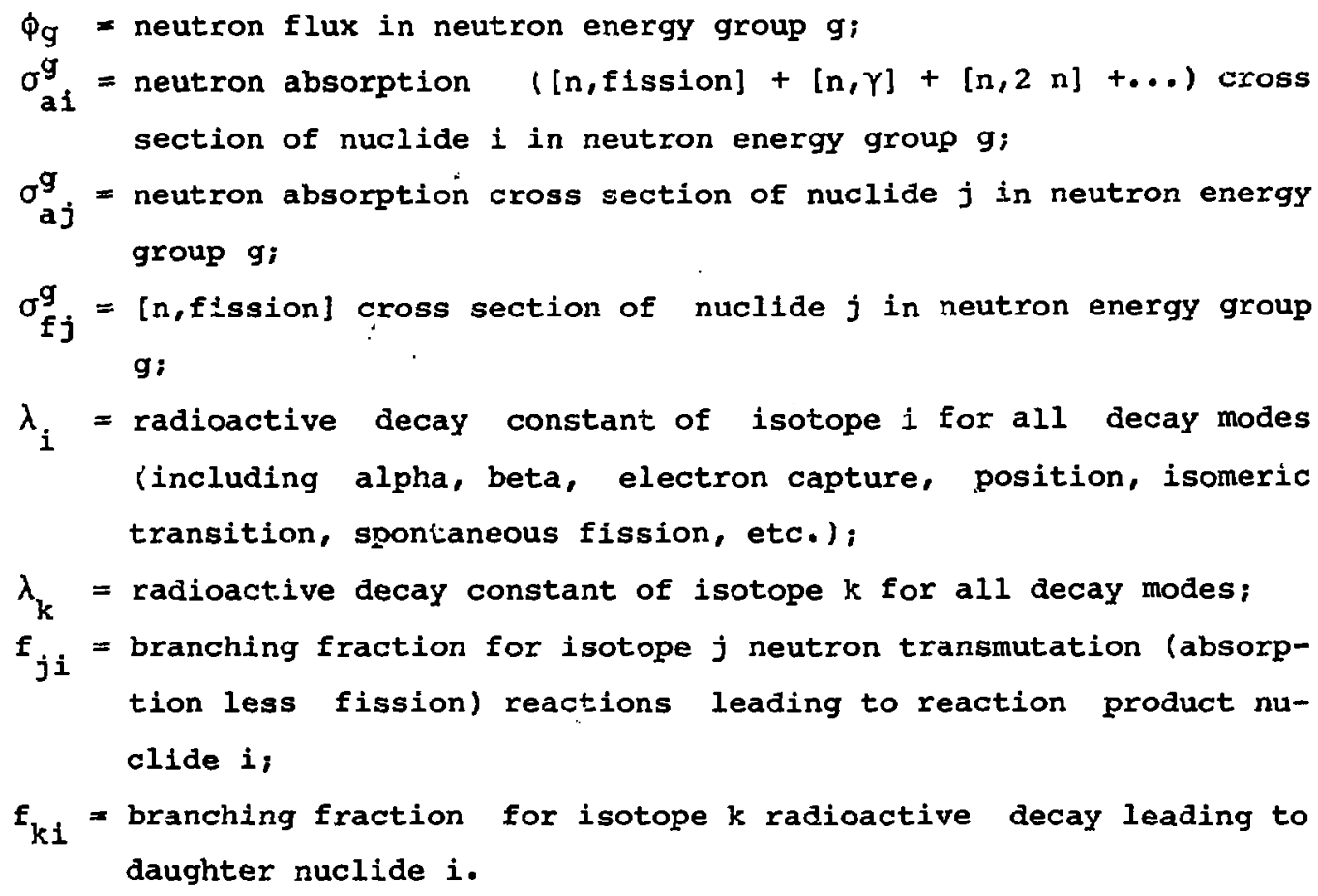

Tr:a solution of nuclide inventories defined by the set of coupled differential Eqs. (1) are obtained by CINDER 2 using a library of basic nuclear data and four-group ( $G=4$ ) neutron reaction cross sections, as well as various parameters defining the fuel's physical and irradiation environment. We have selected four of the latter that can affect isotope inventories and, thus, the measurable signatures of spent-fuel assemblies. These are

- initial ${ }^{235} \mathrm{U}$ enrichment,

- initial $\mathrm{UO}_{2}$ fuel mass density,

- power level, and

- irradiation history.

For each of these sensitivity studies, one of the reference parameters in Table III was varied over an applicable range, while the remaining parameters were kept constant. Altering each parameter will affect the three terms in Eq. (1) in a unique manner that depends on the cross section of the specific actinide and its precursors as well as on the decay constants of the $\mathrm{N}_{i}$ and $N_{k}$ isotopes. The study shows if a particular measurable signature is sensitive to various parameters.

This study serves two purposes. First, for best results in measuring signal. from an irradiated assembly, measurable signals should be as insensitive as possible to reactor operating conditions. By performing the sensitivity 
TABLE III

REFERENCE PWR PARAMETERS

Linear power level

$\mathrm{UO}_{2}$

Initial $235 \mathrm{U}$ enrichment

Irradiation history
$200 \mathrm{w} / \mathrm{cm}$

90.814 \&TD

2.56 wt8

Continuous $200 \mathrm{w} / \mathrm{cm}$

linear power study on the isotopics and indirectly on the inherent, associated neutron signals, we achieve an understanding of signal sensitivities that can be used to establish procedures best characterizing the measured signal.

Second, by performing sensitivity studies and then verifying them experimentally, calculated factors can be used to compensate for a particular parameter. For example, ${ }^{242} \mathrm{~cm}$, which

has a relatively short half-life, contributes significantly to the passive neutron signal for cooling times of less than $2 \mathrm{yr}$, depending on the exposure of the fuel assembly. Generally, ${ }^{244} \mathrm{Cm}$ dominates the remaining signal. Several correlations, which have been established between ${ }^{244} \mathrm{Cm}$ and other parameters such as the total plutonium content in the fuel, ${ }^{2}$ are not valid for short cooling times unless the ${ }^{244} \mathrm{Cm}$ concentration is known. This concentration can be deduced from the neutron signal if we correct for the ${ }^{242} \mathrm{~cm}$ contribution with calculationally derived quantities.

1. Initial ${ }^{235} \mathrm{U}$ Enrichment variations. The initial ${ }^{235} \mathrm{U}$ enrichments studied ranged from 2.2 to 4.5 wto; PWRs typically have enrichments in the 2.0 to 3.58 range. To achieve burnups, future fuel may have higher initial ${ }^{235}$ enrichments in the 4.0 to 4.58 range. In these enrichment sensitivity stuaies, the linear power is maintained at $200 \mathrm{w} / \mathrm{cm}$. For a lower enriched fuel (2 to 3 wt 8 ), compared to a higher wriched fuel ( 3 to 4 wtz), a higher flux level is needed to maintain this power level. similarly, a higher fluence is needed for a lower enriched fuel to achieve the same exposure. In some cases, higher flux levels cause variations in the isotopics. However, for most actinides discussed here, the effects of different initial enrichments are due primarily to the total fluence differences ard not to flux differences.

2. Initial UO 2 Mass Lensity Variations. Initial $\mathrm{UO}_{2}$ mass density does not vary significantly in sintered reactor fuels. Usually, the density ranges from 90 to 958 of the theoretical density of $\mathrm{UO}_{2}\left(10.96 \mathrm{~g} / \mathrm{cm}^{3}\right)$. We exanined mass densities that were 90.814 and 948 of the theoretical density. variations 
in $t$ je mass density affect the fuel loading. The fissile loading will affect the flux and fluence levels needed to obtain power levels and exposures, although ${ }^{238} \mathrm{U}$ concentrations affect the build-up of higher transuranic isotopes. Because the range of possible densities is limited, effects of mass density differences are not very large.

3. Power Level Variations. We used linear power levels of 160, 200, and $240 \mathrm{w} / \mathrm{cm}$. For isotopes produced and depleted principally by neutron capture, relative changes in the concentration depend on the capture cross sections of the isotope and its precursor; the concentration at a given exposure depends on the total fluence and not on the flux magnitude. If the isotope is produced or depleted primarily through radioactive decay, relative changes in the concentration depend on the flux level. If, for instance, the isotope is produced by racioactive decay and depletes through neutron capture, the production process depends on the precursor's half-life and the depletion depends on the flux level. The production rate will remain constant if the flux level is changed, but the depletion will not. At a given exposure level, the isotope concentration depends on the flux level (or power level) at which the fuei operated.

4. Irradiation History Variations. Actinide nuclide inventories seem most sensitive to irradiation history; this is particularly true for shortlived nuclides. An irradiation history accounts for periods of full power operation, for shutdown periods, and for periods after the fuel is removed from the core. Long-lived isotopes build up and deplete during continuous periods of full-power operations. During shutdowns these isotopes remain relatively constant, except for slight build-up when the isotope is the daughter of a short half-life radioactive precursor. When full-power operation resumes, the long-lived isotope generally continues the build-up and depletion process from the same stage as before shutdown.

For short-lived isotopes, the build-up and depletion process still occurs during reactor operations. During shutdown periods, short-lived isotopes decay appreciably. As a result, when the reactor is restarted the isotope has decayed and, depending on feed material, may not reach concentration levels normally obtained during continuous operation. Therefore, concentrations of these isotopes depend strongly on irradiation history. 
Irradiation histories in this study assumed combinations of $1-y r$ fullpower irradiation cycles and l-yr shutdown cycles. The 1-yr shutdown cycle simulated a fuel assembly being removed for a full 1-yr cycle and then returned to the core. For all irradiation history cases considered, the flel was removed from the core when a maximum of about $50 \mathrm{GWd} / \mathrm{tU}$ (five full-power irradiation cycles) was obtained.

:II. ACTINIDE ISOTOPE PRODUCTION, DEPLETION, AND DECAY

A. Uranium Isotopes

Four uranium isotopes, ${ }^{234} \mathrm{U}, 235 \mathrm{U}, 236 \mathrm{U}$, and ${ }^{238} \mathrm{U}$, initially are present in uranium dioxide $\left(\mathrm{UO}_{2}\right.$ ) fuels, with only ${ }^{235} \mathrm{U}$ and ${ }^{238_{\mathrm{U}}}$ occurring in large quantities. The combined ${ }^{234} \mathrm{U}$ and ${ }^{236} \mathrm{U}$ isotopes are less than 0.1 wtr of the initial heavy metal loading. In unirradiated fuel, actual amounts of the uranium isotopes depend on che initial ${ }^{235} \mathrm{U}$ enrichment, which typically varies from 2.0 to 4.5 wt8. Concentrations of ${ }^{234} \mathrm{U},{ }^{235} \mathrm{U}$, and ${ }^{238} \mathrm{U}$ deplete with increasing exposures, but ${ }^{236} \mathrm{U}$ is produced. The behavior of the uranium isotopes depends primaxily on the uncomplicated neutron capture chains in Fig. 1 .

of the uranium isotopes in spent-fuel assemblies, ${ }^{235} \mathrm{U}$ is of primary interest for aafeguards purposes. From a measurement standpoint, ${ }^{235} \mathrm{U}$ can significantly affect neutron signatures of spent-fuel assemblies. Neutron multiplication of either inherent neutrons or external interrogation-source neutrons depends on the amount of fissile material. Neutron measurement systems designed to determine various spent-fuel parameters must consider the multiplication effects.

1. Uranium-234 ( $t_{1 / 2}=2.45 \times 10^{5} \mathrm{yr}$ ). Uranium-234 (Fig. 2) depletes through neutron capture to form additional $235 \mathrm{U}$. Uranium-234 is a long-lived isotope basically unaffected by reactor shutdown or fuel discharge from the reactor. Over long cooling periods, minute quantities of ${ }^{234} \mathrm{U}$ are produced through alpha emissions in ${ }^{238}$ Pu.

2. Uranium-235 (t $\left.1 / 2=7.04 \times 10^{8} \mathrm{yr}\right)$. Uranium-235 (Fig. 3) depletes through neutron absorption. After absorbing a neutron, the ${ }^{235} \mathrm{U}$ atom fissions or forms $236 \mathrm{U}$. Like ${ }^{234} \mathrm{U}, 235 \mathrm{U}$ is long lived and therefore unaffected by reactor shutdown. 


\section{Mass Number}

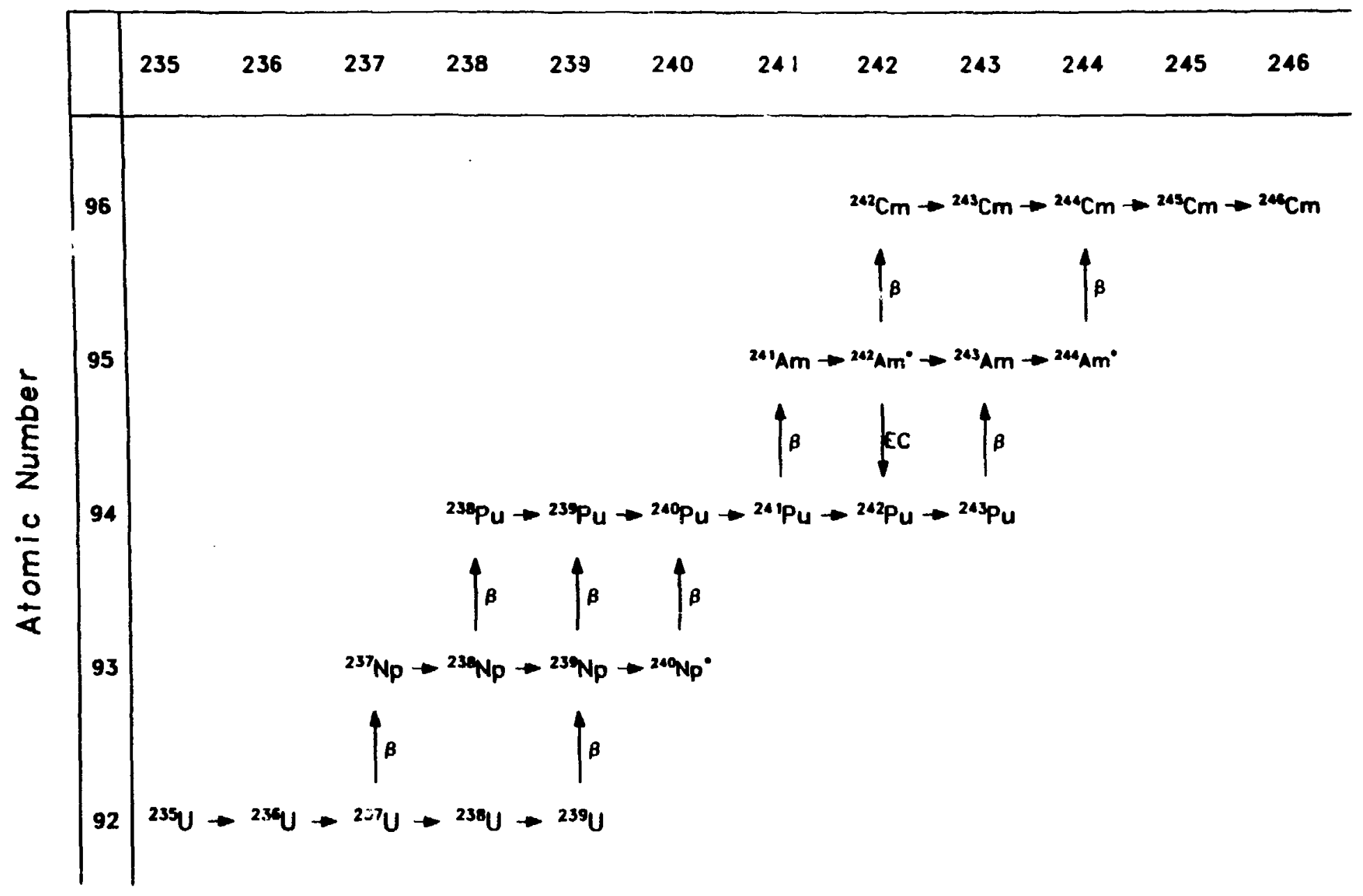

- Melastable stotes exist for ${ }^{240 \mathrm{~Np} .}{ }^{242} \mathrm{Am}$, ond ${ }^{244} \mathrm{Am}$ 

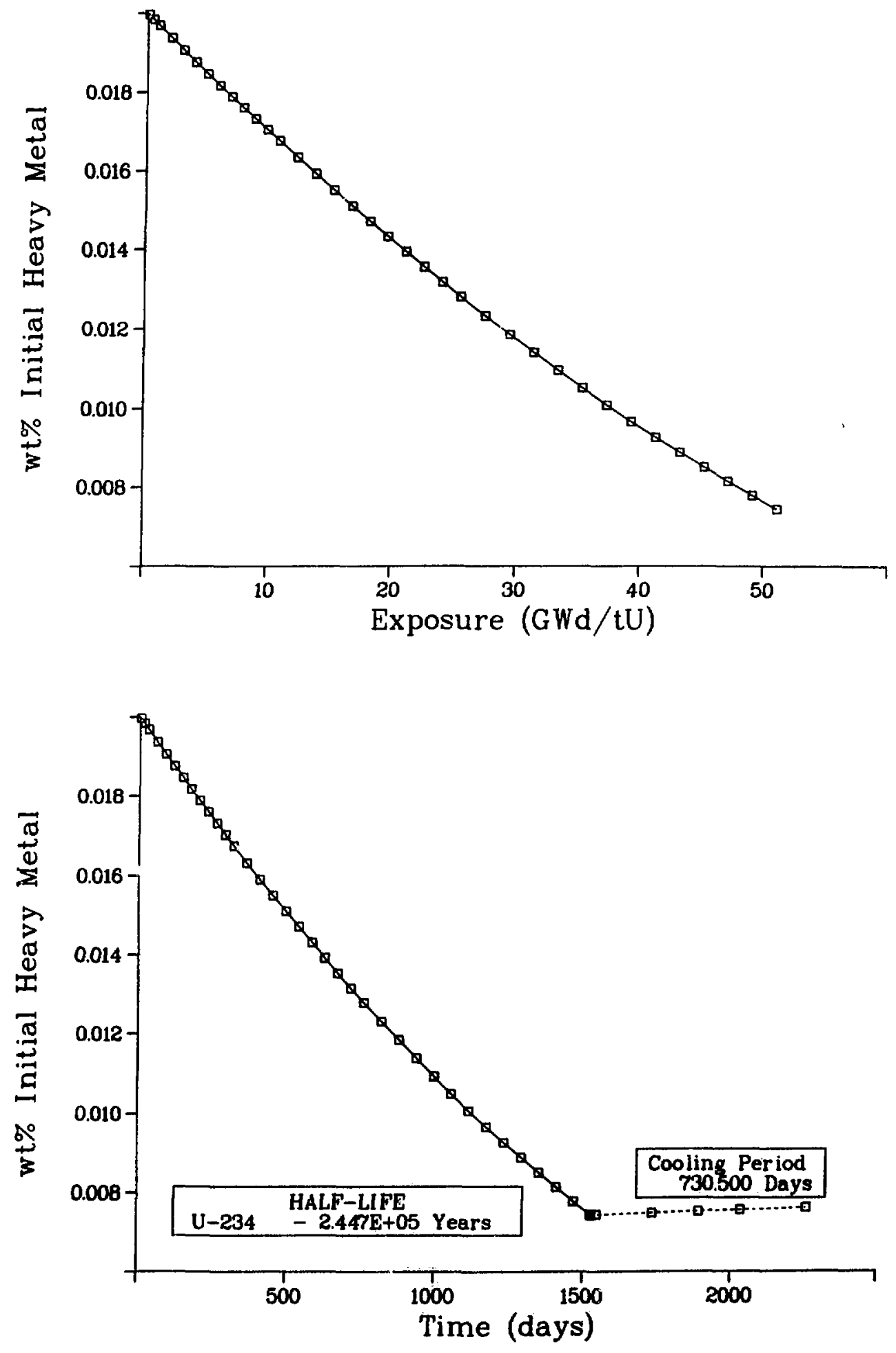

Fig. 2.

Concentration of $234 \mathrm{U}$ as a function of exposure and irradiation/ cooling time. 

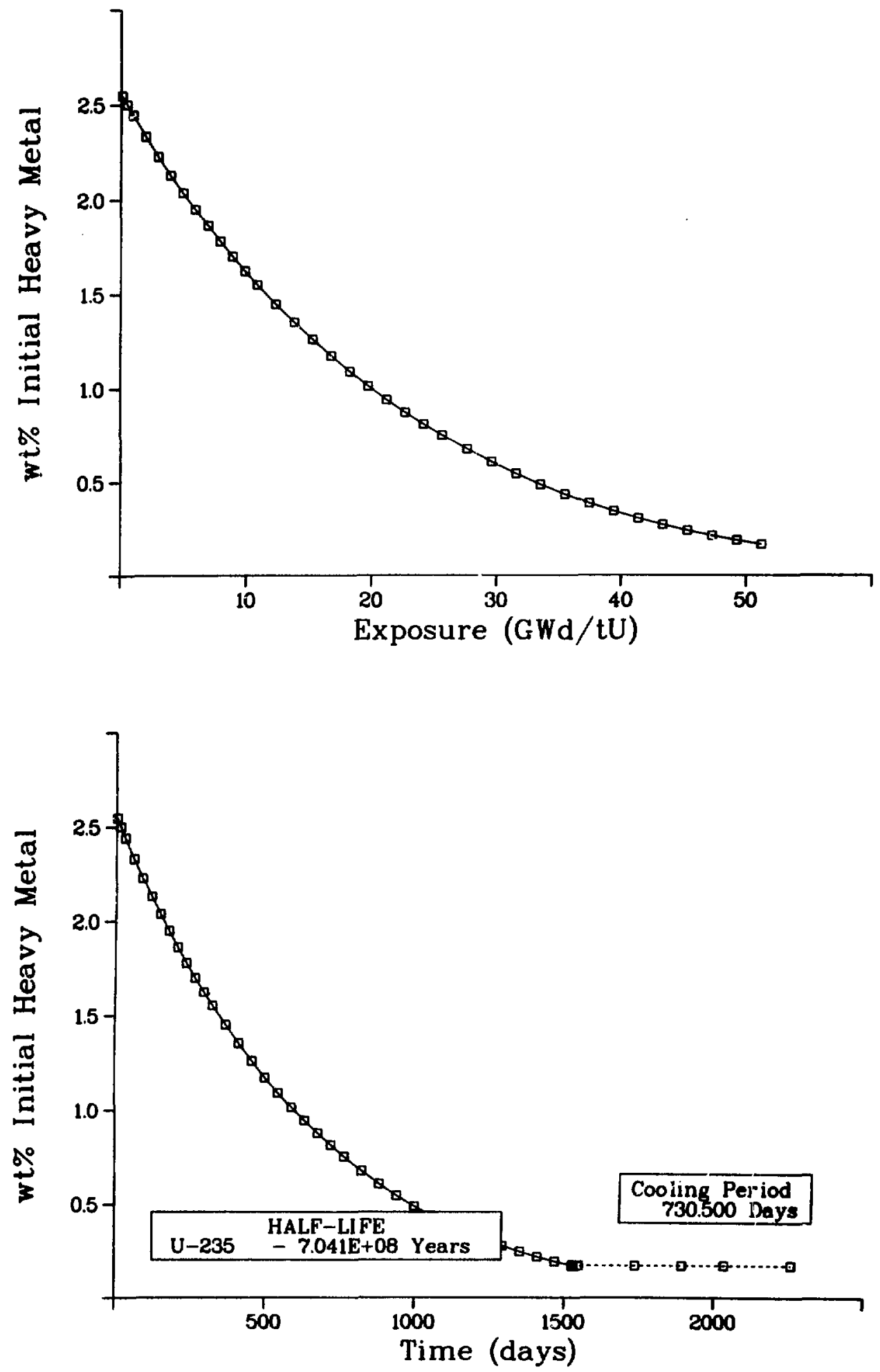

Fig. 3.

concentration of $235 \mathrm{v}$ as a function of exposure and irradiation/ cooling time. 
3. Uranium-236 $\left(t_{1 / 2}=2.34 \times 10^{7} \mathrm{yr}\right)$. The ${ }^{236} \mathrm{U}$ thermal capture cross section is small compared to the same ${ }^{235} \mathrm{U}$ cross section. As a result, during reactor-operation more ${ }^{236} \mathrm{U}$ is produced than is lost (Fig. 4). The ${ }^{236} \mathrm{v}$ concentration reaches a maximum at high exposures and is reduced by neutron capture, yielding ${ }^{237} \mathrm{U}$. Because of its long half-life, the ${ }^{236} \mathrm{U}$ concentration remains nearly constant after a fuel assembly is discharged from a reactor.

4. Uranium-237 ( $t_{1 / 2}=6.75$ days). Uranium-237 (Fig. 5) is produced from neutron capture in $236 \mathrm{v}$. Although some neutron capture and subsequent formation of ${ }^{238} \mathrm{U}$ occurs in ${ }^{237} \mathrm{U}$, this ${ }^{237} \mathrm{U}$ isotope depletes primarily through beta decay to form ${ }^{237} \mathrm{~Np}$. The very short half-life results in nearly total depletion of $237 \mathrm{~J}$ during reactor shutdown until its low concentration is in equilibrium with the alpha decay of the parent ${ }^{241} \mathrm{Pu}$.

5. Uranium-238 ( $\left.t_{1 / 2}=4.47 \times 10^{9} \mathrm{yr}\right)$. Uranium-238 has the largest heavy metal mass in LWR fuel assemblies. As shown in Fig. $6,{ }^{238}$ depletes during reactor operation. Whereas some high-energy neutrons will induce fissicns in ${ }^{238} \mathrm{U}$, most neutron absorption events in $23 \varepsilon_{\mathrm{U}}$ result in the formation of ${ }^{239} \mathrm{U}$. For exposures greater than $50 \mathrm{GWd} / \mathrm{tU}$, nearly 48 of the initial ${ }^{238} \mathrm{U}$ is depleted by neutron capture and fission. Uranium-238 remains constant during reactor shutdown.

6. Uranium-239 (t $\left.{ }_{1 / 2}=23.5 \mathrm{~min}\right)$. Uranium-239 concentrations (Fig. 7 ), formed from neutron capture in ${ }^{238} \mathrm{U}$, decay rapidly because of the very short half-life. The beta decay of ${ }^{239} \mathrm{U}$ resul.ts in ${ }^{239} \mathrm{~Np}$, which also rapidly undergoes beta decay, to form the important fissile isotope ${ }^{239} \mathrm{Pu}$.

7. Sensitivity of Fissile Uranium Isotope-- ${ }^{235} \mathrm{U}$. Figure 8 shows sensitivity effects for ${ }^{235} \mathrm{U}$. Although the obvious sensitivity to initial ${ }^{235_{\mathrm{U}}}$ enrichment is shown, ${ }^{235} \mathrm{U}$ has little or no sensitivity to the other parameters. (In Fig. 8 and all similar plots, $U$ indicates a $1-y r$ constant power period at $200 \mathrm{w} / \mathrm{cm}$ and $\mathrm{D}$ indicates a l-yr shutdown period. A series of these letters, such as UDUU, indicates a 4-yr period with $1 \mathrm{yr}$ in the core followed by 1 yr out of core or in a shutdown mode followed by 2 yr of full power.) The ${ }^{235} \mathrm{U}$ isotope's dependence on initial enrichment, also evident for most other transuranic isotopes, indicates that techniques for verifying fissile content in 

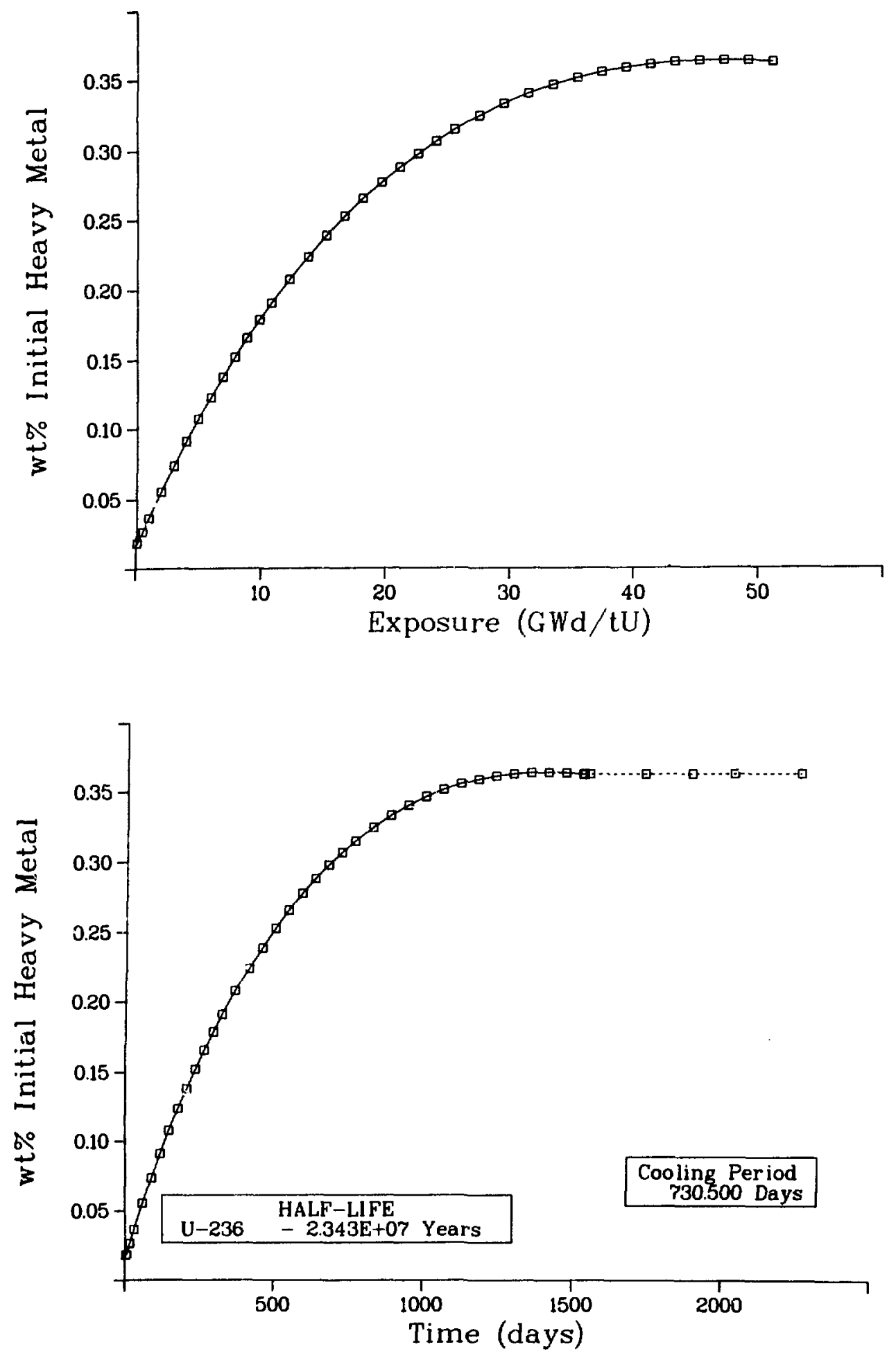

Fig. 4 .

Concentration of $236 \mathrm{U}$ as a function of exposure and irradiation/ cooling time. 

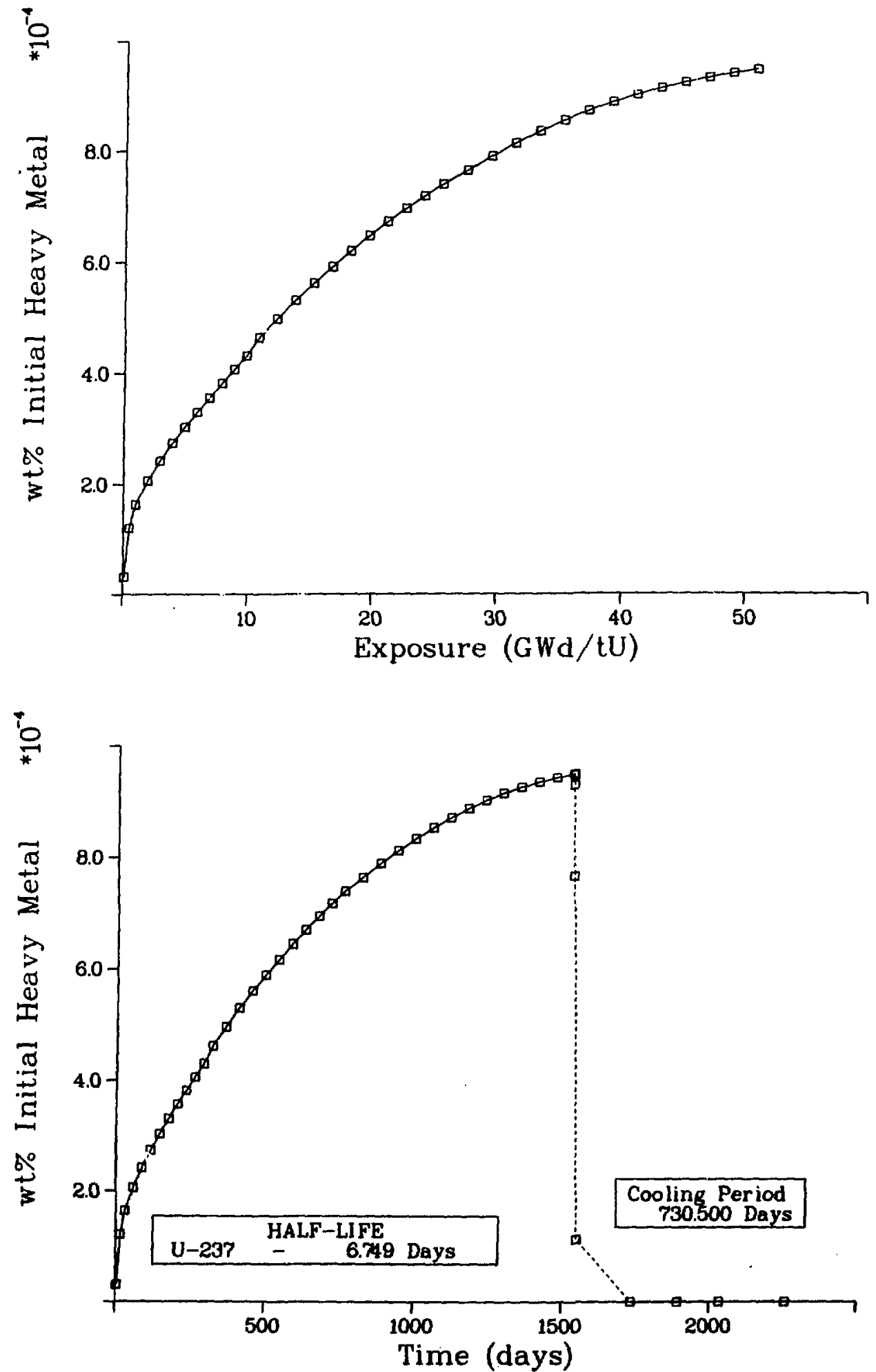

Concentration of $237 \mathrm{U}$ as a function of exposure and irradiation/ cooling time. 

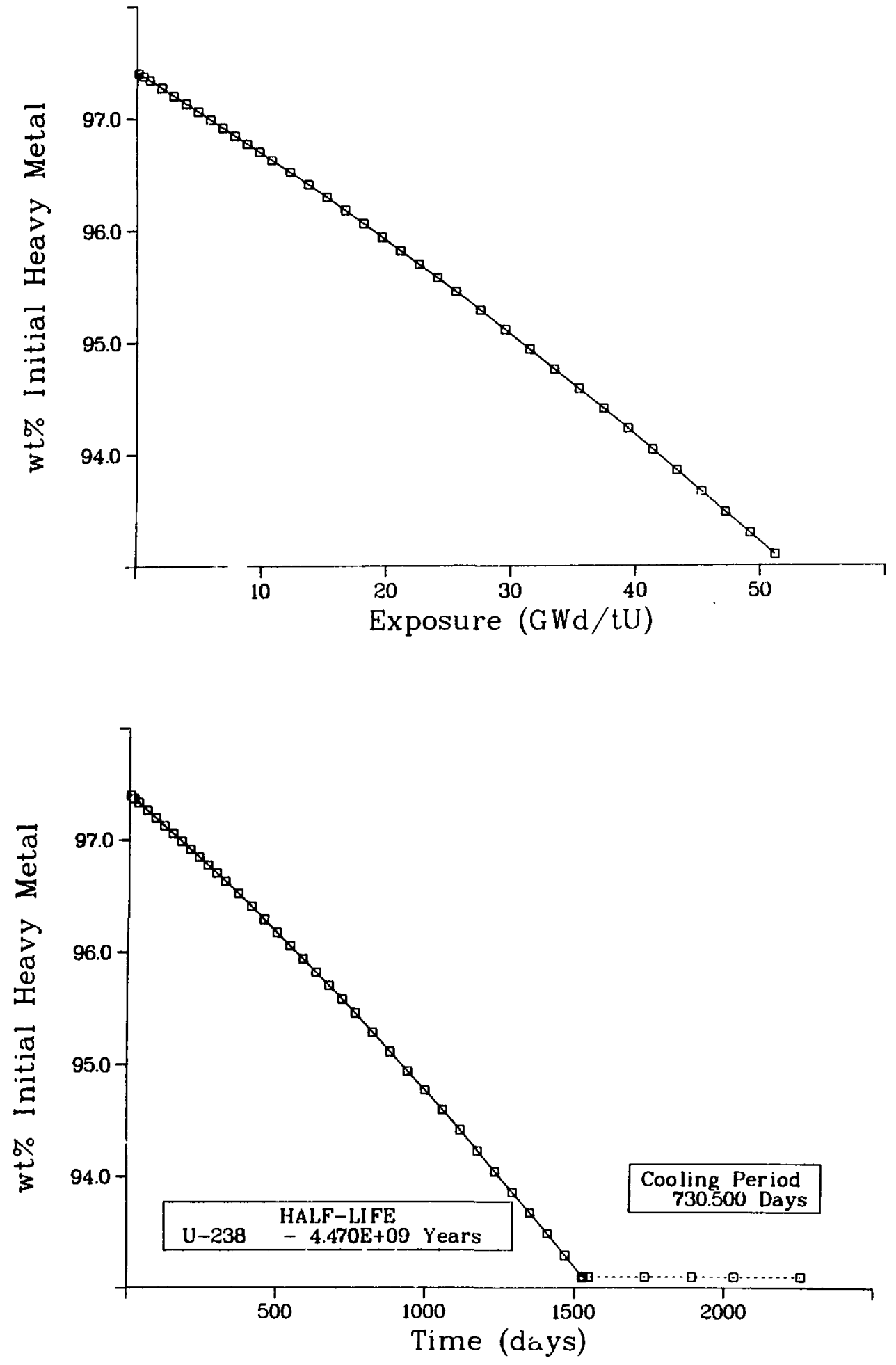

Fig. 6 .

Concentration of $238_{\mathrm{U}}$ as a function of expusure and irradiation/ cooling time. 

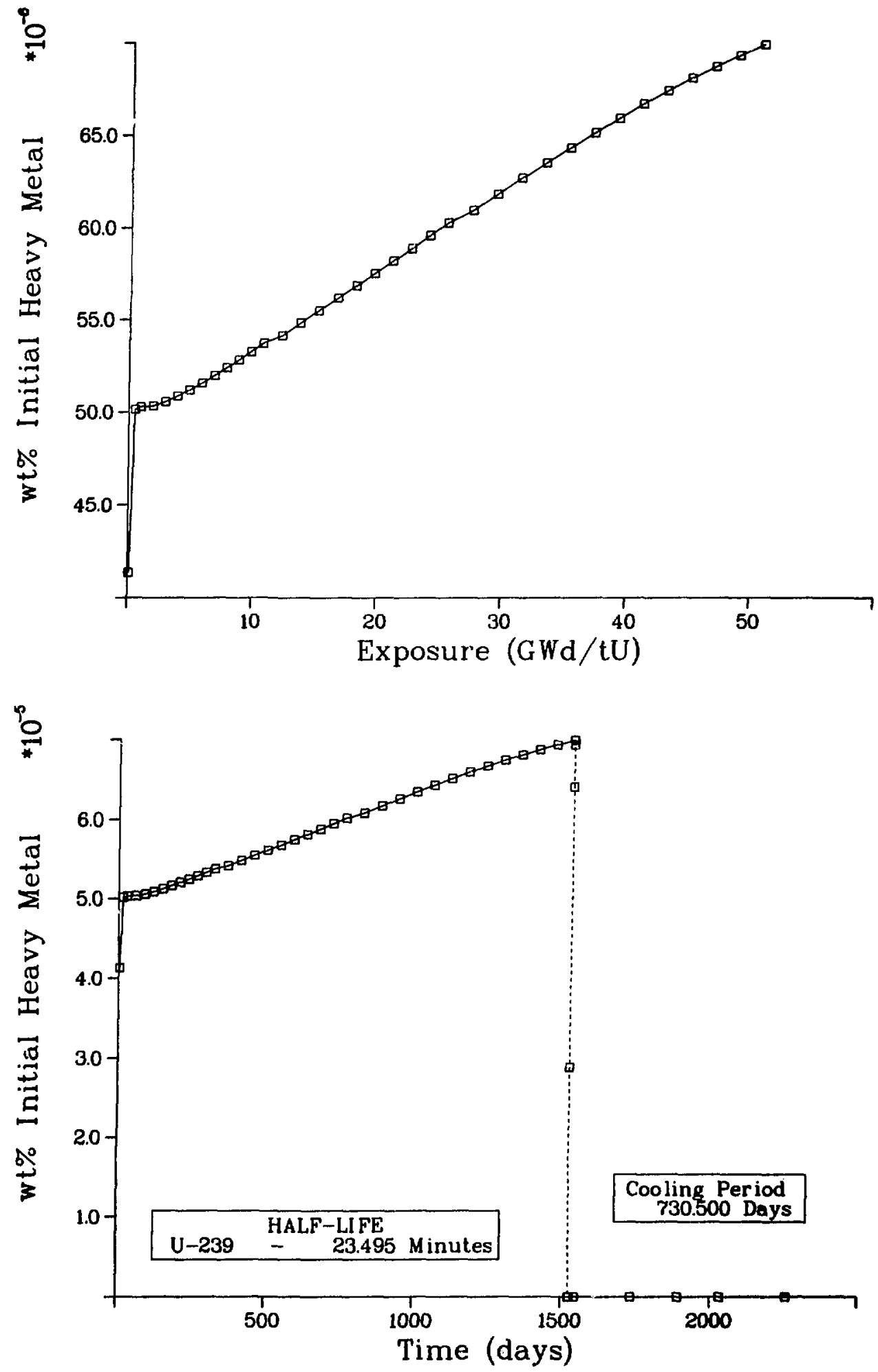

Fig. 7.

Concentration of ${ }^{239} \mathrm{U}$ as a function of exposure and irradiation/ cooling time. 

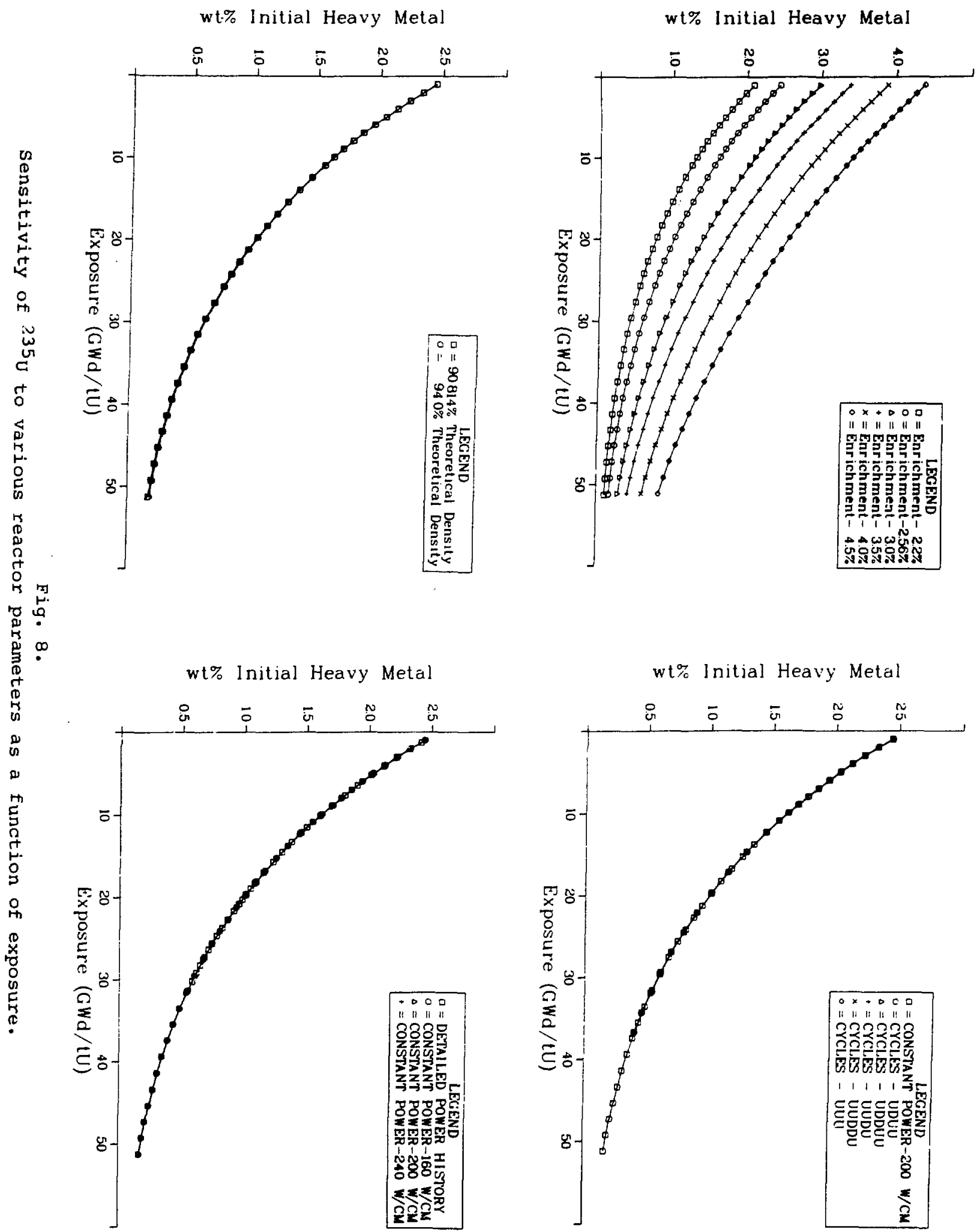
spent-fuel assemblies probably require knowledge of the assembly's initial enrichment.

\section{B. Neptunium Isotopes}

The neptunium isotopes in Fig. 1 are important because they are precursors to the formation of the plutonium isotopes. Of the neptunium isotopes of interest, ${ }^{237} \mathrm{~Np},{ }^{238} \mathrm{~Np},{ }^{239} \mathrm{~Np}$, and ${ }^{240} \mathrm{~Np}$, only ${ }^{237} \mathrm{~Np}$ has a long half-life. The others beta decay quickly to form various plutonium isotopes.

1. Neptunium-237 $\left(t_{1 / 2}=2.14 \times 10^{6} \mathrm{yr}\right) \cdot$. Neptunium-237 concentrations (Fig. 9) are formed from the beta decay of ${ }^{237} \mathrm{U}$. After removal from the reactor, a short-term increase in ${ }^{237} \mathrm{~Np}$ concentration occurs as the remaining ${ }^{237} \mathrm{U}$ decays.

2. Neptunium-238 $(t / 2=50.8 \mathrm{~h})$. The ${ }^{238} \mathrm{~Np}$ (Fig. 20 ) is formed from neutron capture in $237 \mathrm{~Np}$. This isotope depletes through beta decay to form ${ }^{238} \mathrm{Pu}$ and through neutron capture to form ${ }^{239} \mathrm{~Np}$. For exposures up to $50 \mathrm{GWd}$ tU, ${ }^{238} \mathrm{~Np}$ does not reach such a maximum becaluse the source material ${ }^{237} \mathrm{~Np}$ continues to increase. With such a short half-life, ${ }^{238}$ Np quickly decays after fuel removal from the reactor.

3. Neptunium-239( $\left.t_{1 / 2}=56.5 \mathrm{~h}\right)$. Neptunium-239 concentrations shown in Fig. 11 are formed from neutron capture in ${ }^{238} \mathrm{~Np}$ and from beta decay of $239 \mathrm{U}$. The similar curves of ${ }^{239}{ }_{U}$ (see Fig. 7) and 239 Np show that most ${ }^{239}$ Np comes from ${ }^{239} \mathrm{U}$. Neptunium-239 depletes by beta decay to form the important fissile isotope ${ }^{239} \mathrm{Pu}$ and by neutron capture to form ${ }^{240} \mathrm{~Np}$. Because of its short halflife, ${ }^{239} \mathrm{~Np}$ quickly decays after the fuel is discharged from the reactor.

4. Neptunium-240 (t $\left.t_{1 / 2}=1.08 \mathrm{~h}\right)$. Neptunium-240 (Fig. 12) forms from neutron capture in $239 \mathrm{~Np}$. A metastable state of $240 \mathrm{~Np}$ is also formed. Borh states deplete through beta decay to form ${ }^{240} \mathrm{Pu}$. As with ${ }^{238} \mathrm{~Np}$ and ${ }^{239} \mathrm{~Np}$, this isotope decays quickly duxing reactor shutdown and after fuel assembly discharge from the reactor.

\section{Plutonium Isotopes}

Two plutonium isotopes, ${ }^{239} \mathrm{Pu}$ and ${ }^{241} \mathrm{Pu}$, are fissile materials of safeguards interest. In low-exposure materials or in reprocessed fuels, the 

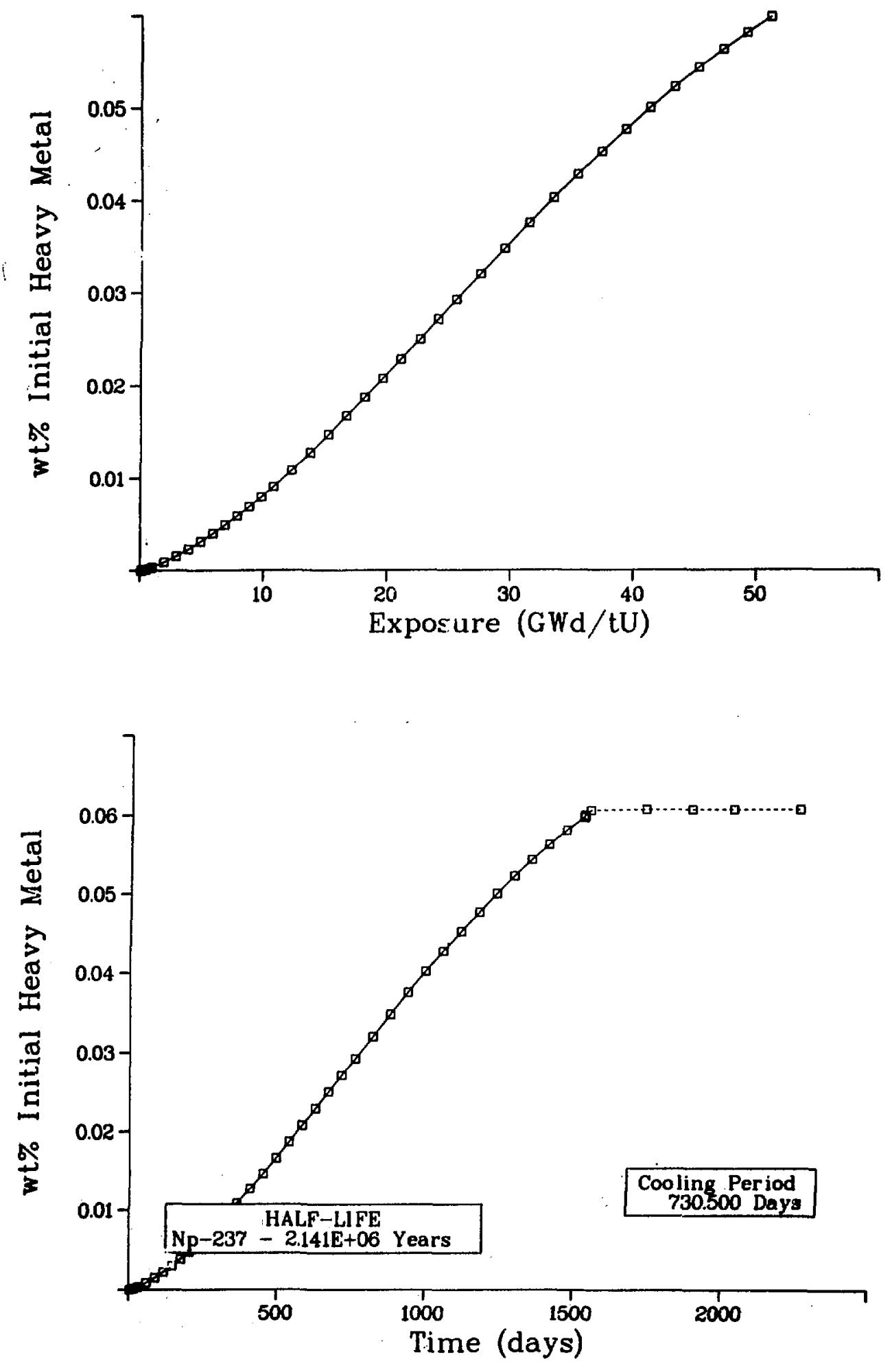

Fig. 9.

Concentration of ${ }^{237} \mathrm{~Np}$ as a function of exposure and irradiation/ cooling time. 

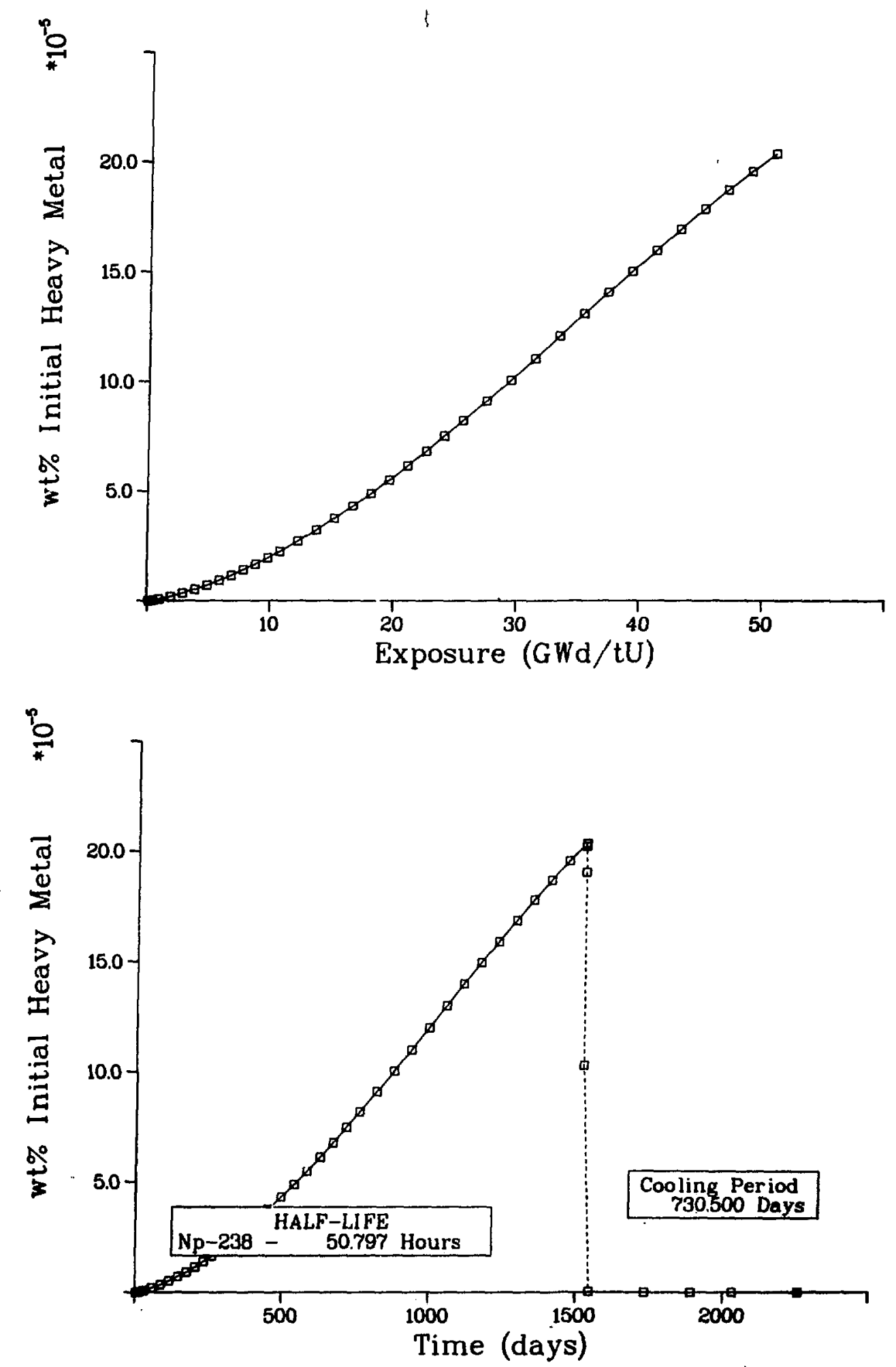

Fig. 10.

Concentration of ${ }^{238} \mathrm{~Np}$ as a function of exposure and ixradiation/ cooling time. 

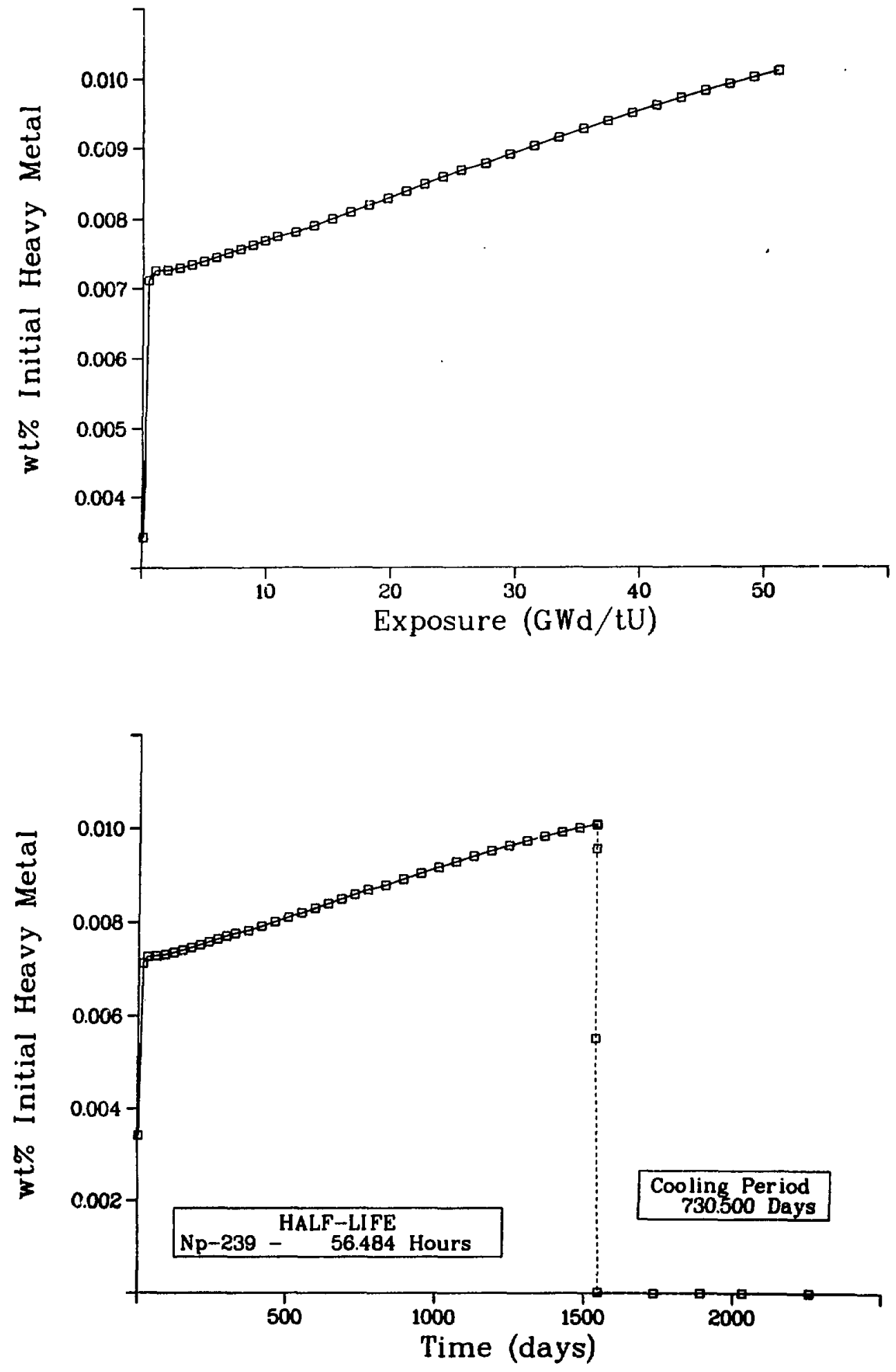

Fig. 11.

Concentration of $239 \mathrm{~Np}$ as a function of exposure and irradiation/ cooling time. 

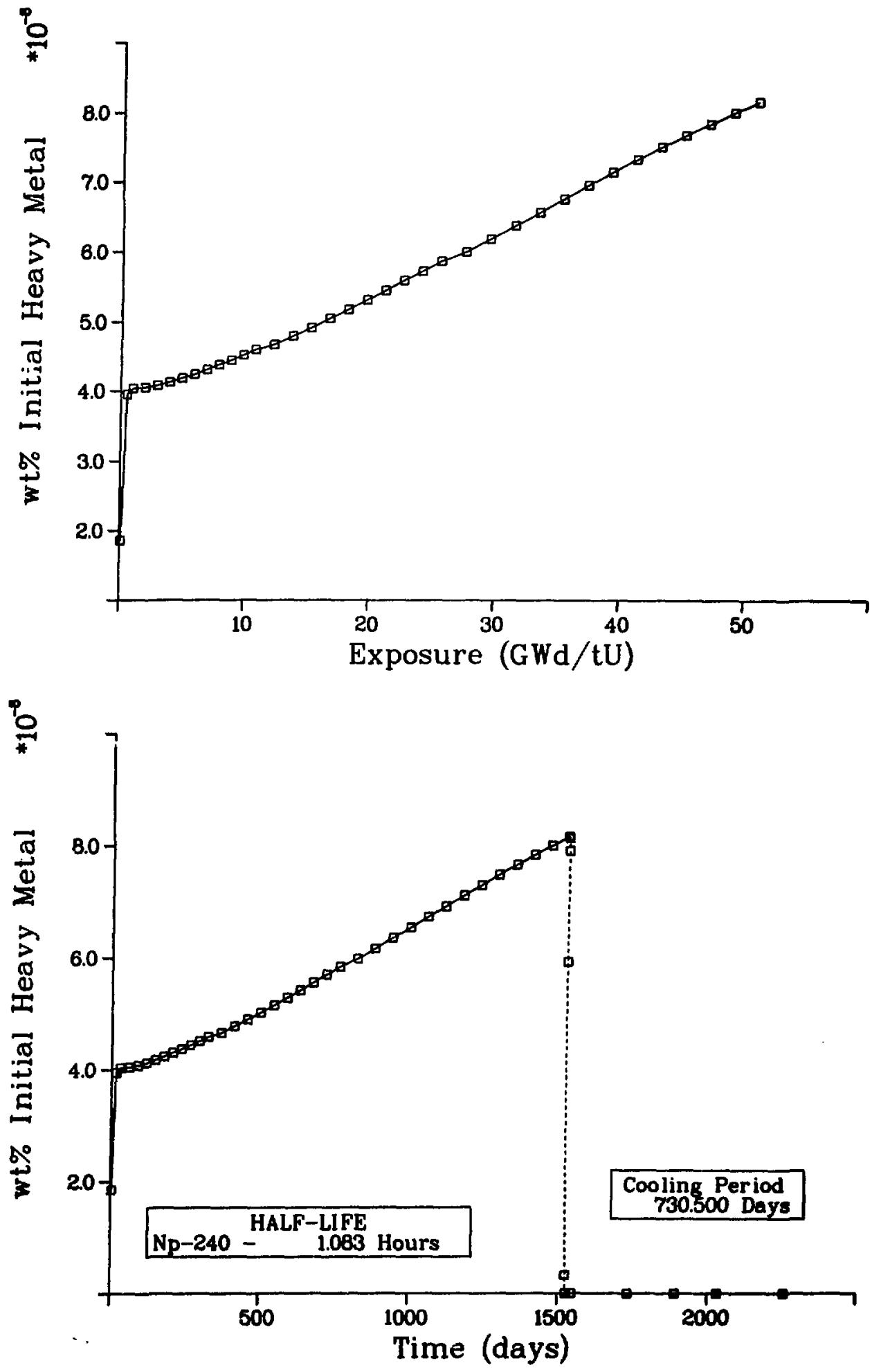

Fig. 12 .

Concentration of ${ }^{240} \mathrm{~Np}$ as a function of exposure and irradiation/ cooling time. 
plutonium isotopes are important neutron emitters. The even mass number plutonium isotopes, ${ }^{238} \mathrm{Pu},{ }^{240} \mathrm{Pu}$, and ${ }^{242} \mathrm{Pu}$, undergo spontaneous fission with subsequent emission of neutrons, as shown in Table IV. Three plutonium isotopes, ${ }^{238} \mathrm{Pu},{ }^{239} \mathrm{Pu}$, and ${ }^{240} \mathrm{Pu}$, emit significant numbers of alpha particles. When these alpha particles are in matrix materials with low atomic numbers, they can interact with the material, resulting in neutron release. For oxygen, the alpha particles interact with ${ }^{17}$ o or ${ }^{18} \mathrm{o}$ to form ${ }^{20} \mathrm{Ne}$ or ${ }^{21} \mathrm{Ne}$ and release neutrons. Other low atomic number isotopes have similar alpha interactions. Figure 1 shows the plutonium production and decay chains.

1. Plutonium $238\left(t_{1 / 2}=87.8 \mathrm{yr}\right)$. Figure 13 shows ${ }^{238}$ Pu building up as a function of time and exposure. This isotope, which has a relatively short half-life (compared to other plutonium isotopes), is produced primarily by the beta decay of ${ }^{238} \mathrm{~Np}$. Additional ${ }^{238} \mathrm{Pu}$ comes from the alpha decay of ${ }^{242} \mathrm{Cm}$. Because ${ }^{238} \mathrm{Pu}$ is not formed principally from neutron capture, it continues to be produced during nonirradiation periods.

2. Plutonium-239 ( $\left.t_{1 / 2}=2.41 \times 10^{4} \mathrm{yr}\right)$. Plutonium-239 as a function of exposure and time is shown in Fig. 14. This isotope is formed principally from beta decay of ${ }^{239} \mathrm{~Np}$; however, small amounts of ${ }^{239} \mathrm{Pu}$ are produced from neutron capture in ${ }^{238} \mathrm{Pu}$. Because of the beta decay of ${ }^{239} \mathrm{~Np}$, small amounts of ${ }^{239} \mathrm{Pu}$ continue to be produced shortly after reactor shutdown. Plutonium-239 reaches a maximum in an exposure range of 25 to $30 \mathrm{GWd} / \mathrm{tU}$. At high exposures, much of the ${ }^{235} \mathrm{U}$ initially present has been depleted. Therefore, to maintain the required power level in the fuel assembly, significant amounts of the ${ }^{239}$ Pu fission, decreasing the ${ }^{239} \mathrm{Pu}$ concentration below its maximum value.

3. Plutonium-240 ( $\left.t_{1 / 2}=6.55 \times 10^{3} \mathrm{yr}\right)$. Plutonium-240 (Fig. 15) is formed primarily from neutron capture in ${ }^{239} \mathrm{Pu}$; some ${ }^{240} \mathrm{Pu}$ is produced from beta decay in ${ }^{240} \mathrm{~Np}$. Plutonium-240 apparently reaches a maximum for exposures in the range of $50 \mathrm{GWd} / \mathrm{tU}$. It depletes through neutron capture to form ${ }^{24 I_{\mathrm{Pu}}}$. with such a long half-life, ${ }^{240} \mathrm{Pu}$ is constant during reactor shutdown.

4. Plutonium-24l $\left(t_{1 / 2}=14.7 \mathrm{yr}\right)$. Plutonium-24l (Fig. 16) is formed from neutron capture in $240 \mathrm{Pu}$. This isotope depletes mainly by three mechanisms: beta decay to form ${ }^{241} \mathrm{Am}$, fissioning, and alpha decay to form ${ }^{237} \mathrm{U}$. 
TABLE IV

NEUTRON YIELDS AND DECAY CONSTAN'S

\begin{tabular}{|c|c|c|c|c|c|c|c|c|c|c|c|c|}
\hline \multirow[b]{2}{*}{ Isotope } & \multirow{2}{*}{$\begin{array}{l}\text { Atomic } \\
\text { Mass } \\
\text { (amu) } \\
\end{array}$} & \multicolumn{5}{|c|}{ Spontaneous Fission ${ }^{b}$} & \multicolumn{6}{|c|}{$(\alpha, n)$ Reaction $^{b}$} \\
\hline & & \multicolumn{2}{|c|}{$\begin{array}{l}\text { Half-life } \\
(y x)\end{array}$} & $\begin{array}{l}\text { Neutrons } \\
\text { per } V_{\text {(sf) }}\end{array}$ & \multicolumn{2}{|c|}{$\begin{array}{l}\text { Neutrons } \\
\text { per g-s }\end{array}$} & \multicolumn{2}{|c|}{$\begin{array}{l}\text { Half-life } \\
(y r) \\
\end{array}$} & \multicolumn{2}{|c|}{$\begin{array}{l}\text { Neutrons } \\
\text { per Decay }\end{array}$} & \multicolumn{2}{|c|}{$\begin{array}{l}\text { Neutrons } \\
\text { per g-s }\end{array}$} \\
\hline & 235.0442 & 3.50 & $E+17$ & 1.86 & 2.99 & $E-04$ & 7.04 & $E+08$ & 8.89 & $E-09$ & 7.11 & $E-04$ \\
\hline $236 \mathrm{U}$ & 236.0458 & 1.95 & $E+16$ & 1.91 & 5.49 & $E-03$ & $2 \cdot 34$ & $E+07$ & 9.89 & $E-09$ & $2 \cdot 37$ & $E-02$ \\
\hline $\mathrm{u}$ & 238.0510 & 8.20 & $E+15$ & 2.01 & $1 \cdot 36$ & $E-02$ & 4.47 & $E+09$ & 6.64 & $E-09$ & 8.26 & E-05 \\
\hline & 237.0482 & 1.00 & $E+18$ & 2.05 & 1.14 & $E-04$ & 2.14 & $\mathbf{E}+06$ & 1.30 & $E-O B$ & 3.39 & E-01 \\
\hline & 236.0457 & 3.52 & $E+19$ & 2.13 & 3.39 & $E-06$ & 2.85 & $E+00$ & 2.52 & $E-08$ & 4.95 & $E+05$ \\
\hline & 237.0484 & 12.00 & $E+15)^{C}$ & $(1.89)^{C}$ & 15.27 & $E-02)^{C}$ & 1.25 & $E-01$ & 6.72 & E-13 & 3.00 & $E+02$ \\
\hline & 238.2134 & 4.77 & $E+10$ & 2.22 & 2.59 & $E+03$ & 8.78 & $E+01$ & 2.12 & E-OB & 1.34 & $E+04$ \\
\hline & 239.0526 & 5.48 & $E+15$ & 2.16 & $2 \cdot 18$ & $E-02$ & 2.41 & $E+04$ & 1.66 & E-OB & 3.81 & $E+01$ \\
\hline & 240.0542 & 1.31 & $E+11$ & 2.16 & 9.09 & $\mathrm{E}+02$ & 6.55 & $E+03$ & 1.68 & $E-0 B$ & 1.41 & $E+02$ \\
\hline & $241 \cdot 0487$ & 12.50 & $E+15)^{C}$ & $(2.25)^{C}$ & 14.94 & $E-02 J^{C}$ & 1.47 & $E+01$ & 3.39 & $E-13$ & 1.27 & $E+00$ \\
\hline & 242.0584 & 6.84 & $E+10$ & 2.15 & 1.72 & $E+03$ & 3.76 & $E+C 5$ & 1.41 & $E-08$ & 2.05 & $E+00$ \\
\hline & 244.0646 & 6.56 & $E+10$ & $2 \cdot 30$ & 1.90 & $E+03$ & 8.20 & $E+07$ & 1.08 & $E-08$ & 7.14 & $E-03$ \\
\hline & 240.0542 & $(1.00$ & $E+15)^{C}$ & $(2.29)^{c}$ & $(1.26$ & $E-01)^{c}$ & 5.80 & $E-03$ & 3.74 & $E-14$ & 3.55 & $\mathrm{k}+02$ \\
\hline & $241 \cdot 0568$ & 1.05 & $E+14$ & 2.27 & 1.18 & $E+00$ & $4 \cdot 32$ & $E+02$ & 2.12 & E-08 & 2.69 & $E+q 3$ \\
\hline & 242.0594 & 9.50 & $E+11$ & $2 \cdot 34$ & 1.35 & $E+02$ & 1.52 & $E+02$ & 9.22 & $E-11$ & 3.31 & $E+01$ \\
\hline & 243.0620 & 3.35 & $\mathbf{E}+13$ & 2.42 & 3.93 & $E+00$ & 7.38 & $E+03$ & 1.82 & $E-08$ & 1.34 & $E+02$ \\
\hline & 240.0542 & 1.90 & $E+06$ & 2.39 & 6.93 & $E+07$ & 7.34 & E-02 & 3.37 & $E-08$ & 2.53 & $E+07$ \\
\hline & 241.0578 & 11.60 & $E+12)^{C}$ & $(2.50)^{C}$ & $(8.57$ & $E+01)^{C}$ & 8.88 & E-02 & 2.79 & $E-10$ & 1.72 & $E+05$ \\
\hline & $24<.0584$ & 6.56 & $E+06$ & 2.52 & 2.10 & $E+07$ & 4.46 & $E-01$ & 3.07 & $E-0 B$ & 3.76 & $E+06$ \\
\hline & 243.0620 & $(1.20$ & $E+11)^{c}$ & $(2.69)^{\mathrm{c}}$ & 11.22 & $E+03)^{C}$ & 2.85 & $E+01$ & 2.62 & $E-08$ & 5.00 & $E+04$ \\
\hline & 244.0626 & 1.35 & $E+07$ & 2.69 & 1.08 & $5+07$ & 1.81 & $\mathrm{E}+01$ & 2.58 & $E-08$ & 7.73 & $E+04$ \\
\hline & 245.0652 & 14.00 & $E+12)^{C}$ & $(2.87)^{C}$ & 13.87 & $E+1)()^{C}$ & 8.48 & $E+03$ & 1.95 & $E-08$ & 1.24 & $\mathrm{E}+02$ \\
\hline & 246.0668 & 1.81 & $E+07$ & 3.18 & 9.45 & $E+06$ & 4.73 & $\mathbf{E}+03$ & 1.97 & $E-08$ & 2.24 & $E+02$ \\
\hline
\end{tabular}

\footnotetext{
${ }^{a}$ Based on the neutron mass of 1.00866497 amu from ENDF/V data base.

bef. 11 .

CValues in parentheses were obtained from Ref. 12 and have estimated accuracies of 2 orders of magnitude.

Metastable state.
} 

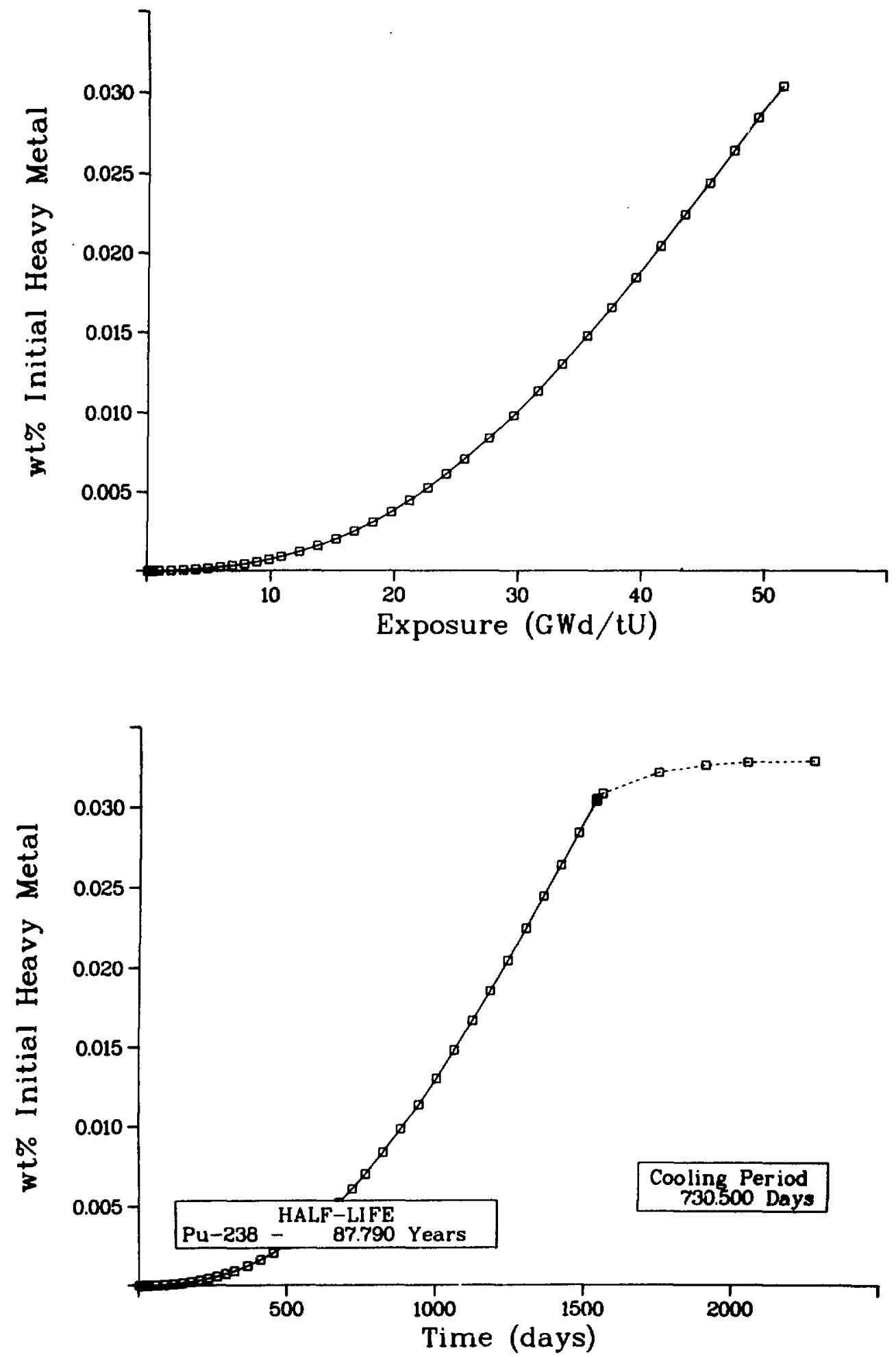

Fig. 13.

concentration of ${ }^{238} \mathrm{Pu}$ as a function of exposure and irradiation/ cooling time. 

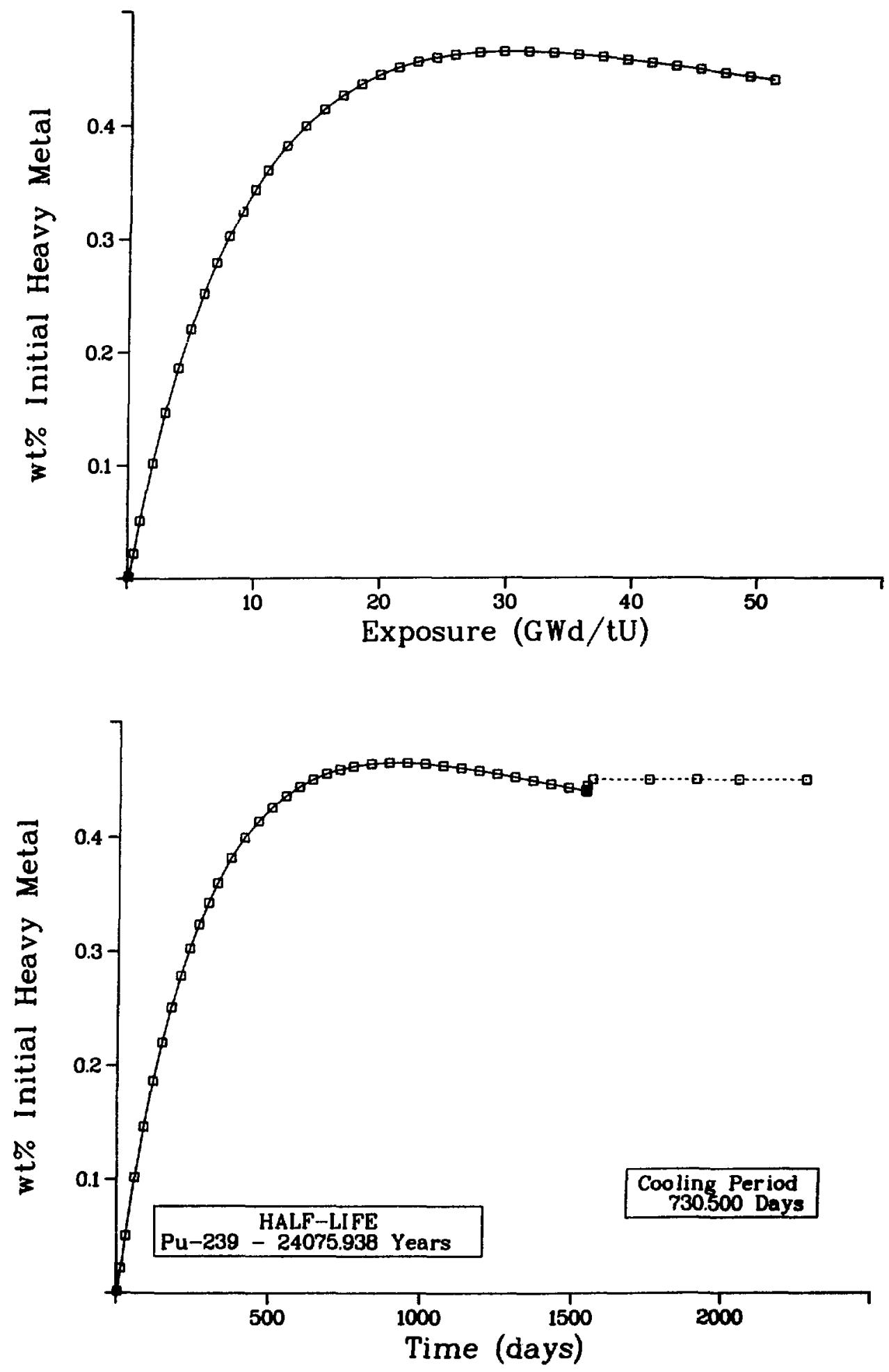

Fig. 14.

Concentration of ${ }^{239} \mathrm{Pu}$ as a function of exposure and irradiation/ cooling time. 

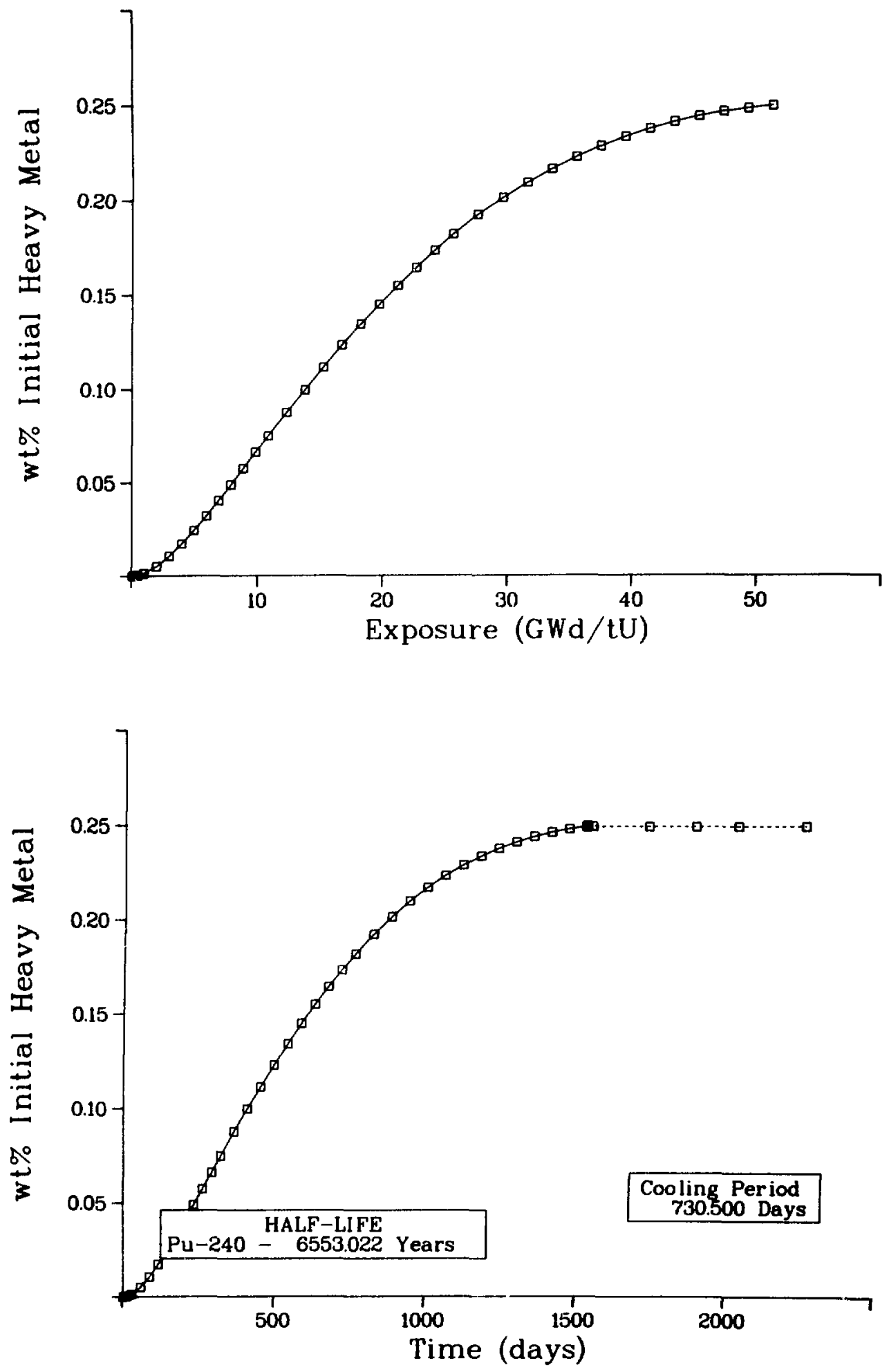

Fig. 15.

Concentration of $240 \mathrm{Pu}$ as a function of exposure and irradiation/ cooling time. 

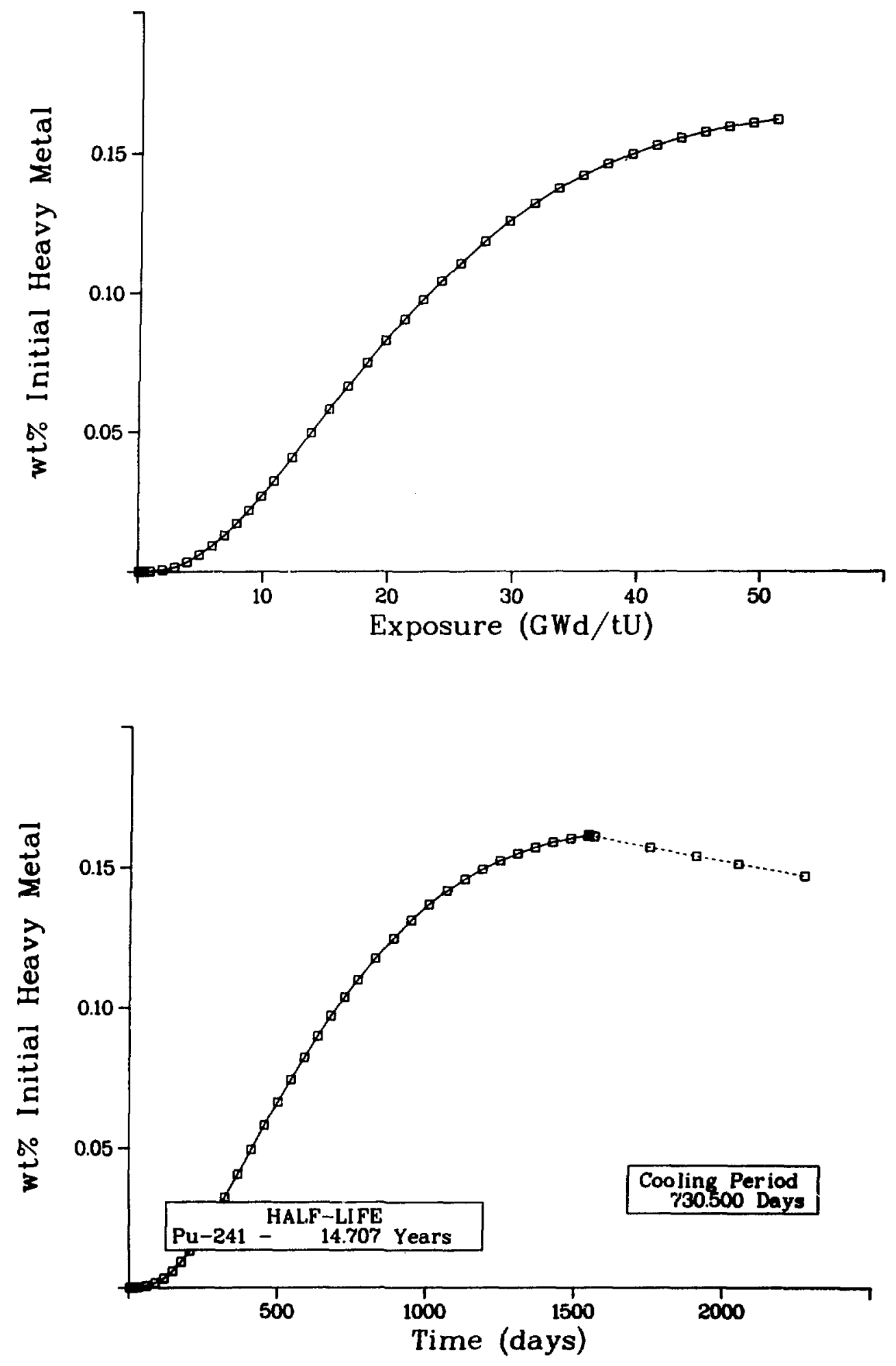

Fig. 16 .

Concentration of $241_{\mathrm{Pu}}$ as a function of exposure and irradiation/ cooling time. 
Small amounts of ${ }^{241} \mathrm{Pu}$ are lost through neutron capture events, producing $242 \mathrm{Pu}$. For high exposures the ${ }^{241} \mathrm{Pu}$ fission rate can be significant, with from 10 to 208 of the generated power coming from this source. The relatively short half-life of ${ }^{241} \mathrm{Pu}$ is evident in Fig. 16, which shows a decreasing concentration after fuel discharge from the reactor.

5. Plutonium-242 (t $\left.1 / 2=3.76 \times 10^{5} \mathrm{yr}\right)$. The ${ }^{242} \mathrm{pu}$ isotope (Fig. 17) is produced principally from neutron capture in ${ }^{241} \mathrm{pu}$. Additional quantities of ${ }^{242} \mathrm{Pu}$ are formed through electron capture in ${ }^{242} \mathrm{Am}$. With a long half-life, ${ }^{242} \mathrm{Pu}$ is constant during nonirradiation periods.

6. Plutonium-243 $\left(t_{1 / 2}=4.96 \mathrm{~h}\right)$. Plutonium-243 shown in Fig. 18 is produced from neutron capture in ${ }^{242} \mathrm{Pu}$. This isotope depletes through beta decay to form ${ }^{243} \mathrm{Am}$. With such a short half-life, ${ }^{243} \mathrm{Pu}$ rapidly depletes after reactor shutduwn.

\section{Sensitivity of Principal Plutonium Isotopes.}

a. Plutonium-239. Plutonium-239 (Fig. 19) is sersitive to initial ${ }^{235} \mathrm{U}$ enrichment and initial UO 2 mass density, but insensitive to power level and irradiation history. In the calculations for enrichment variations, the power level was held constant throughout the entire irradiation period. For lower

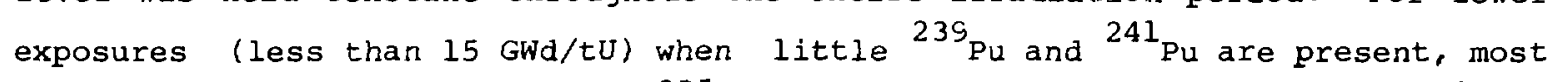
of the power is obtained from ${ }^{235} \mathrm{U}$ fissions. In this exposure domain, ${ }^{239} \mathrm{Pu}$ is produced from the ${ }^{238} \mathrm{U} \rightarrow{ }^{239} \mathrm{U} \rightarrow{ }^{239} \mathrm{NP} \rightarrow{ }^{239} \mathrm{Pu}$ chain that depends on the amount of ${ }^{238} \mathrm{U}$ present. Because the ${ }^{238} \mathrm{U}$ concentration complements the initial ${ }^{235} \mathrm{U}$ enrichment, with these low exposures ${ }^{239} \mathrm{Pu}$ production is higher in fuels with lower $235_{\mathrm{J}}$ enrichment.

For exposures above $15 \mathrm{GWd} / \mathrm{tU}$, the initial ${ }^{235} \mathrm{U}$ enrichment in the fuel material affects ${ }^{239} \mathrm{Pu}$ production, but the relationship is not linear. In this exposure range, as ${ }^{235} \mathrm{U}$ is depleted, higher fission rates must occur in the 239 pu to maintain a constant power level. For fuels with lower ${ }^{235} \mathrm{U}$ enrichments, more ${ }^{239} \mathrm{Pu}$ fissioning occurs again to maintain a constant power level. Because of this higher fission rate in ${ }^{239} \mathrm{Pu}$, the maximum levels of the ${ }^{239} \mathrm{Pu}$ concentrations are smaller for the lower initial ${ }^{235} \mathrm{U}$ enrichments. 

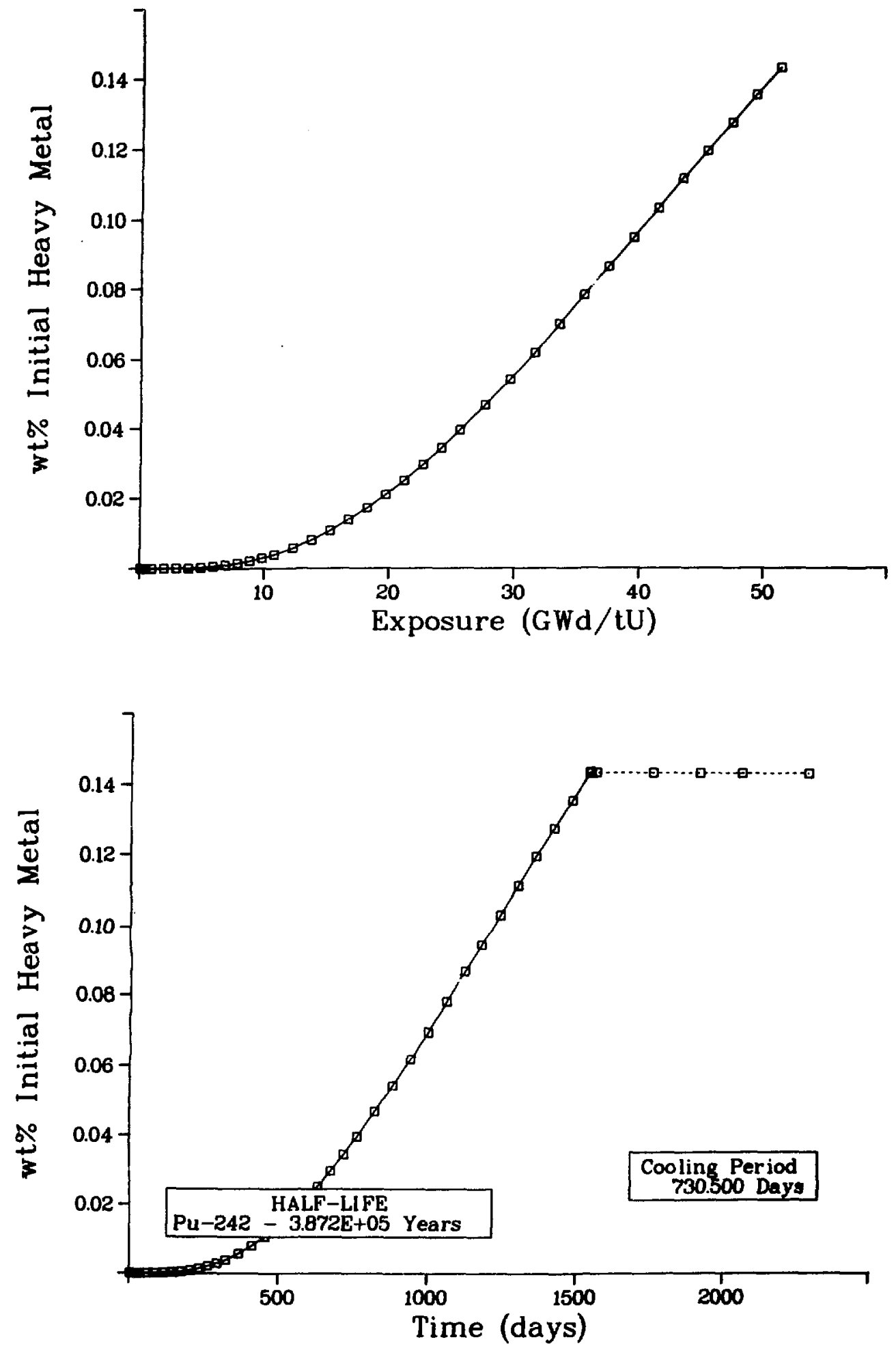

Fig. 17.

Concentration of ${ }^{242} \mathrm{Pu}$ as a function of exposure and irradiation/ cooling time. 

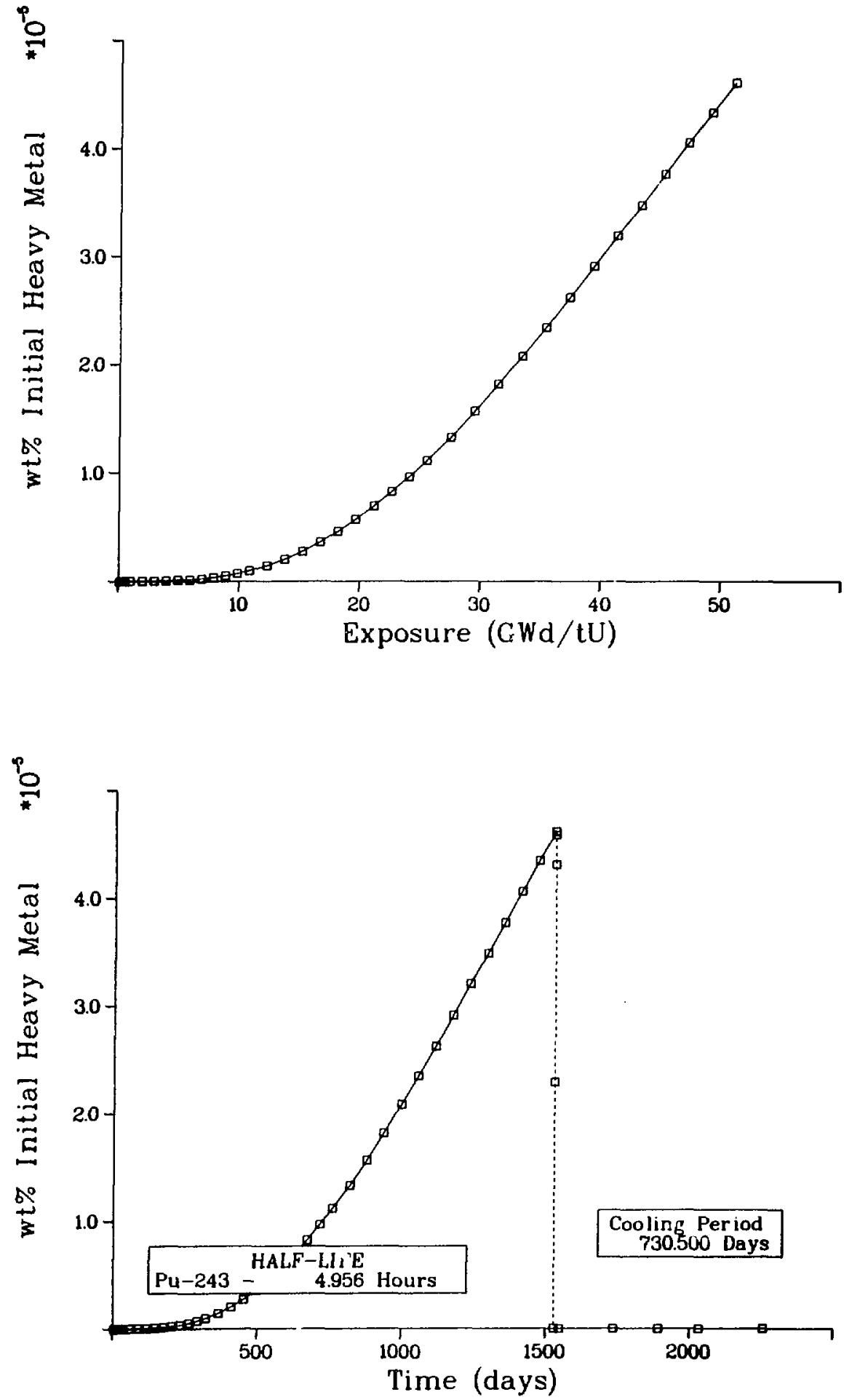

Fig. 18 .

concentration of ${ }^{243} \mathrm{Pu}$ as a function of exposure and irradiation/ sopling time. 

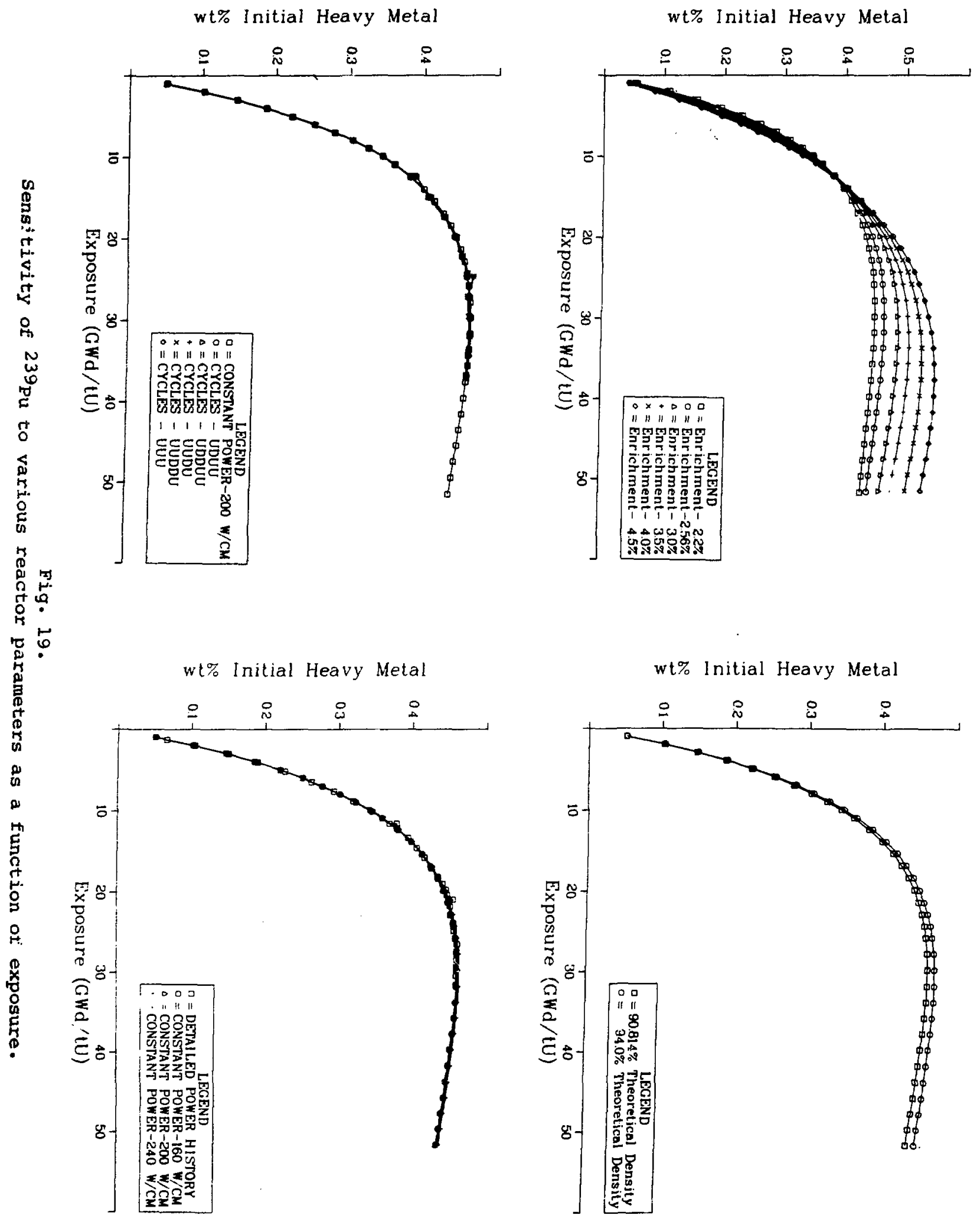
The ${ }^{239} \mathrm{Pu}$ dependence on initial $\mathrm{UO}_{2}$ mass density shown in Fig. $19 \mathrm{~b}$ is due to the amount of ${ }^{238} \mathrm{U}$. For higher mass densities, more ${ }^{238} \mathrm{U}$ atoms/cm ${ }^{3}$ are present, and as a result more ${ }^{239} \mathrm{Pu}$ is produced.

b. Plutonium-240. The isotope ${ }^{240} \mathrm{Pu}$ (Fig. 20 ) depends on initial ${ }^{235_{\mathrm{U}}}$ enrichment. Such dependence results primarily from the flux levels required to mairtain a constant power of $200 \mathrm{w} / \mathrm{cm}$. High initial ${ }^{235} \mathrm{U}$ enrichments have lower flux levels, resulting in lower ${ }^{240} \mathrm{Pu}$ concentrations. Conversely, low ${ }^{235} \mathrm{U}$ enrichments require higher fluxes, resulting in higher ${ }^{240} \mathrm{Pu}$ concentrations. For exposures above $45 \mathrm{GWd} / \mathrm{tU}$, the enrichment curves begin to converge as a result of ${ }^{239} \mathrm{Pu}$ decreasing more rapidly for the lower initial ${ }^{235} \mathrm{U}$ enrichments. Because ${ }^{239} \mathrm{Pu}$ is the ${ }^{240} \mathrm{Pu}$ precursor, proportionately less ${ }^{240} \mathrm{Pu}$ is produced. Plutonium-240 is independent of the other variables shown in Fig. 20.

c. Plutonium-241. Plutonium-241 (Fig. 21), dependent on initial ${ }^{235} \mathrm{U}$ enrichment and slightly dependent on initial $\mathrm{No}_{2}$ mass density, is independent of power level. Because of its relatively short half-life, some ${ }^{241}$ Pu will decay during long shutdown periods (see the bottom right graph of Fig. 21).

The precursor of ${ }^{241} \mathrm{Pu}$ is ${ }^{240} \mathrm{Pu}$. Therefore, when comparing the initial ${ }^{235} \mathrm{U}$ enrichments in Fig. 21, we see that the behavior of ${ }^{241} \mathrm{Pu}$ is the saise as that of ${ }^{240} \mathrm{Pu}$ for exposures up to $35 \mathrm{GWd} / \mathrm{tU}$. Above $35 \mathrm{GWd} / \mathrm{tU}$, more ${ }^{241} \mathrm{Pu} \mathrm{f}$ issioning occurs to maintain a constant power level. In this exposure range, the lower initial ${ }^{235} \mathrm{U}$ enrichment fuels require more ${ }^{241} \mathrm{Pu}$ fissioning, resulting in a more rapid depletion of ${ }^{241} \mathrm{Pu}$.

The slight dependence of ${ }^{241} \mathrm{Pu}$ on initial $\mathrm{UO}_{2}$ mass density results from more ${ }^{238} \mathrm{U}$ feed material present in the high-density fuel.

d. Plutonium-242. As sts 2 in Fig. 22, ${ }^{242} \mathrm{Pu}$ is sersitive only to initial ${ }^{235} \mathrm{U}$ enrichment. Because $:$ precursor is ${ }^{241} \mathrm{Pu},{ }^{242} \mathrm{Pu}$ has the same behavior as ${ }^{241}$ pu does, except for high exposures. At these high exposures, ${ }^{242} \mathrm{Pu}$, with its long half-life and lack of fissioning, continues to build up when significant quantities of ${ }^{241} \mathrm{Pu}$ are depleting through the fissioning process. 

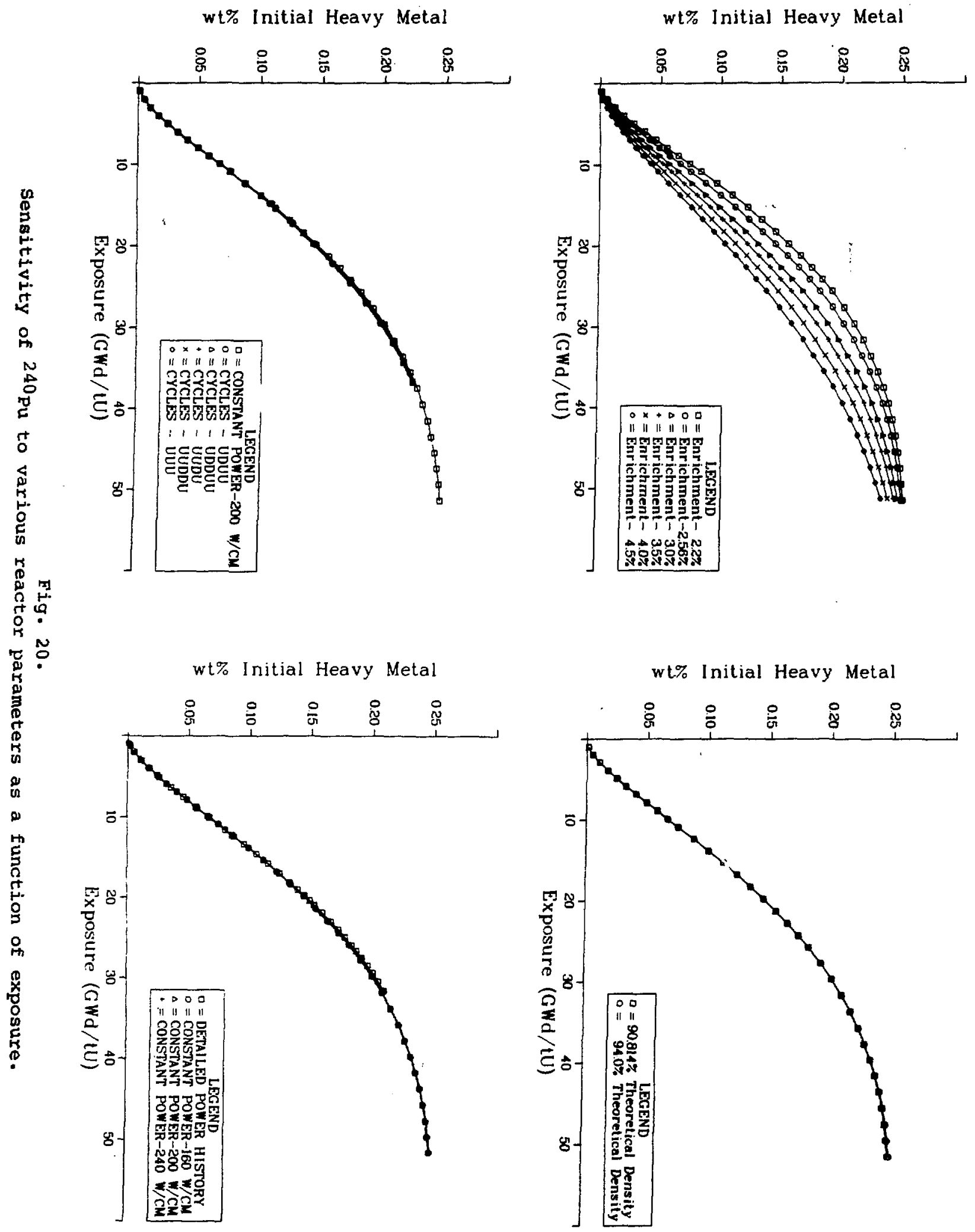


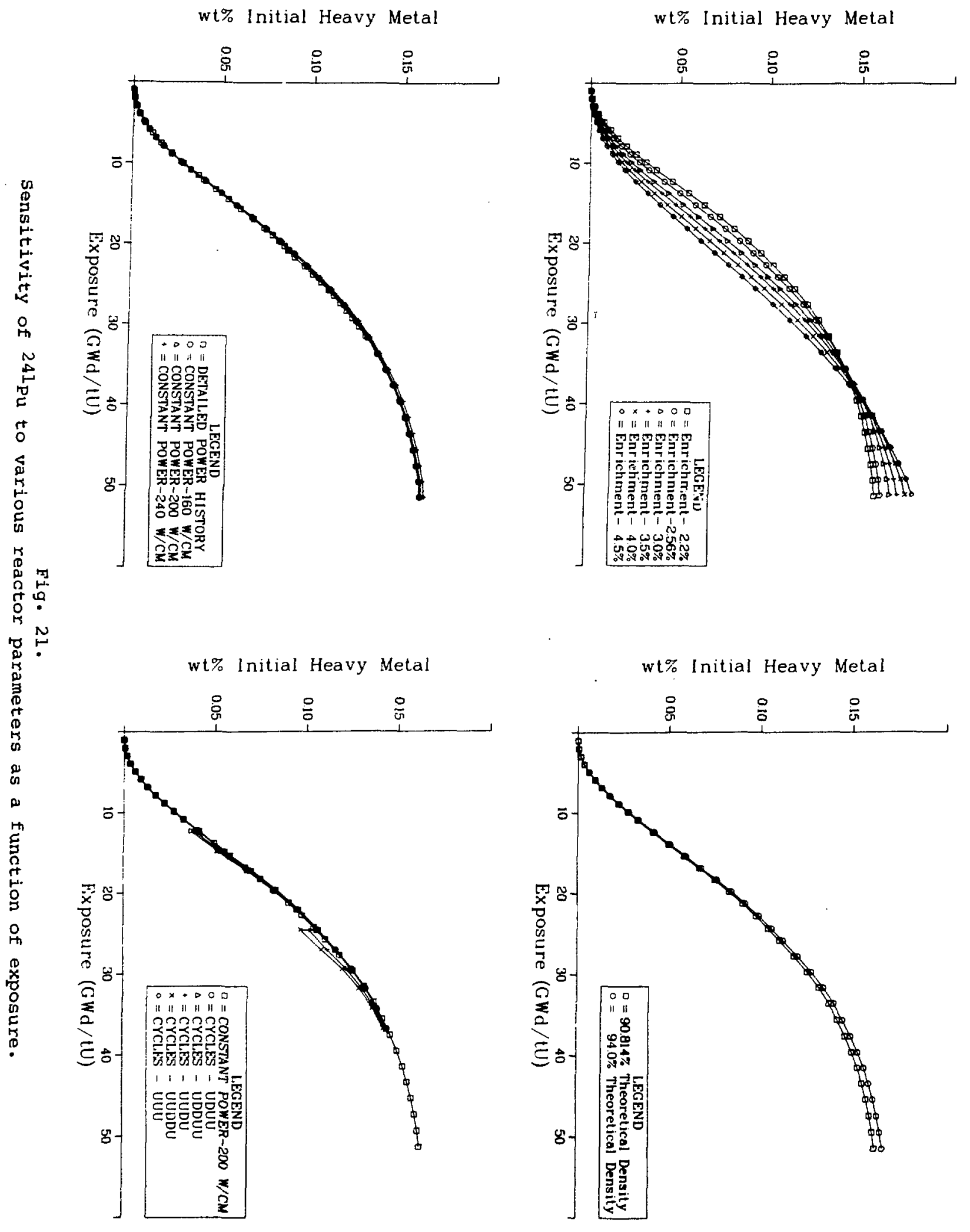



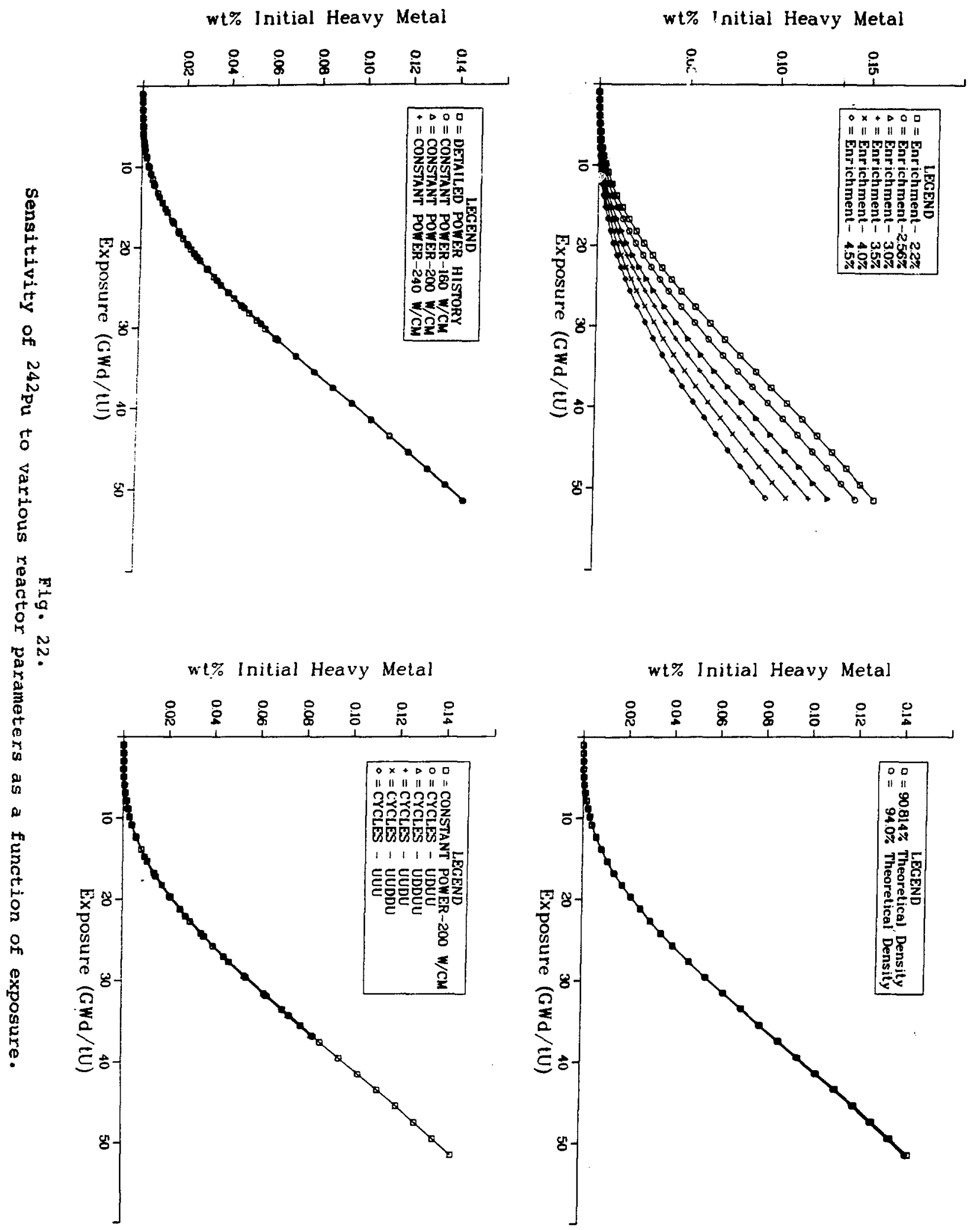
The americium isotopes are important for two reasons: (1) they are precursors of the important neutron-producing curium isotopes and (2) in some situations ${ }^{24 l_{A m}}$ can be a significant neutron producer from $(\alpha, n)$ reactions. Americium-241 production and depletion chains are shown in Fig. 1.

1. Americium-241 $\left(t_{1 / 2}=4.32 \times 10^{2} \mathrm{yr}\right)$. Figure 23 shows $241 \mathrm{Am}$ as a function of exposure and time for a detailed power history. This isotope is formed primarily from beta decay of ${ }^{241} \mathrm{Pu}$. Because ${ }^{241} \mathrm{Pu}$ has a relatively short half-life, ${ }^{241}$ Am continues to build up during shutdown and after fuel discharge from the reactor. Americium-241 depletes through neutron capture to form ${ }^{242}$ Am and by alpha decay.

2. Americium-242 (t $/ 2=16.0 \mathrm{~h}) \cdot$ Americium-242 (Fig. 24) is produced from neutron capture in $24 \mathrm{Im}_{\mathrm{Am}}$. In addition to the ground state, a metastable state of ${ }^{242} \mathrm{Am}$ with a half-life of approximately $152 \mathrm{yr}$ is formed. This isotope depletes in two ways: through neutron capture to form ${ }^{243} \mathrm{Am}$ and through electron capture to form ${ }^{242} \mathrm{Pu}$. As a result of its very short half-life, the ground state of ${ }^{242} \mathrm{Am}$ decays rapidly during shutdown and after fuel discharge.

3 . Americium-243 $\left(t_{1}=7.38 \times 10^{3} \mathrm{yr}\right)$
of $243 \mathrm{Am}$. This isotope builds up principally from beta decay in $243_{\mathrm{Pu}}$; some $243 \mathrm{Am}$ also is produced from neutron capture in ${ }^{242} \mathrm{Am}$. Americium-243 depletes principally through neutron capture to form ${ }^{244} \mathrm{Am}$. Because the half-life of $243 \mathrm{Am}$ is long, concentrations of this isotope are unaffected by shutdowns and cooling periods.

4. Americium-244 $t_{1 / 2}=10.1 \mathrm{~h}$. The most important precursor of $244 \mathrm{~cm}$ is $244 \mathrm{Am}$ (Fig. 26). Its production results from neutron capture in $243 \mathrm{Am}$ and a metastable state of ${ }^{244} \mathrm{Am}$ with a half-life of approximately $26 \mathrm{~min}$ is also produced. Both the ground state and metastable state beta decay to form ${ }^{244} \mathrm{~cm}$. As a result of its short half-1ife, concentrations of ${ }^{244}$ Am decay rapidly during shutdown and after fuel discharge. 

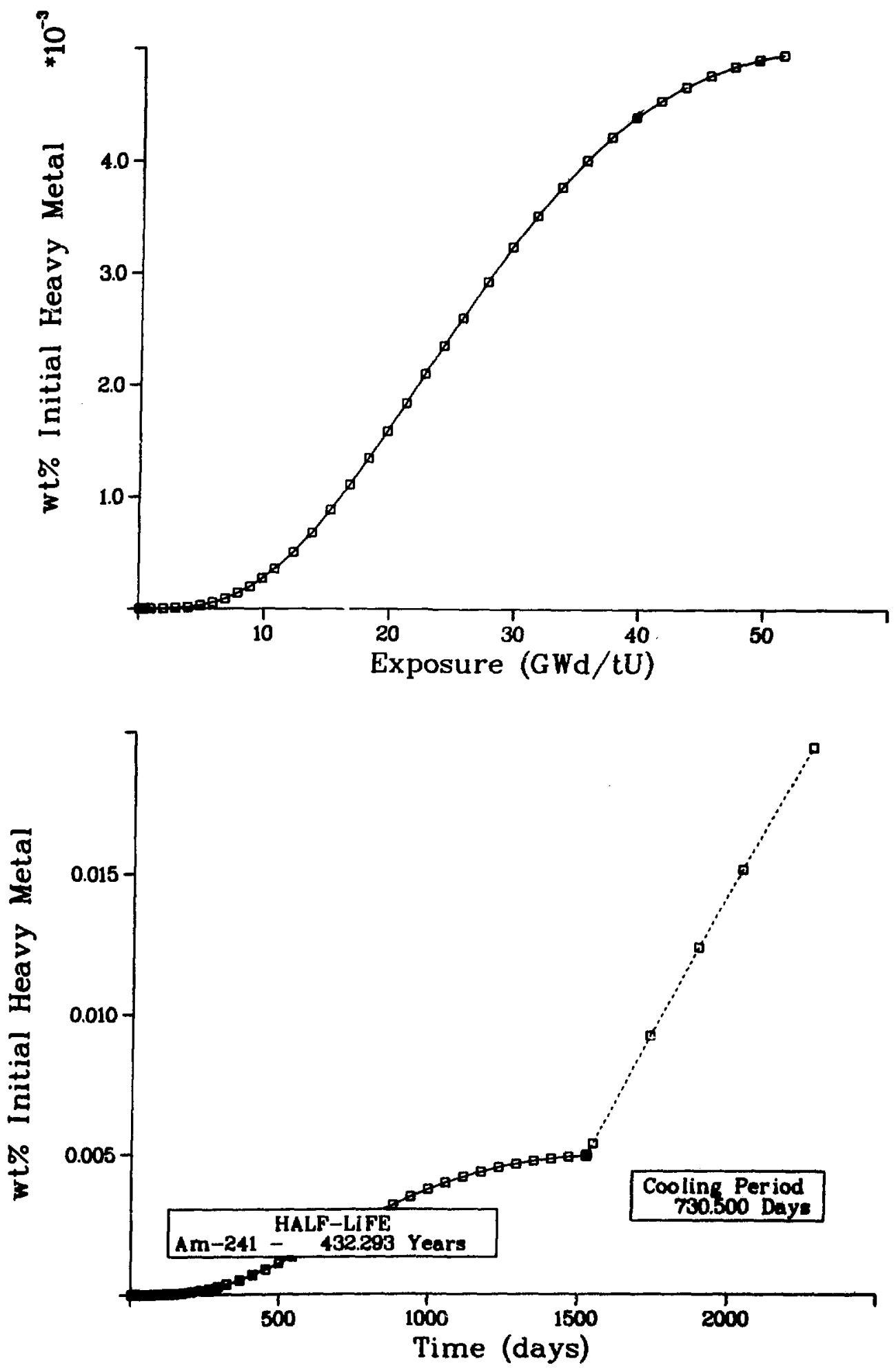

Fig. 23.

Concentration of ${ }^{241} \mathrm{Am}$ as a function of exposure and irradiation/ cooling time. 

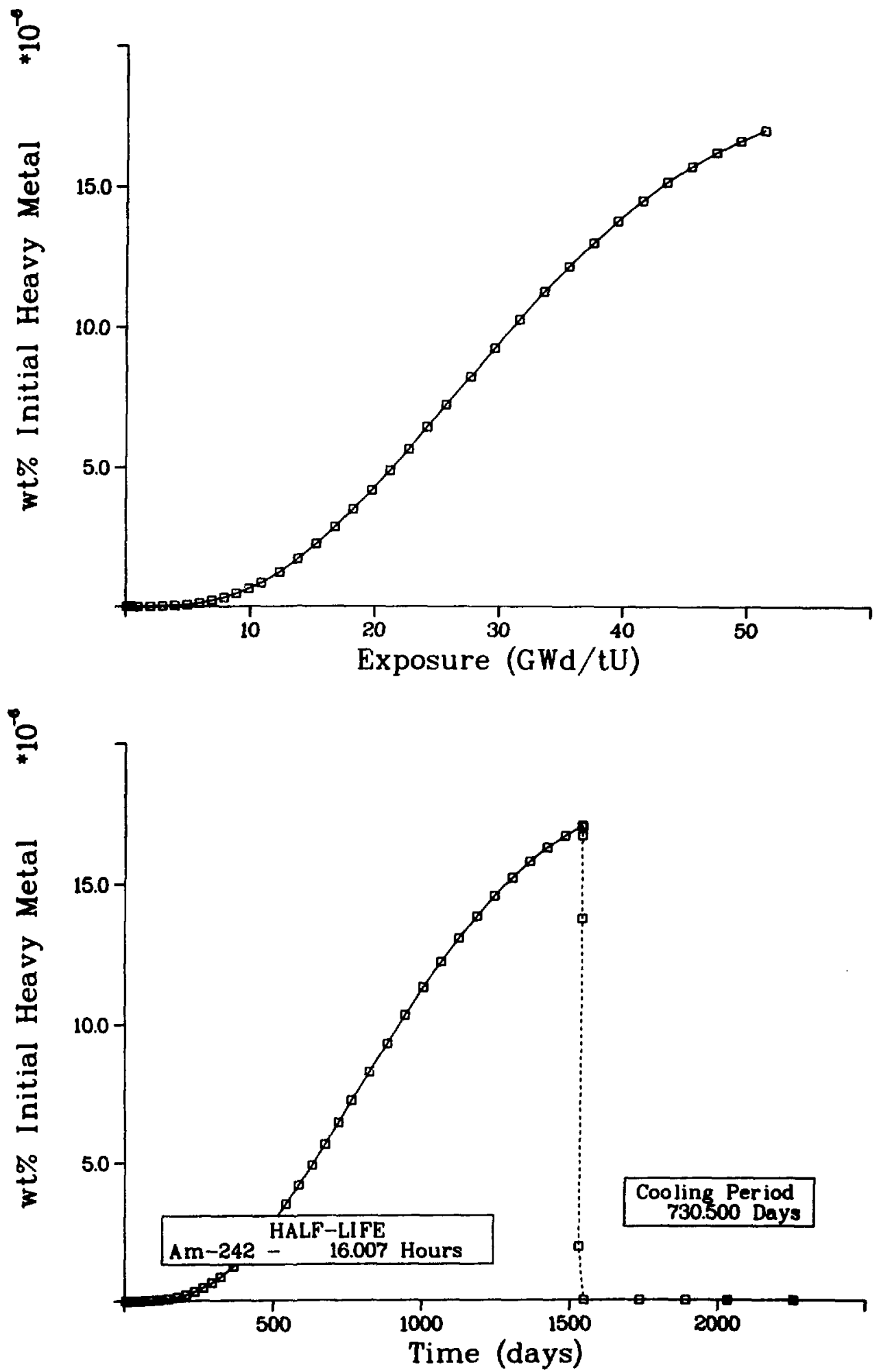

Fig. 24 .

Concentration of $242 \mathrm{Am}$ as a function of exposure and irradiation/ cooling time. 

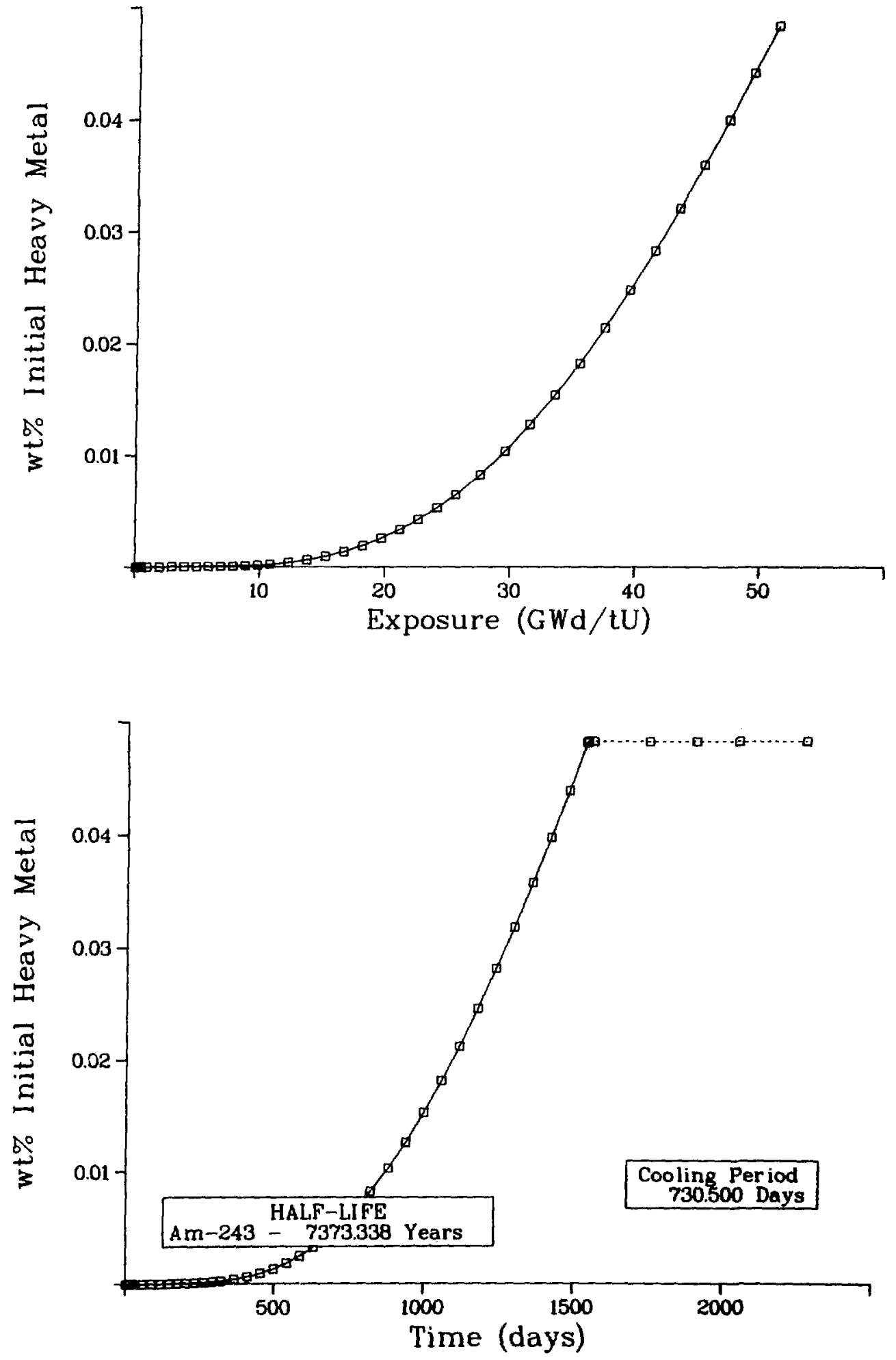

Fig. 25.

Concentration of ${ }^{243} \mathrm{Am}$ as a function of exposure and irradiation/ cooling time. 

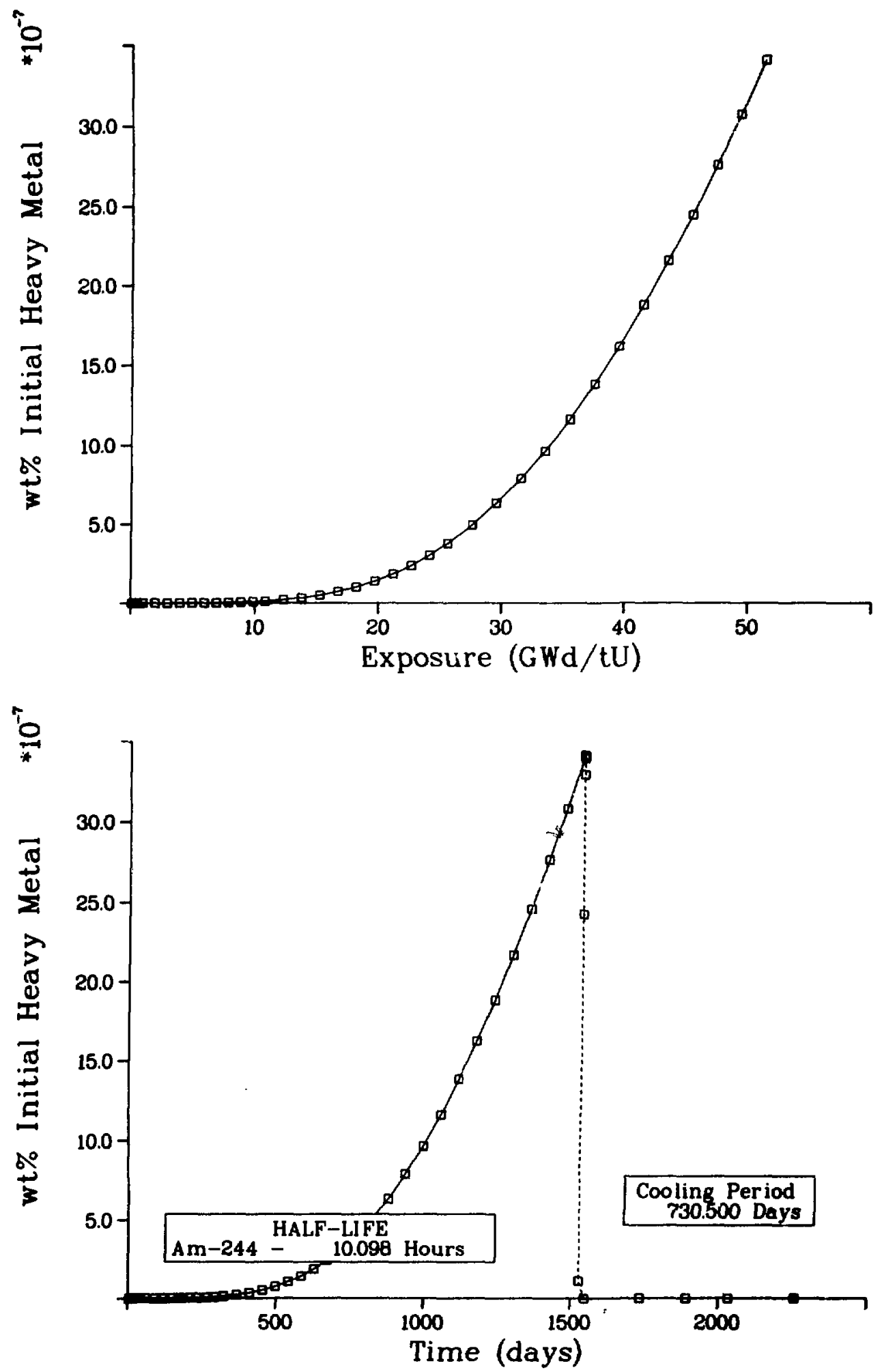

Concentration of ${ }^{244} \mathrm{Am}$ as a function of exposure and irradiation/ cooling time. 


\section{Sensitivity of Principal Americium Isotopes.}

a. Anericium-241. Results of the sensitivity studies of ${ }^{241} \mathrm{Am}$ are shown in Fig. 27. Because ${ }^{24}{ }_{\mathrm{Am}}$ builds up from beta decay in ${ }^{241}$ Pu, its sensitivity to initial ${ }^{235} \mathrm{U}$ enrichment is similar to ${ }^{241} \mathrm{Pu}$ behaviox. For high exposures, ${ }^{241} \mathrm{Am}$ is proportional to the initial ${ }^{235} \mathrm{U}$ enrichment, and for low exposures the ${ }^{241} \mathrm{Am}$ concentration is inversely dependent on initial ${ }^{235} \mathrm{U}$ enrichment. For

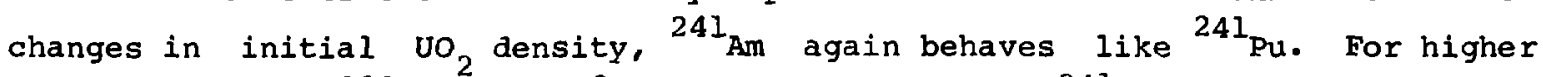

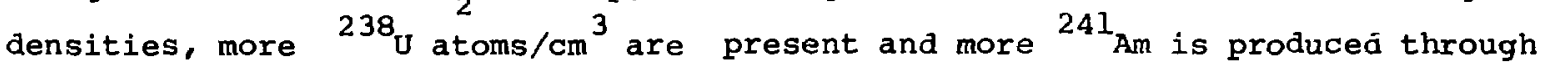
the appropriate chains.

Americium-24l sensitivity to power level is shown in the lower left curves of Fig. 27. With the same initial ${ }^{235} \mathrm{U}$ enrichment, higher power levels are accomplished only with higher flux levels. Because of these higher flux levels, more ${ }^{24 l_{\mathrm{Pu}}}$ fissioning occurs and less ${ }^{24 l_{\mathrm{Pu}}}$ is available for beta decay to

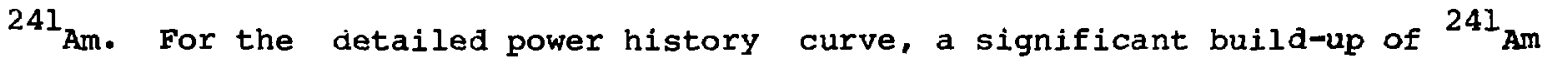
occurred during a 69-day reactor shutdown.

In the buttom right set of curves of Fig. $27,{ }^{241} \mathrm{Am}$ sensitivity to the shutdown again is observed. During the 1-yr shutdown periods, ${ }^{241} \mathrm{Am}$ continues to build up. Because some ${ }^{241} \mathrm{Pu}$ has decayed during the shutdown, immediately after the reactor is brought on-line more ${ }^{241} \mathrm{Am}$ is depleted than is produccd. Eventually, when ${ }^{241} \mathrm{Pu}$ concentrations again are high enough, the ${ }^{241}$ Am production rate exceeds the capture rate.

b. Americium 242. Sensitivity effects of $242 \mathrm{Am}$ are shown in Fig. 28. Because ${ }^{242} \mathrm{Am}$ is produced from neutron capture in ${ }^{241} \mathrm{Am}$, the ${ }^{242} \mathrm{Am}$ dependence on initial ${ }^{235} \mathrm{U}$ enrichment behaves like the ${ }^{241} \mathrm{Am}$. Note that for high exposures the curves in the upper left graph of Fig. 28 are just beginning to change from being inversely proportional to initial ${ }^{235} \mathrm{U}$ enrichment to the opposite. As shown in the upper right graph of Fig. 28, ${ }^{242}$ Am has the same dependence on initial $\mathrm{UO}_{2}$ mass density as does its precursor ${ }^{241} \mathrm{Am}$. Continuous power levels have little effect on ${ }^{242} \mathrm{Am}$ as shown by three of the curves in the lower left graph of Fig. 28. For the detailed power history, ${ }^{242}$ Am rapidly depletes during shutdown. Note the same behavior in the lower right graph of Fig. 28. After the reactor is brought back to power, a rapid build-up of 242 An occurs because the ${ }^{241}$ Am source material has built up during the shutdown. 


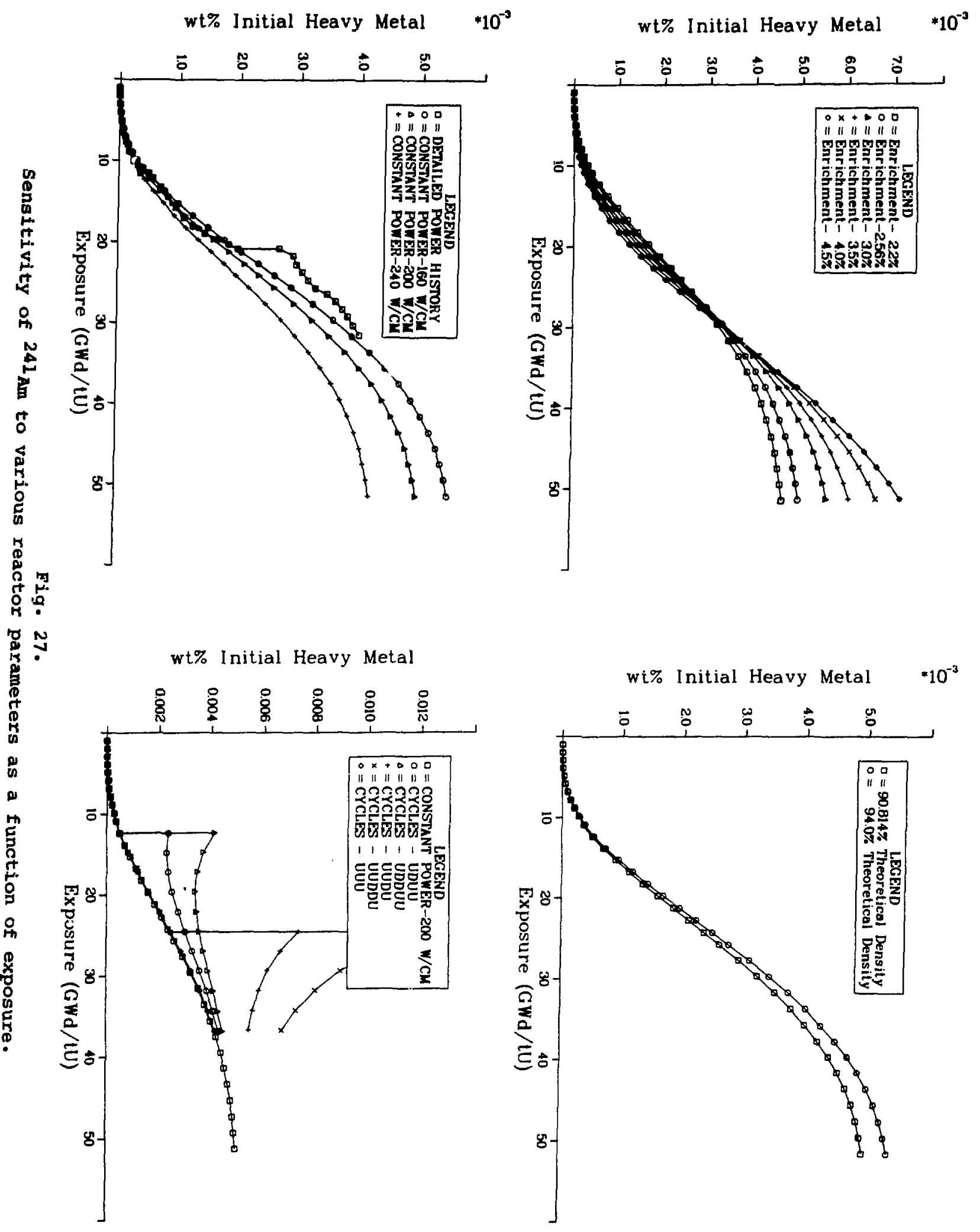




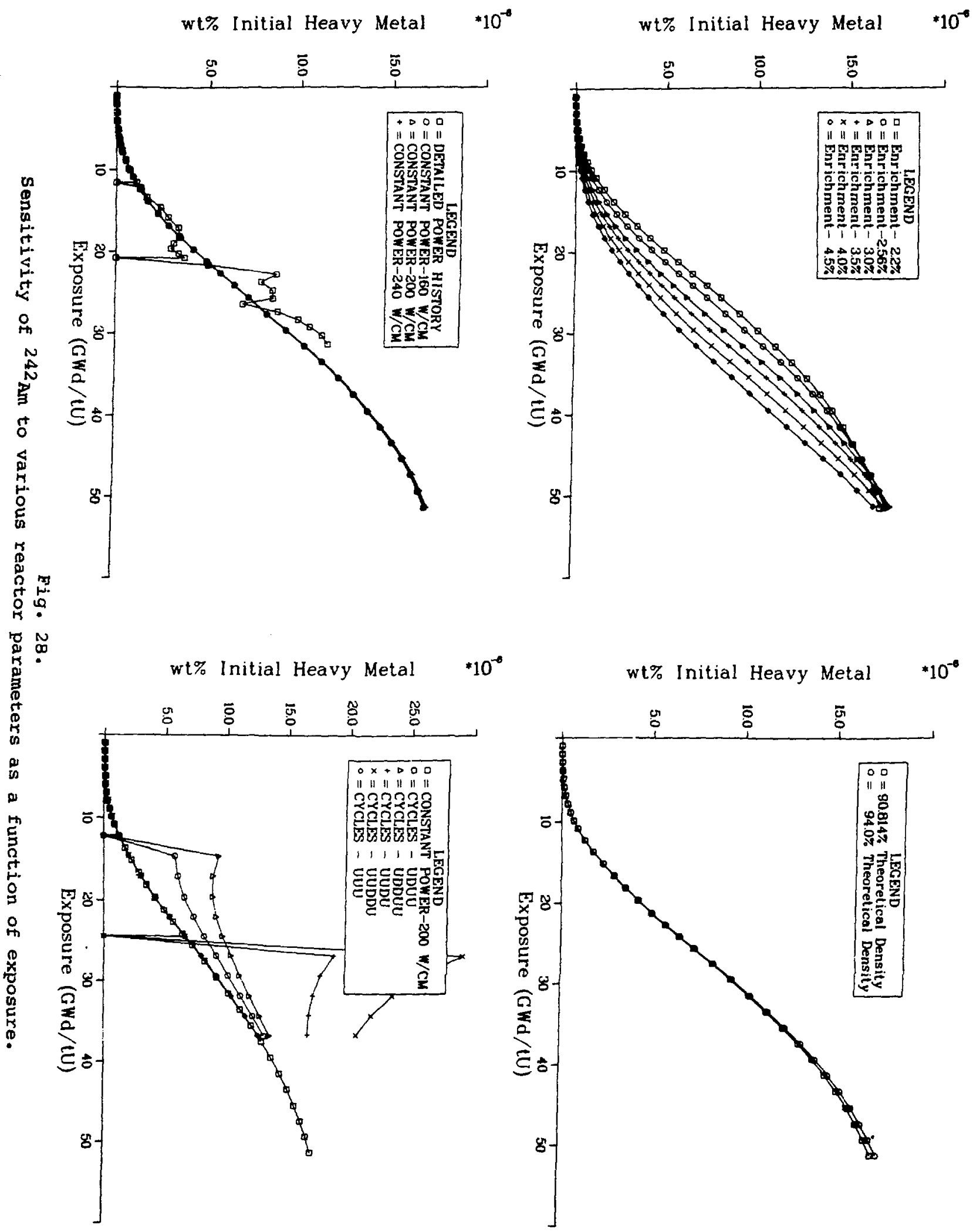


c. Americium-243. Sensitivity plots of ${ }^{243} \mathrm{Am}$ are shown in Fig. 29. The initiai ${ }^{235} \mathrm{U}$ enrichment sensitivity follows the behavior of the principal precursor ${ }^{243} \mathrm{Pu}$. Americium-243 has little sensitivity to the other three variables (initial Uo 2 mass density, power level, and irradiation history).

d. Americium-244. Americium-244 sensitivities are shown in Fig. 30 . This isotope has the same sensitivity to initial ${ }^{235} \mathrm{U}$ enrichment as does its precursor $243 \mathrm{Am}$. A slight sensitivity to initial $\mathrm{NO}_{2}$ density occurs. In the lower left graph of Fig. 30, higher flux levels necessary to achieve higher power levels cause more ${ }^{244} \mathrm{Am}$. As shown in the lower right graph of Fig. 30, $244 \mathrm{Am}_{\mathrm{m}}$ is insensitive to irradiation history. During shutdowns, ${ }^{244} \mathrm{Am}$ decays rapidly; however, because its precursor ${ }^{243} \mathrm{Am}$ has a long half-life, $244 \mathrm{Am}$ quickly builds up after the reactor is restarted.

\section{E. Curium Isotopes}

The importance of the curium isotopes in LWR spent-fuel assemblies is well known. As shown in Table IV, spontaneous fission and $(\alpha, n)$ neutron yields from ${ }^{242} \mathrm{~cm}$ are much larger than corresponding yields of other actinide isotopes produced in spent fuel. For exposures above $10 \mathrm{GWJ} / \mathrm{tU}$, significant quantities of ${ }^{242} \mathrm{~cm}$ and ${ }^{244} \mathrm{Cm}$ are produced, making these isotopes the dominant neutron sources in a LWR assembly. Curium-240 and -246 are not produced in large enough quantities to be important neutron sources. Because of the curium dominance as neutron sources, any passive neutron measurement technique used to monitor spent-fuel assemblies must incorporate knowledge of the production and decay of the curium isotopes.

1. Curiun-242 (t ${ }_{1 / 2}=162.9$ days). Figure 31 shows ${ }^{242} \mathrm{~cm}$ build-up. This isotope is produced primarily through beta decay of ${ }^{242} \mathrm{Am}$; it depletes through alpha decay, spontaneous fission, and neutron capture. With its fairly short half-J.ife, significant amounts of ${ }^{242} \mathrm{Cm}$ deplete during reactor shutdown. This is an important point. Correlations between ${ }^{244} \mathrm{Cn}$ concentrations and parameters such as plutonium content depend on measuring accurately count rates resulting only from ${ }^{244} \mathrm{Cm}$ neutrons. Interference from ${ }^{242} \mathrm{Cm}$ neutrons can be avoided by measuxing fuel assemblies with cooling times long enough such that most of the ${ }^{242} \mathrm{~cm}$ has decayed. Generally, spent-fuel assemblies with cooling times of 2 yr or more contribute little ${ }^{242} \mathrm{Cm}$ to the neutron rate. 


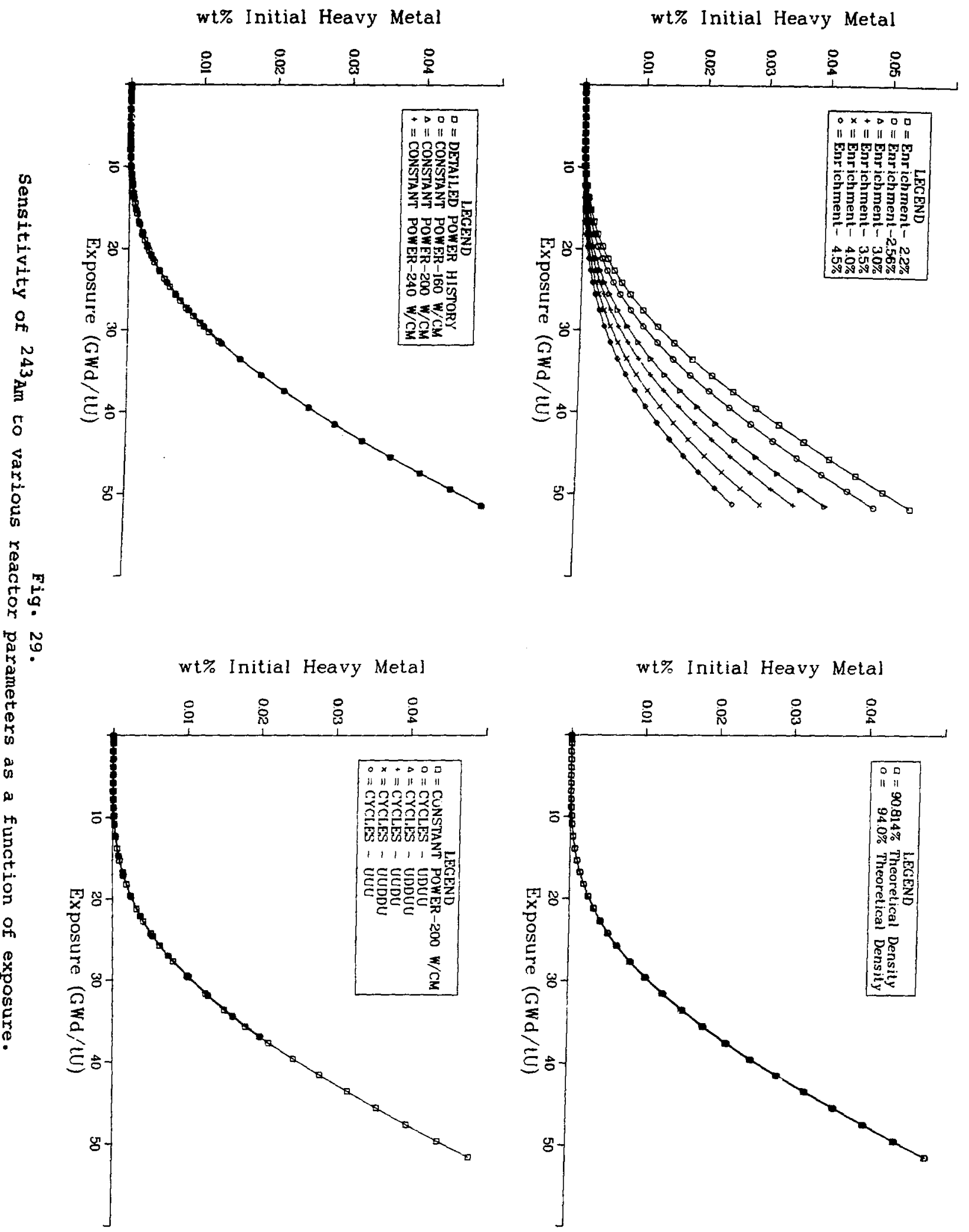




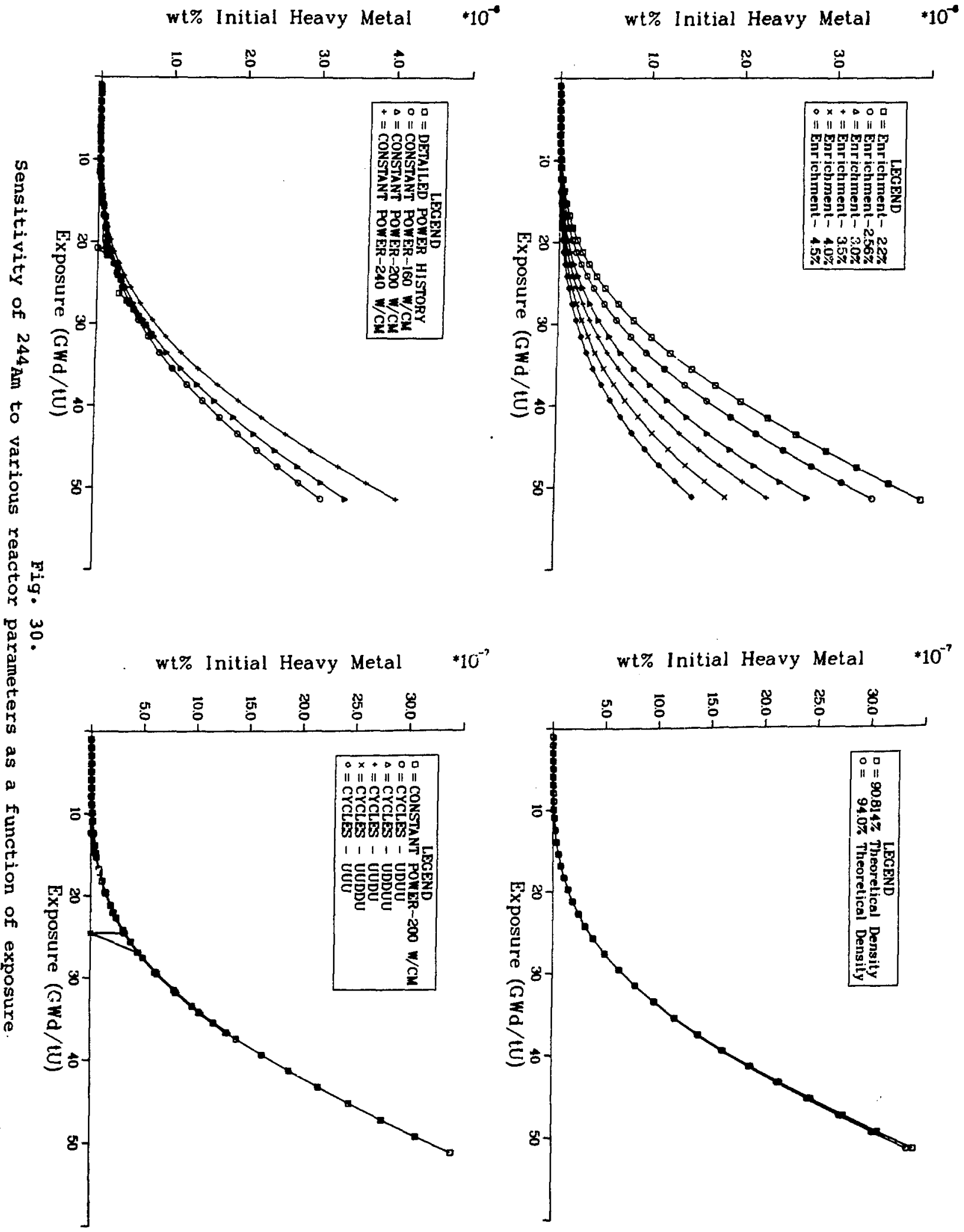



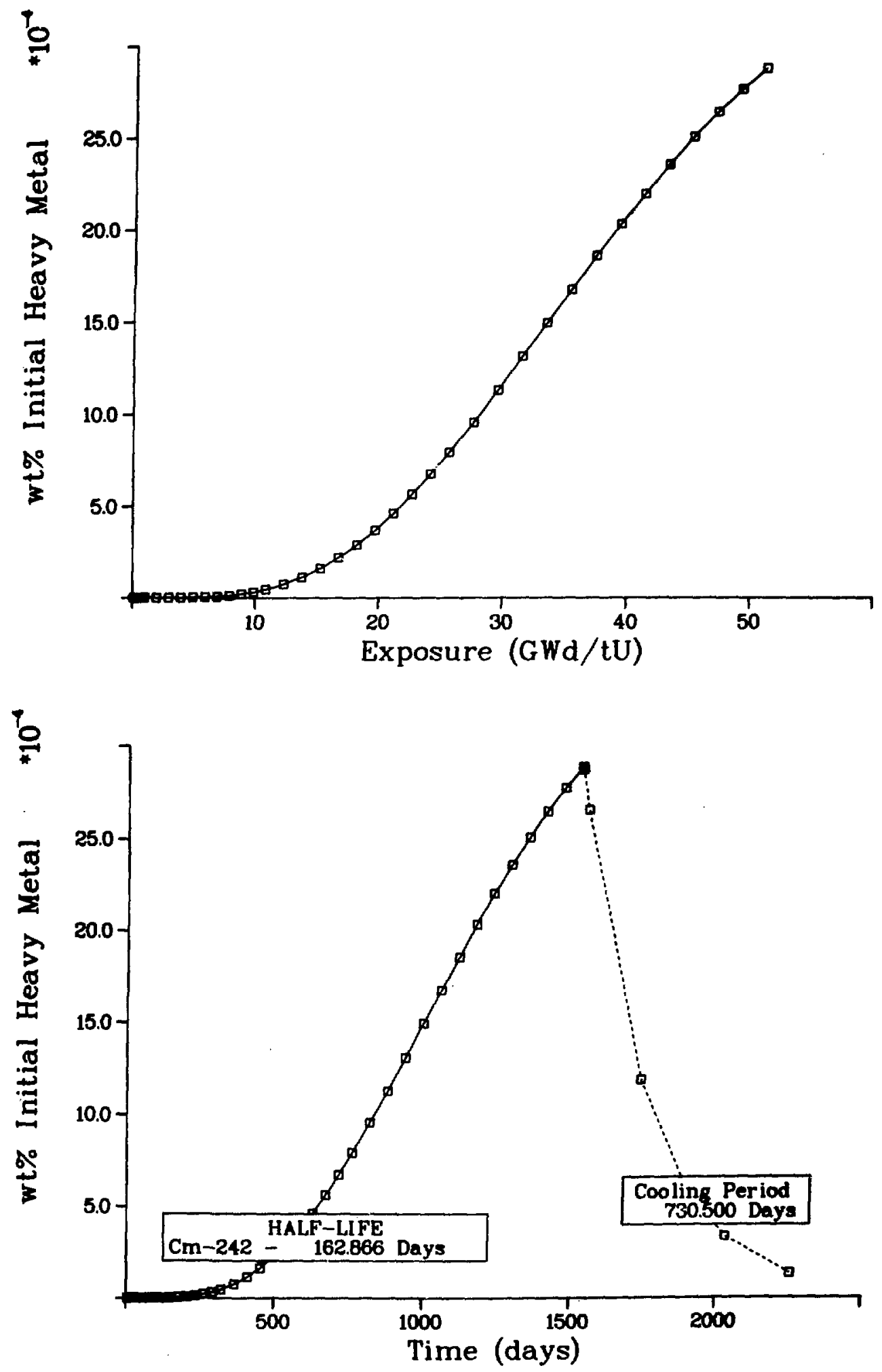

Fig. 31.

Concentration of ${ }^{242} \mathrm{Cm}$ as a function of exposure and irradiation/ cooling time. 
2. Curium-243 (t $1 / 2=28.5 \mathrm{yr}$ ). Curium-243 (Fig. 32), produced from neutron capture in ${ }^{242} \mathrm{~cm}$, depletes by neutron capture and alpha decay. With a 28.5-yr half-life, ${ }^{343} \mathrm{Cm}$ decays slowly after a fuel assembly is discharged from the reactor.

3. Curium-244 ( $\left.t_{1 / 2}=18.1 \mathrm{yr}\right)$. Curium-244 (Fig. 33) forms principally from beta decay in $244 \mathrm{Am}$, with some additional production from neutron capture in $243 \mathrm{~cm}$. Note that ${ }^{244} \mathrm{~cm}$ and ${ }^{242} \mathrm{~cm}$ are formed through different plutonium and americium precursors. Curium-242 is produced primarily from the ${ }^{241_{\mathrm{Pu}}} \rightarrow{ }^{241_{\mathrm{Am}}}$ $\rightarrow{ }^{242} \mathrm{Am} \rightarrow{ }^{242} \mathrm{Cm}$ chain, whereas most $244 \mathrm{Cm}$ comes from a ${ }^{243} \mathrm{Pu} \rightarrow 243_{\mathrm{Am}} \rightarrow{ }^{244} \mathrm{Am}$ $\rightarrow{ }^{244} \mathrm{Cm}$ chain. Curium-244 depletes through neutron capture, spontaneous fission, and alpha decay. With an 18.1-yr half-life, it decays gradually after discharge from a reactor.

4. Curium-245 ( $t_{1 / 2}=\frac{\left.8.48 \times 10^{3} \mathrm{yr}\right)}{244}$. Curium-245 (Fig. 34) forms principally from neutron capture in ${ }^{244} \mathrm{~cm}$ and depletes through alpha emission and neutron capture. The ${ }^{245} \mathrm{Cm}$ concentrations are not affected by periods of reactor shutdown or after the fuel is permanently removed from the reactor.

5. Curium-246 $\left(t_{1} / 2=4.73 \times 10^{3} \mathrm{yr}\right)$. Curium-246 (Fig. 35) is produced through neutron capture in ${ }^{245} \mathrm{Cm}$. The ${ }^{246} \mathrm{Cm}$ production is small compared to that of ${ }^{244} \mathrm{Cm}$ (see relative scales in Figs. 33 and 35 ). Because little ${ }^{246} \mathrm{Cm}$ is produced, it is not a principal source of neutrons in a spent-fuel assembly, despite its large spontaneous fission yield. This isotope also depletes through alpha emission and neutron capture. Because of its long half-life, concentrations of ${ }^{246} \mathrm{~cm}$ remain constant during reactor shutdown and after fuel discharge from the core.

\section{Sensitivity of Principal Curium Isotopes}

a. Curium-242. Curium-242 (Fig. 36) has the same sensitivities to initial ${ }^{235} \mathrm{U}$ enrichment and initial $\mathrm{UO}_{2}$ mass density as does its principal precursor ${ }^{242} \mathrm{Am}$. Curium-242 is sensitive to power level, as shown in the lower left graph of Fig. 36. In this case, higher fluxes associated with higher power levels convert more ${ }^{242} \mathrm{~cm}$ to ${ }^{243} \mathrm{~cm}$. As a result, lower power levels have higher ${ }^{242} \mathrm{Cm}$ concentrations. 

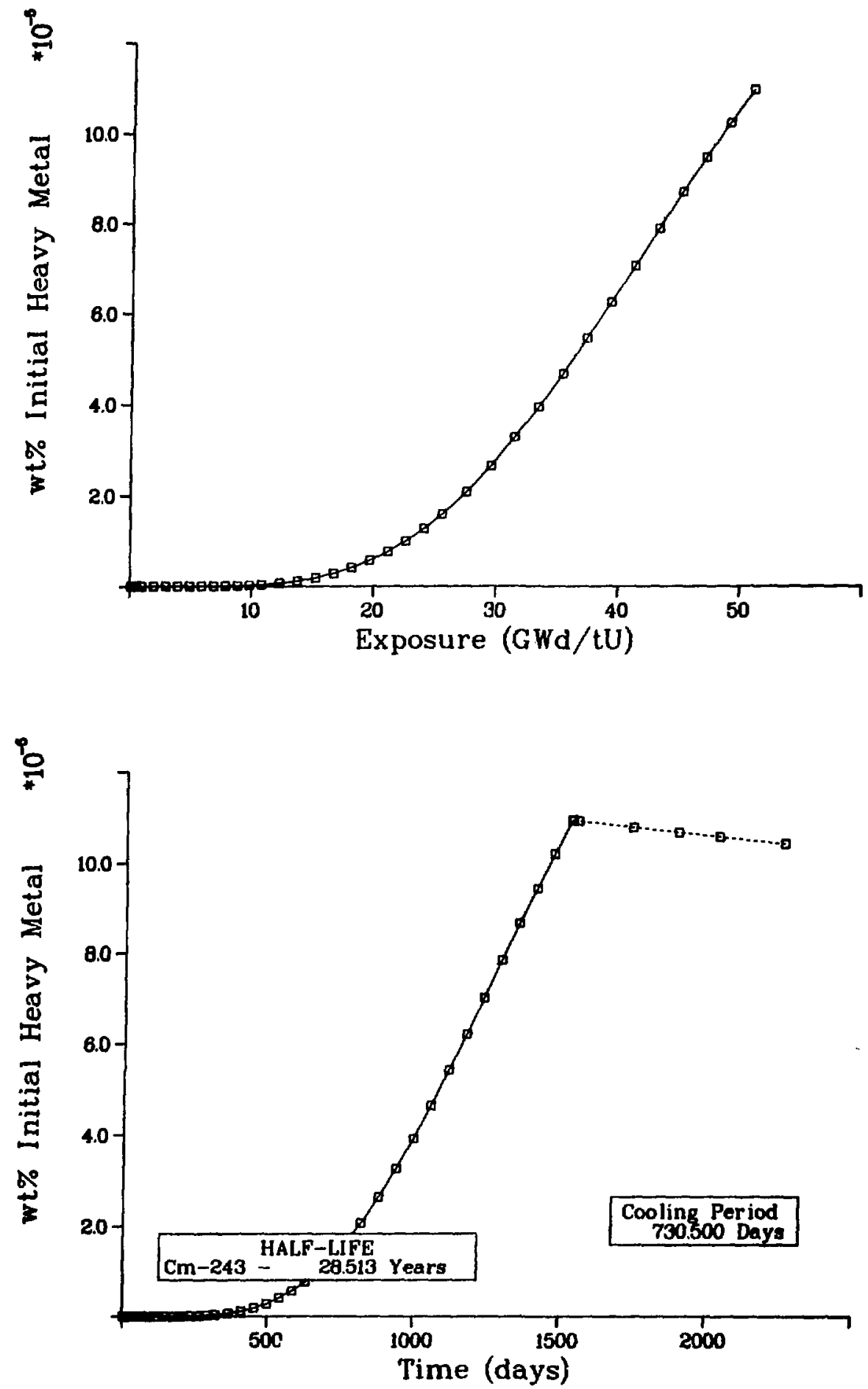

Fig. 32.

Concentration of $243 \mathrm{~cm}$ as a function of exposure and irradiation/ cooling time. 

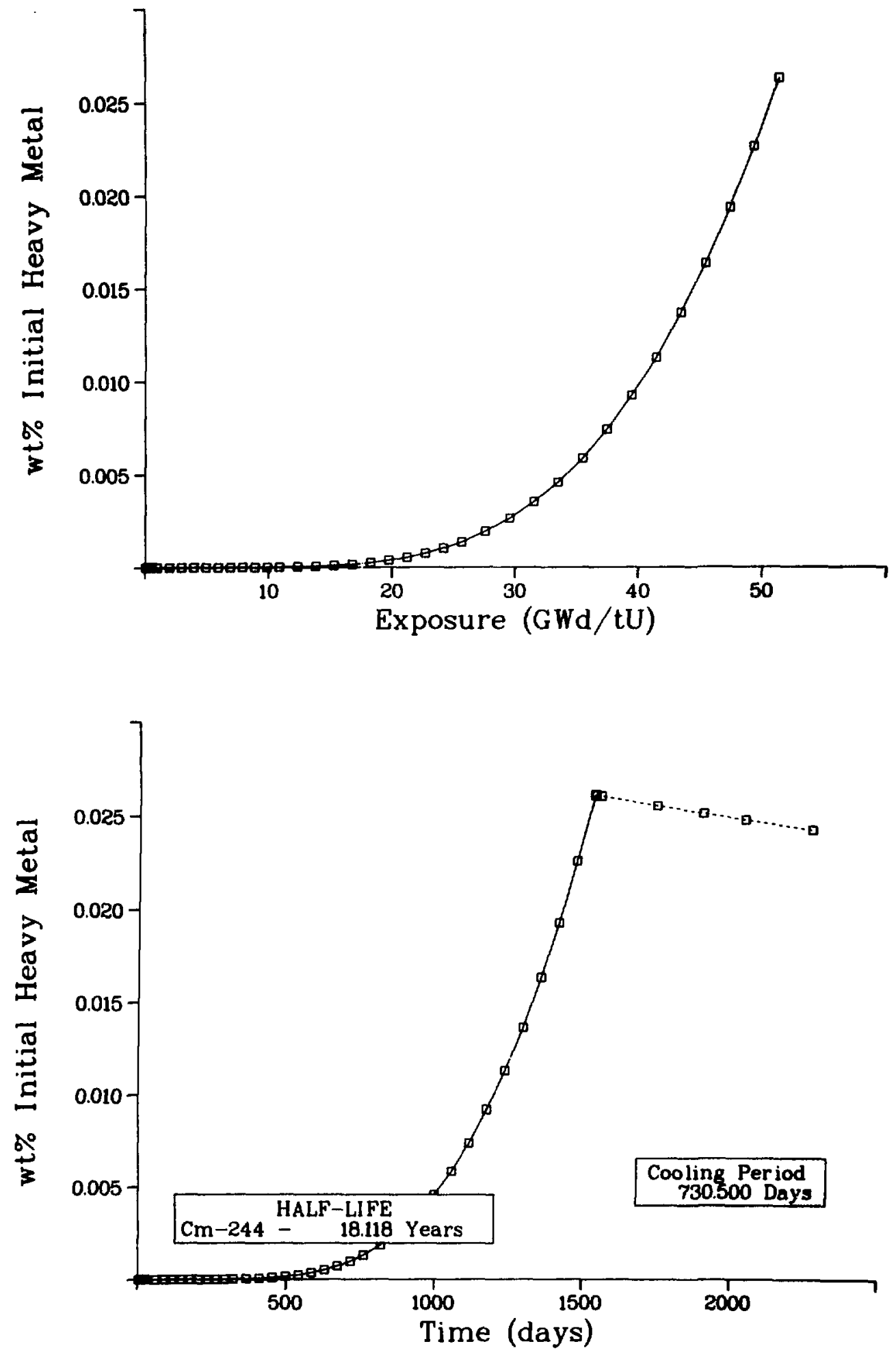

Fig. 33 .

Concentration of $244 \mathrm{~cm}$ as a function of exposure and irradiation/ cooling time. 

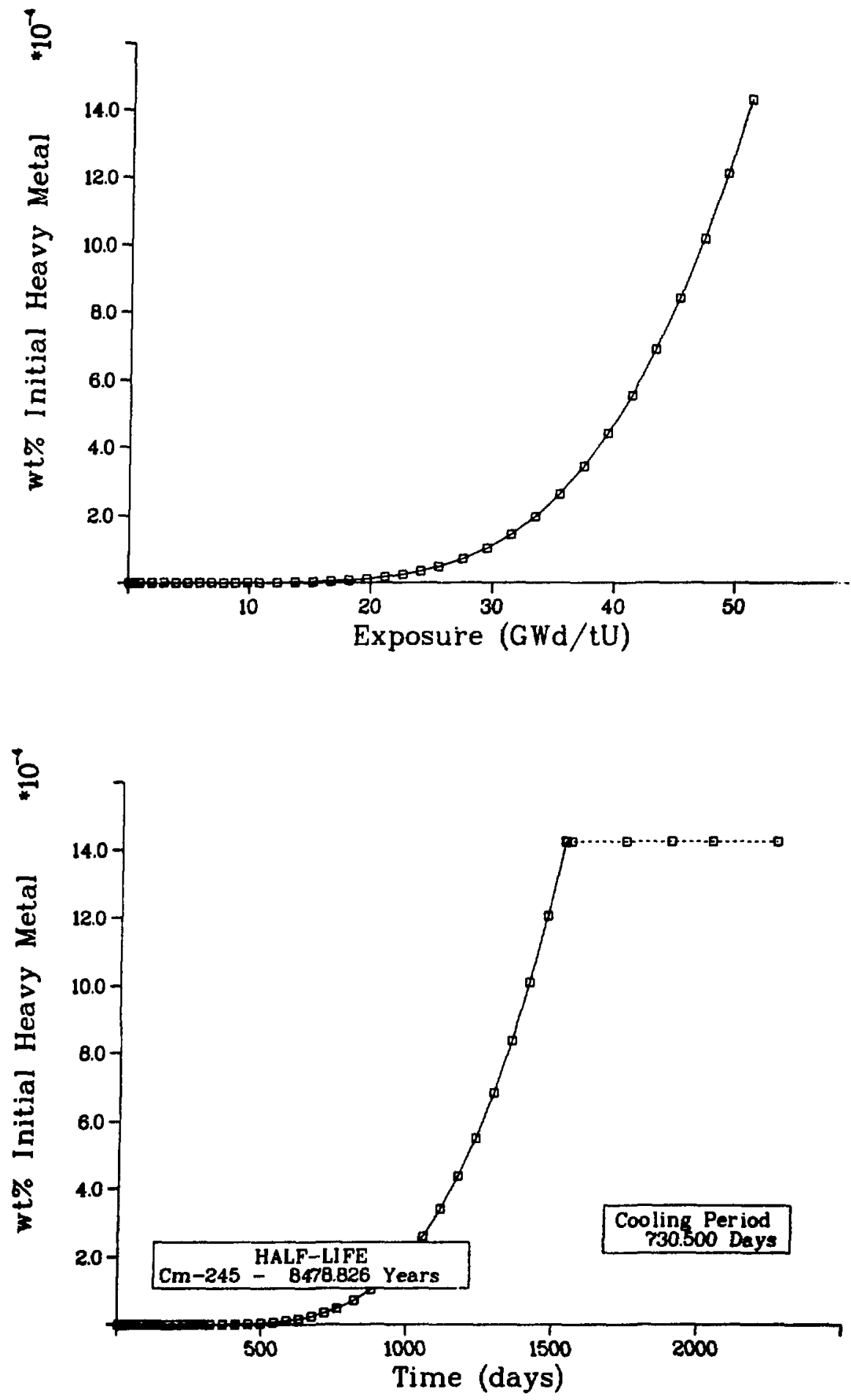

Fig. 34.

Concentration of $245 \mathrm{~cm}$ as a function of exposure and irradiation/ cooling time. 

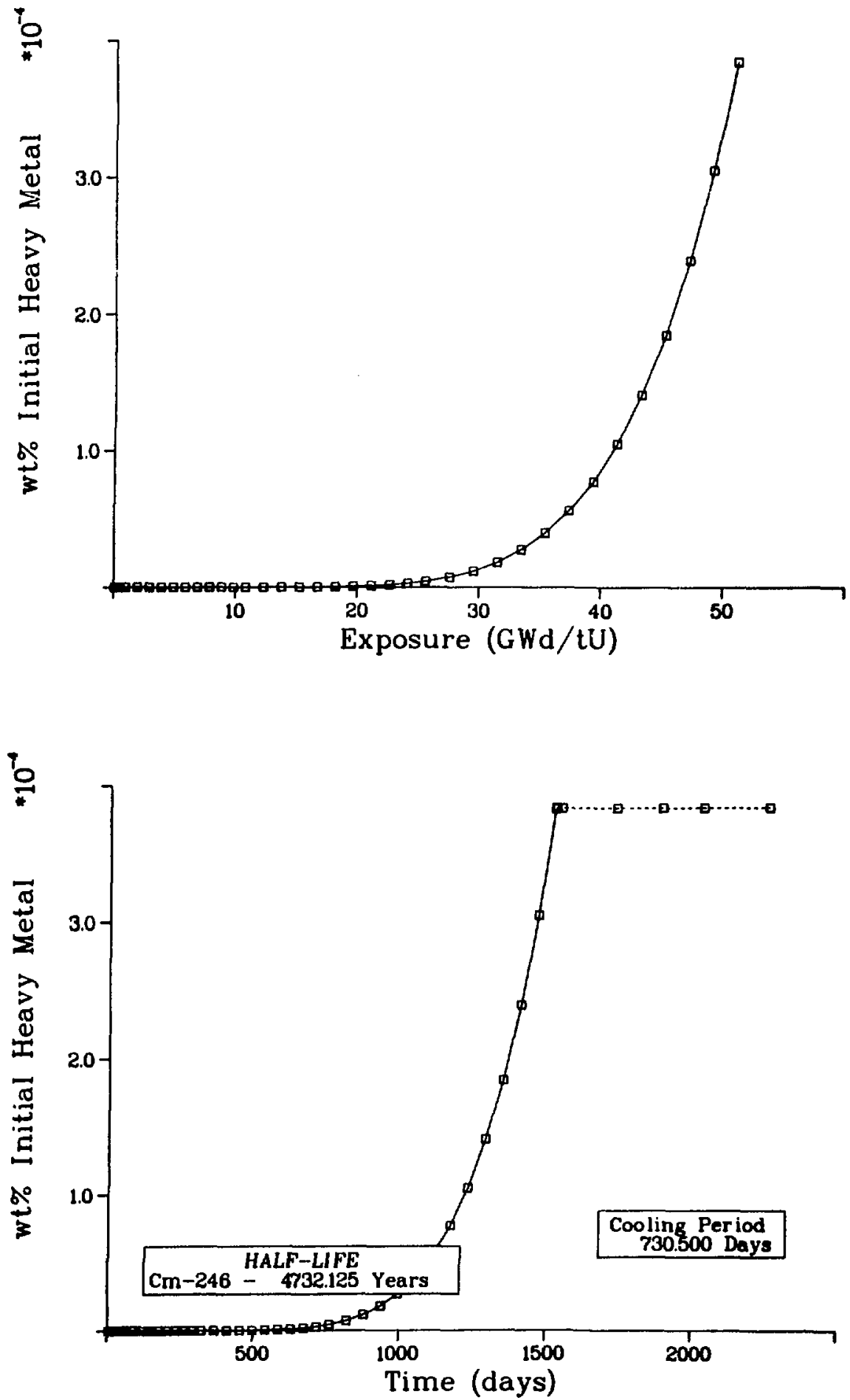

Fig. 35.

Concentration of ${ }^{246} \mathrm{~cm}$ as a function of exposure and irradiation/ cooling time. 


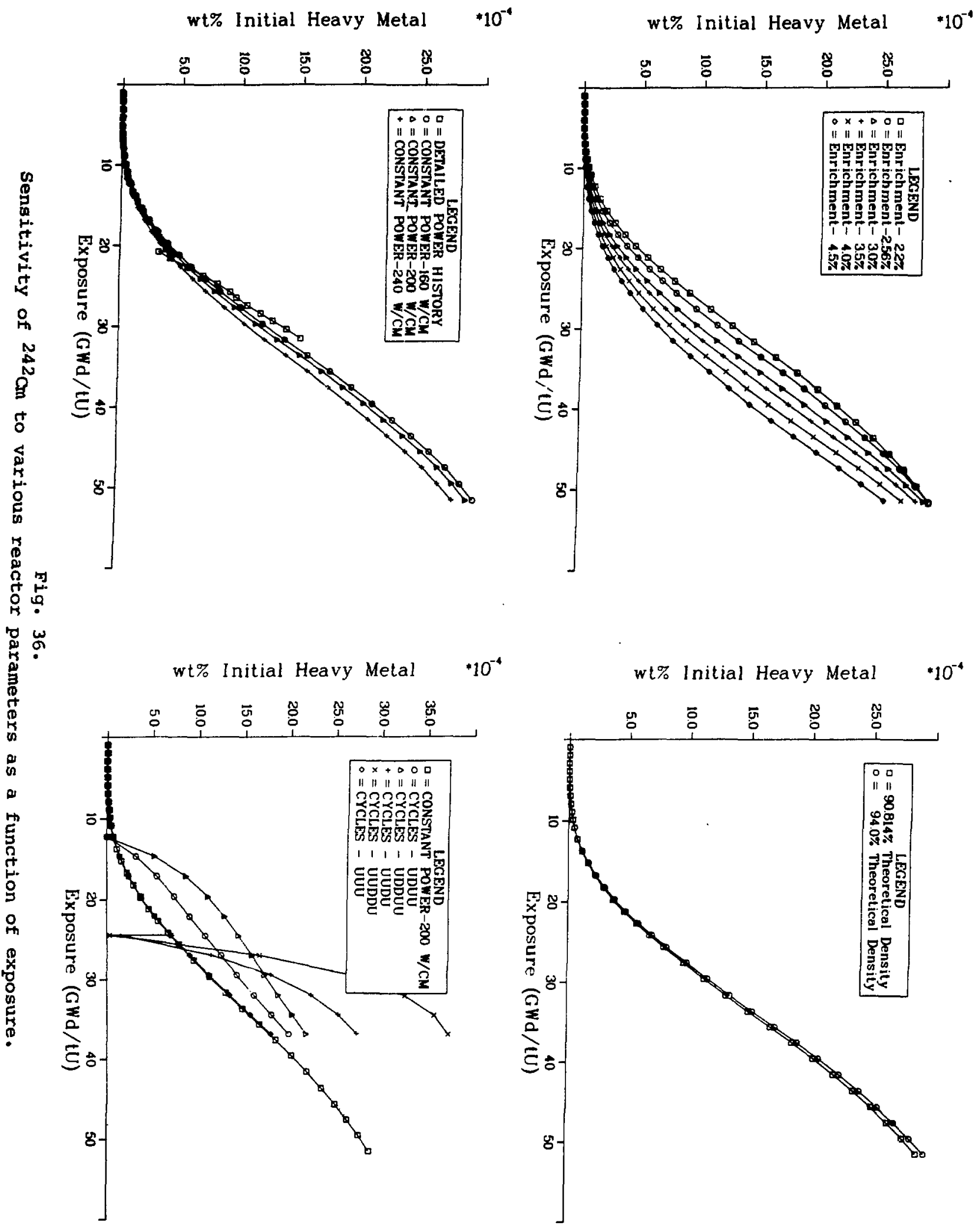


Irradiation history effects on ${ }^{242} \mathrm{Cm}$ are shown in the lower right graph of Fig. 36. For 1-yr shutdowns, significant quantities of ${ }^{242} \mathrm{~cm}$ decay. However, soon after restart, the ${ }^{242} \mathrm{~cm}$ quickly builds back in because of the increased ${ }^{241} \mathrm{Am}$ source material produced from the beta decay of ${ }^{241} \mathrm{pu}$.

b. Curium-244. Curium-244 sensitivities are shown in Fig. 37. Its sensitivity to initial $235_{\mathrm{U}}$ enrichment and initial vo ${ }_{2}$ mass density follows the behavior of its principal precursor ${ }^{244} \mathrm{Am}$. Because of its sufficiently long half-life, ${ }^{244} \mathrm{~cm}$ is not affected by changes in power levels or irradiation histories.

IV. DATA ANALYSIS AND POTENTIAL APPLICATIONS

Sensitivity results for total plutonium and uranium are shown in Figs. 38 and 39. Although the isotopic composition varies, depending on initial conditions, the total plutonium and uranium concentrations are insensitive to initial ${ }^{235} \mathrm{U}$ enrichment, $\mathrm{UO}_{2}$ mass density, power level, and irradiation history. Typical plutonium isotopic dependence on exposure is shown in Figs. 40 and 41 . In Fig. 40, the isotopics are displayed as a function of the heavy metal content; in Fig. 4l, the variations are relative to the total plutonium.

Generally, plutonium isotopic data, either operator declared or destructively measured, are reported as weight per cent of the total plutonium. Therefore, data resembling those in Fig. 41 can be used to verify operatordeclarea values, and available destructive data can be used to establish the accuracy of the calculated curves.

To verify operator-declared values, an inspector first determines through nondestructive measurement techniques (perhaps neutron measurements) the exposure level of the material sample. From curves like those in Fig. 41, which represent the type of material being analyzed, the inspector uses the measured data to estimate the sample's isotopic content. Although the absolute accuracy of the technique depends partly on how well the parameters used to generate the isotopic concentration curves match similar parameters for the sample being evaluated, this method should be sufficiently accurate in alerting the inspector to possible discrepancies needing further investigation. 

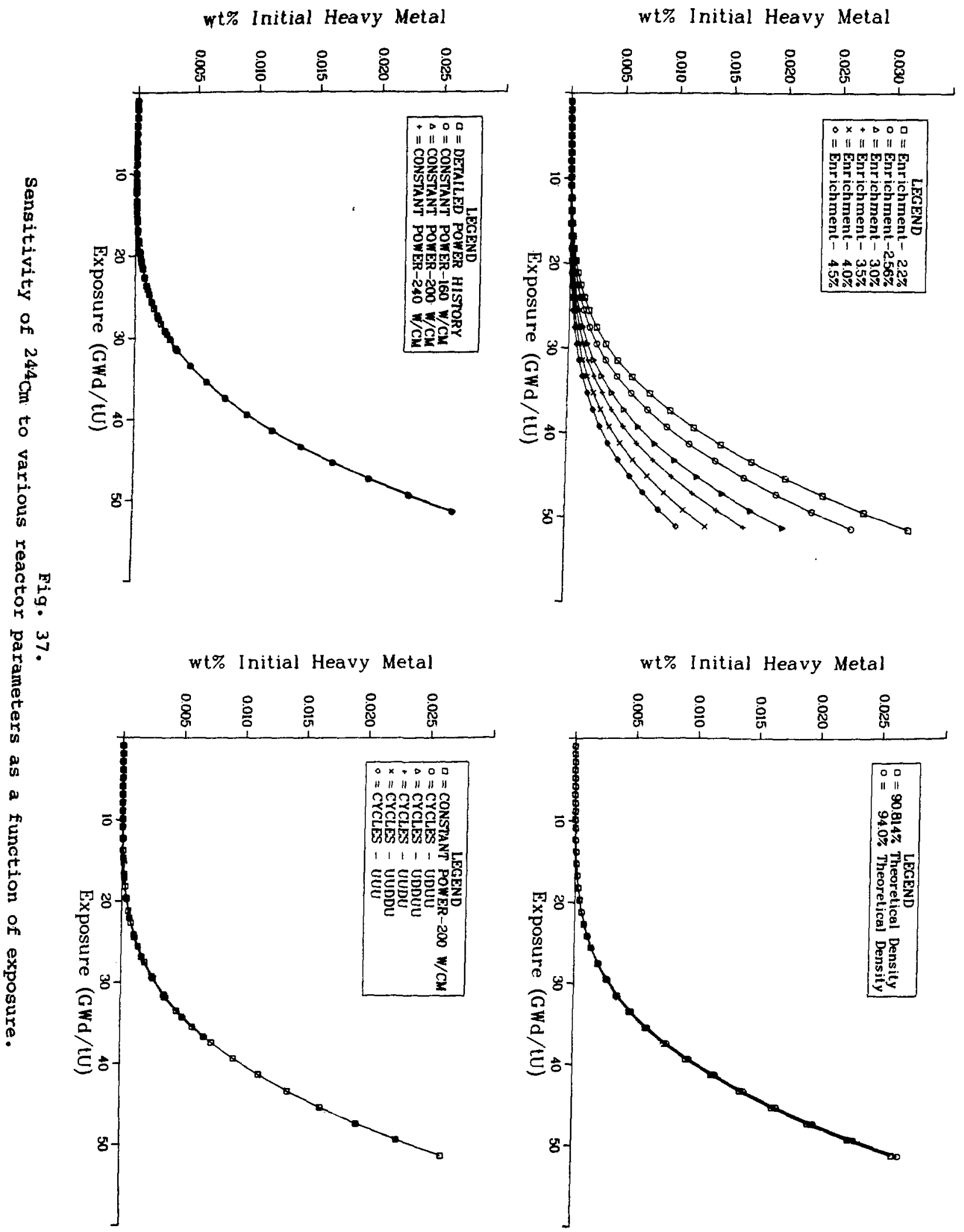

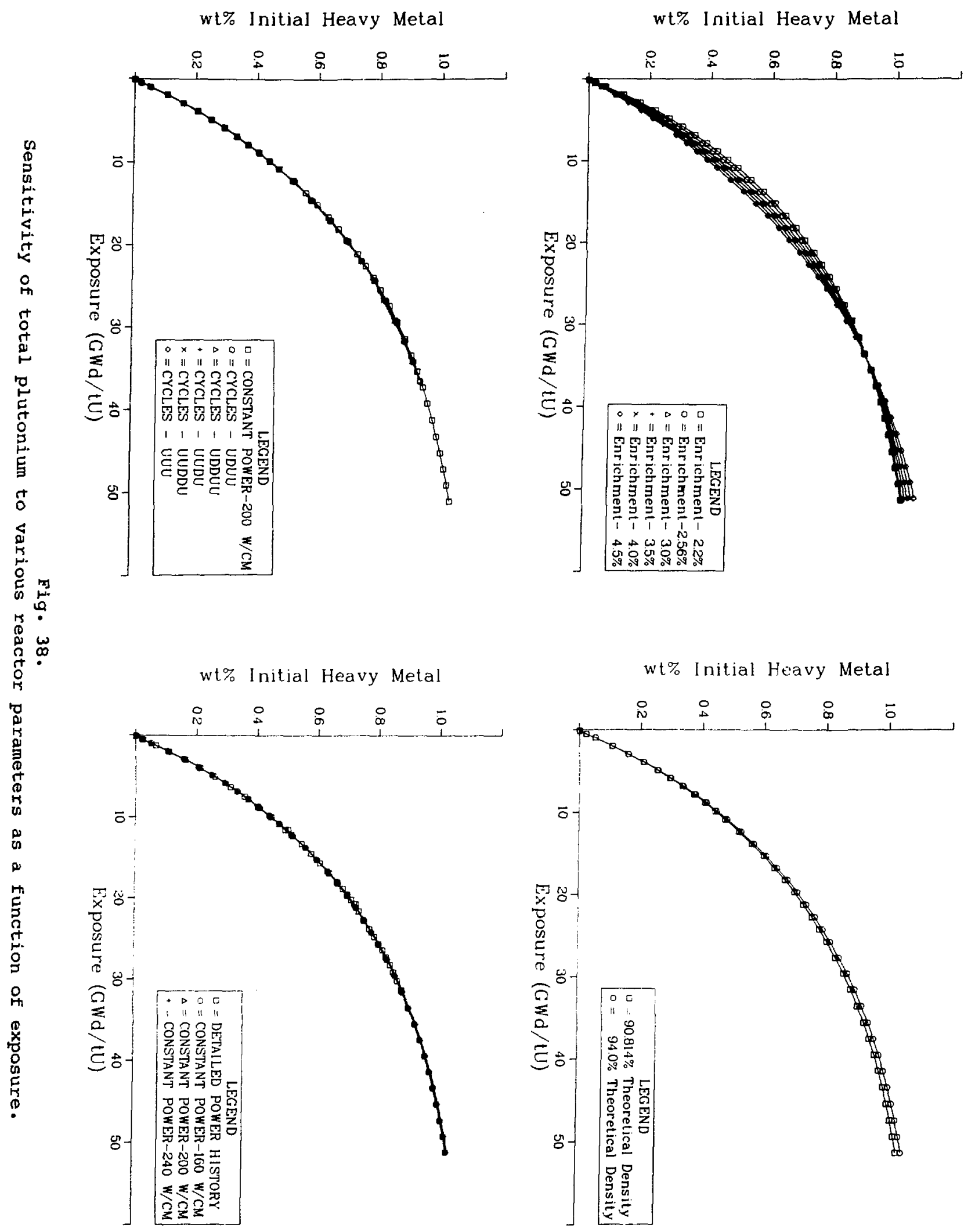
wt\% Initial Heavy Metal

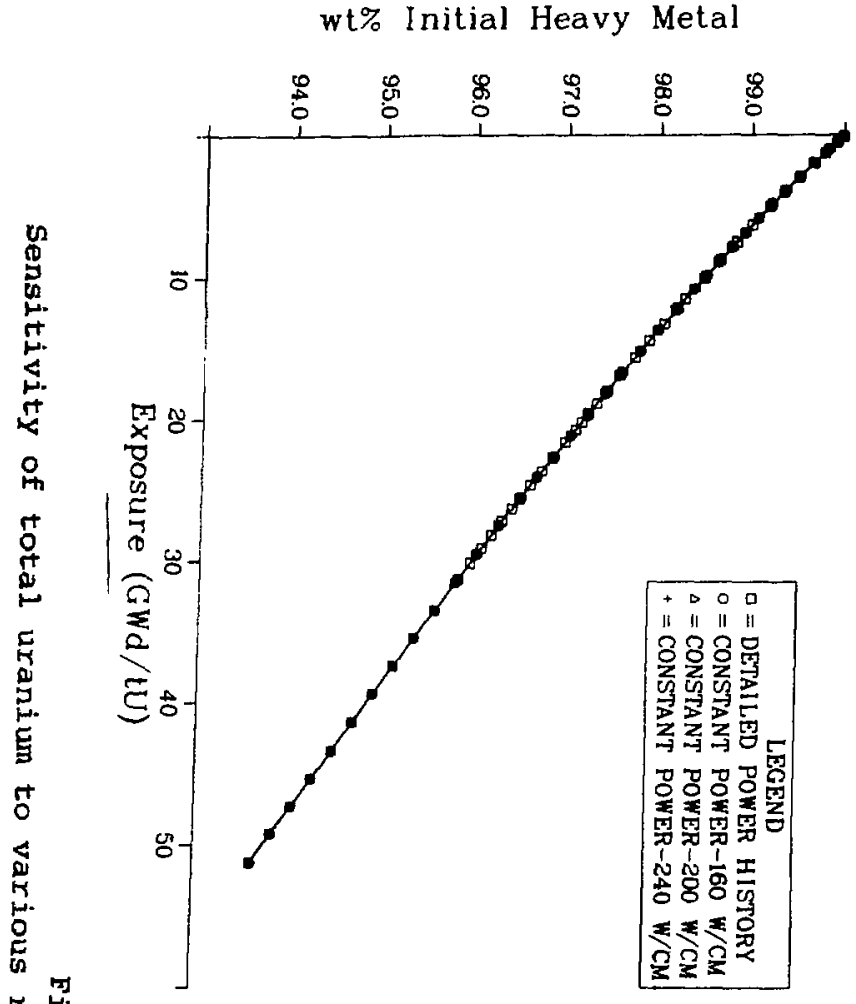

盟

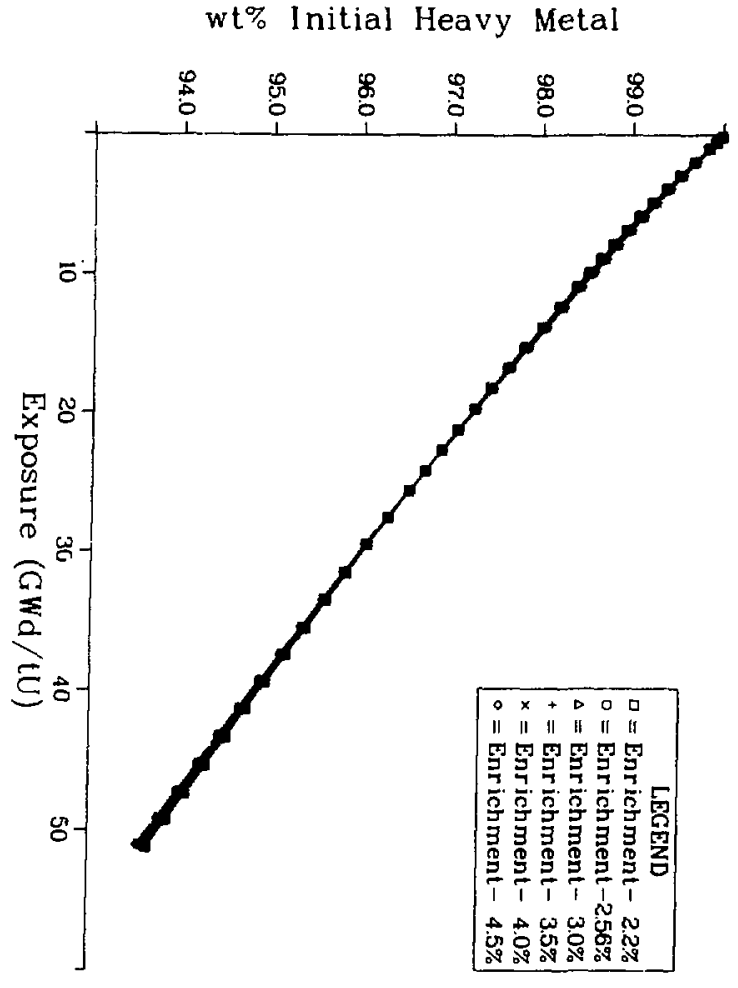

م

तै
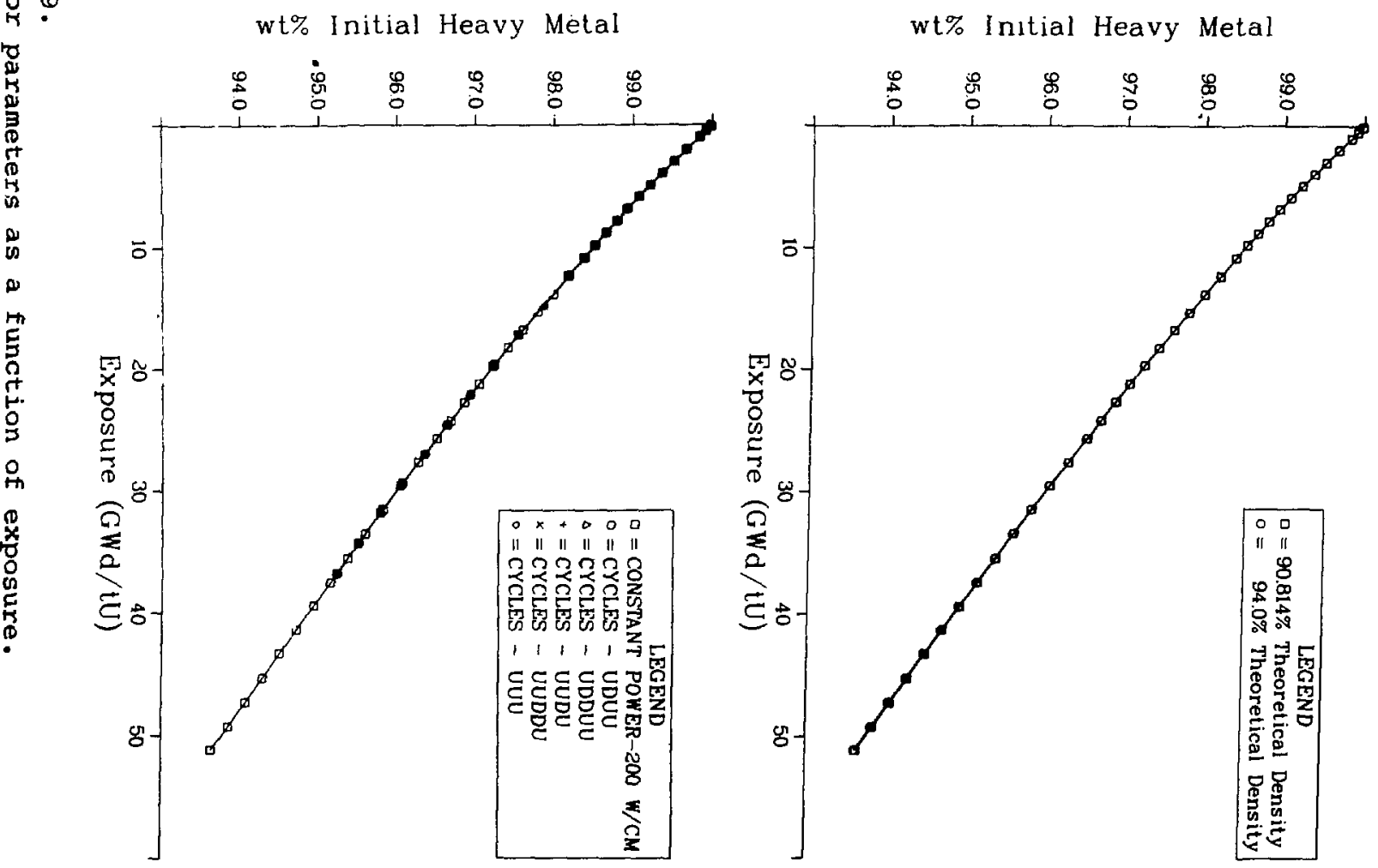

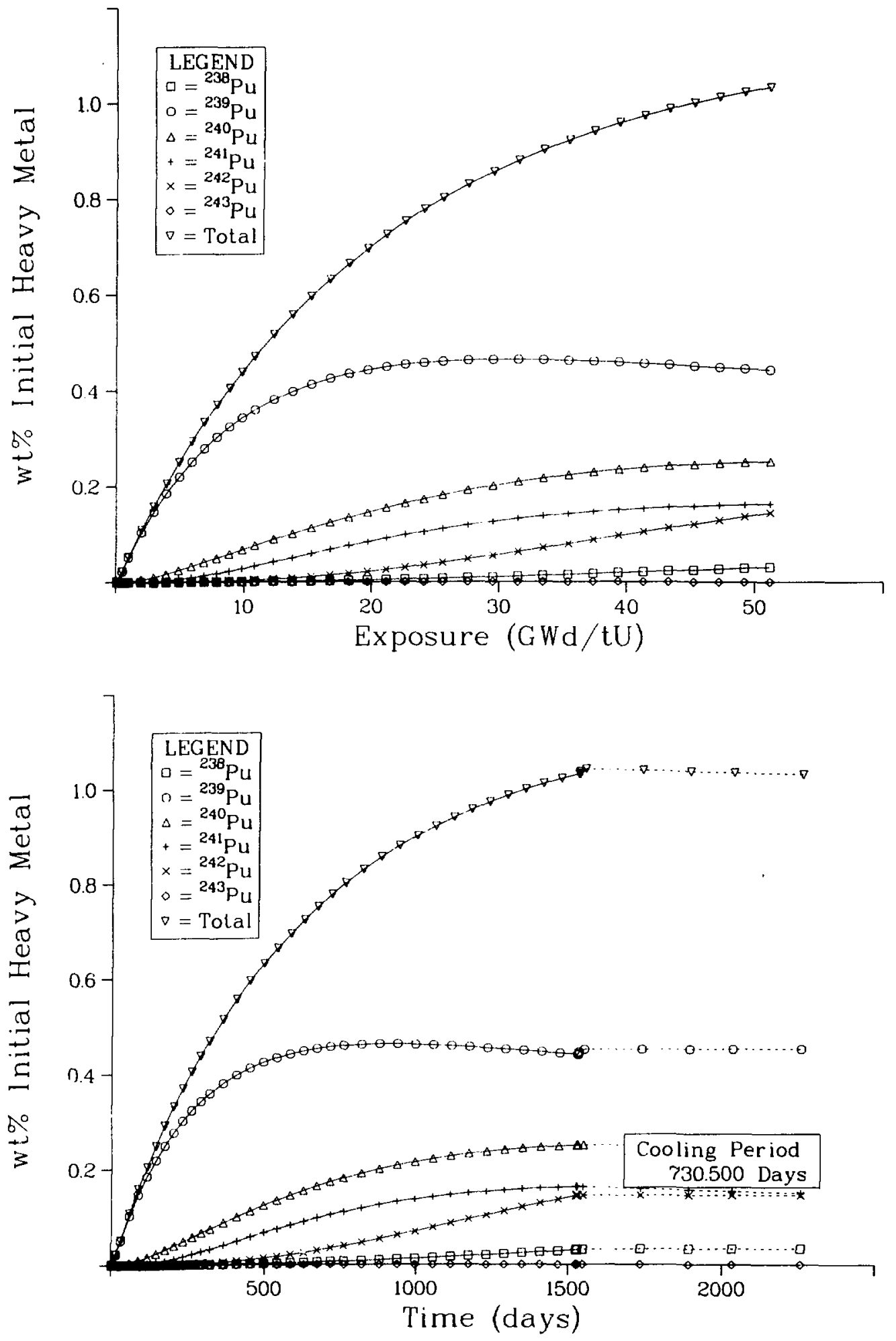

Fig. 40 .

Relative concentrations for the plutonium isotopes as a function of exposure and irradiation/cooling time. Displayed as wts of the initial heavy metal concentration. 

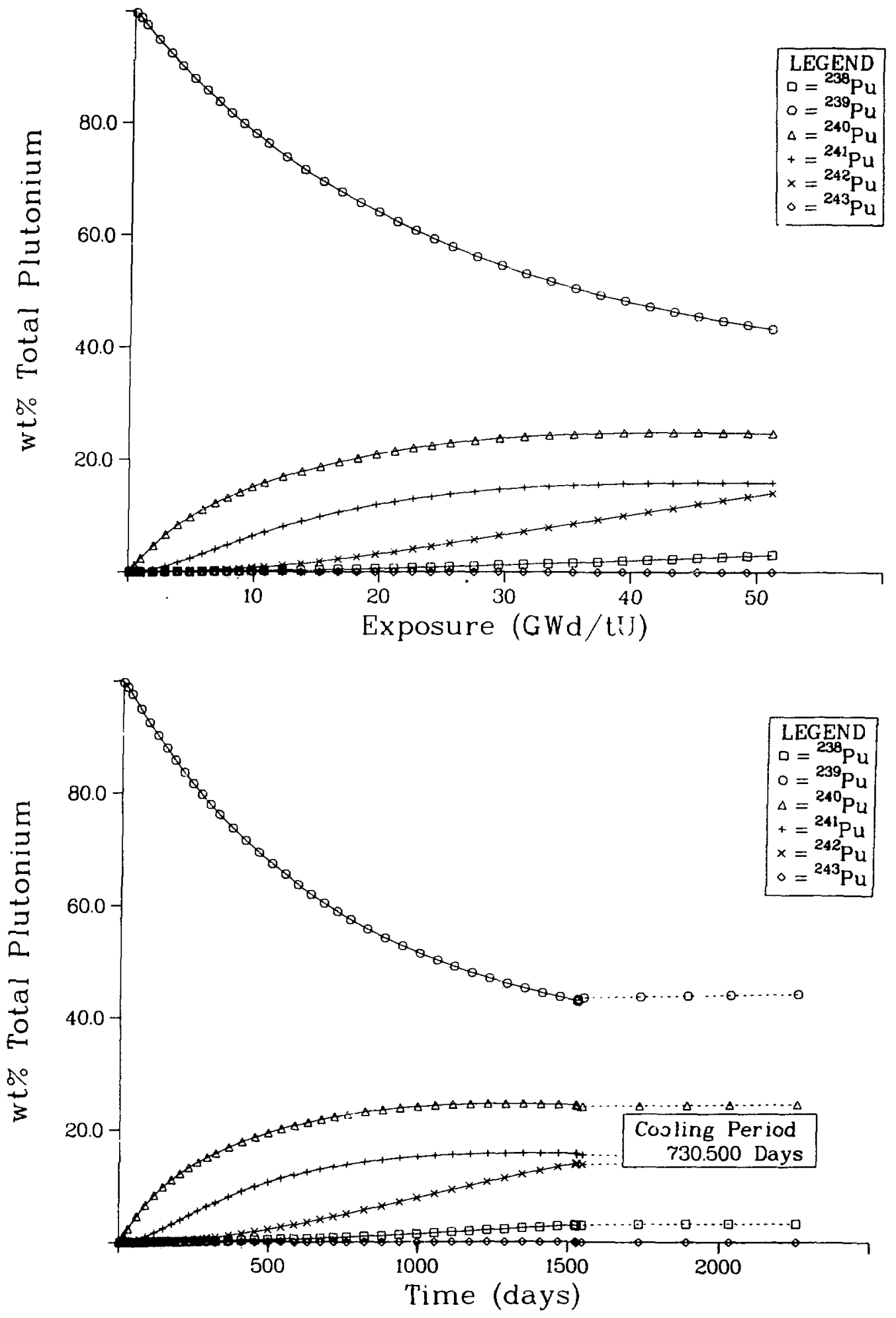

Fig. 41 .

Relative concentrations of the plutonium isotopes as a function of exposure and irradiation/cooling time. Displayed as wto of the total plutonium present. 
For a reprocessing facility operator, the data in Fig. 41 can be used to determine isotope composition in the manner described for safeguards. The data would aid in resolving shipper/receiver differences and in providing information for process control and criticality control.

The principal uxanium isotopic concentrations, excluding $238 \mathrm{U}$, are shown in Fig. 42. Note the ${ }^{236} \mathrm{U}$ concentration relative to that of ${ }^{235} \mathrm{U}$, particularly for higher exposures. Because of the resonance capture cross sections in ${ }^{236_{U}}$, this isotope can be a significant neutron absorber in irradiated fuel materials. Calculations investigating neutron transport effects in irradiated fuel materials should include ${ }^{236} \mathrm{U}$. Curves like those in Fig. 42 help determine the proper mix of the uranium isotopes, which should be used in transport calculations.

In Fig. 43, the principal fissile isotope concentrations are shown as a function of exposure and irradiation/cooling tine. Total fissile content decreases with exposure. For high exposure, the ${ }^{235} U$ decreases whereas the ${ }^{239} \mathrm{Pu}$ and ${ }^{241} \mathrm{Pu}$ concentrations increase. The sensitivity of total fissile concentration to various parameters is shown in Fig. 44. As expected, the principal dependence is on initial ${ }^{235} \mathrm{U}$ enrichment. Other parametric variations exhibit little or no effect on the total fissile concentration, which is important in estimating multiplication effects in irradiated fuel. Curves in Fig. 44 show that neutron multip?ication should be less for irradiated fuel than for fresh fuel assemblies.

Figure 45 shows sensitivities of the total macroscopic thermal cross section $\left(\Sigma_{f}\right)$. Again, the main dependence is on initial enrichment, not on the other parameters. The slopes of the curves in Fig. 45 are less than the corresponding slopes in Fig. 44. The thermal fission cross section for ${ }^{239} \mathrm{Pu}$ and ${ }^{241} \mathrm{Pu}$ is larger than that for ${ }^{235} \mathrm{U}$. Thus, in the high-exposure region where plutonium fissile concentrations begin to dominate, the relative macroscopic fission cross section increases.

similarly, the average induced-fission neutron yield $\left(\bar{v} * \Sigma_{f}\right.$, where $\bar{v}$ is the average number of neutrons released per fission) is shown in Fig. 46. Because the neutron yields in ${ }^{239} \mathrm{Pu}$ and ${ }^{241} \mathrm{Pu}$ are higher than those in $235_{\mathrm{U}}$, the neutron yield curves also have less slope than the corresponding curves in Fig. 44.

Figures 44, 45, and 46 clearly demonstrate the decreasing dependence of the fissile content, macroscopic fission cross section, and induced-fission 

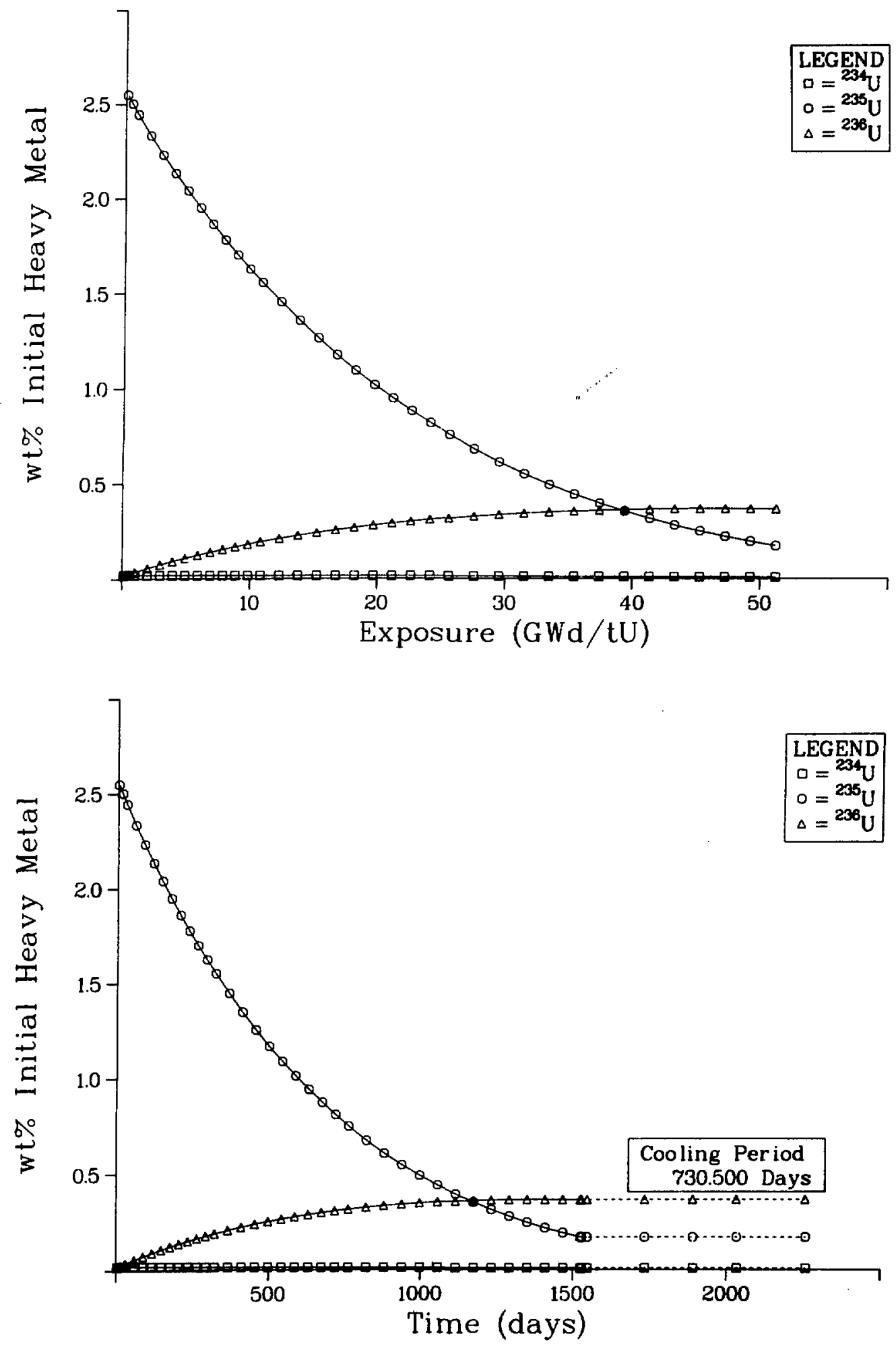

Fig. 42.

Principal uranium isotopes, excluding ${ }^{238} \mathrm{U}$, as a function of exposure and irradiation/cooling time. 

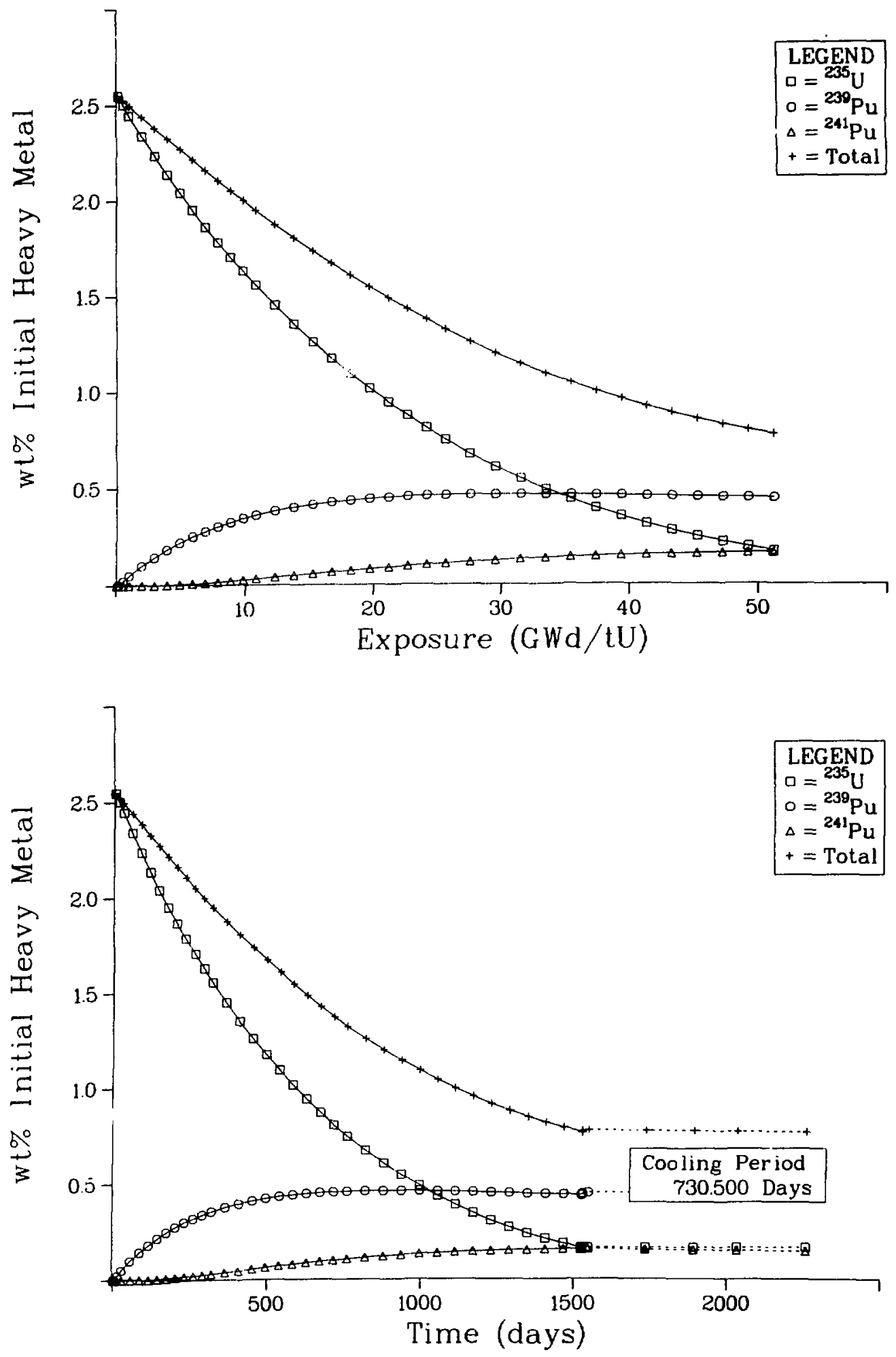

Fig. 43.

Fissile isotopes as a function of exposure and irradiation/cooling time. 
wt\% Initial Heavy Metal

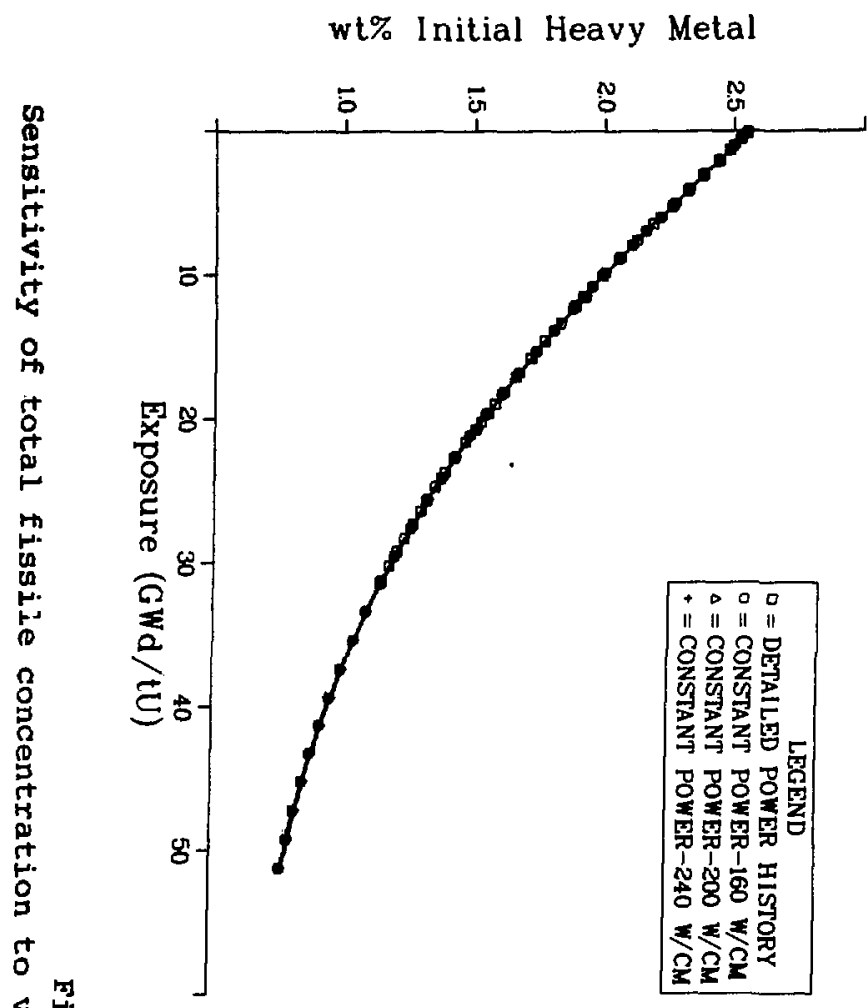

wt\% Initial Heavy Metal

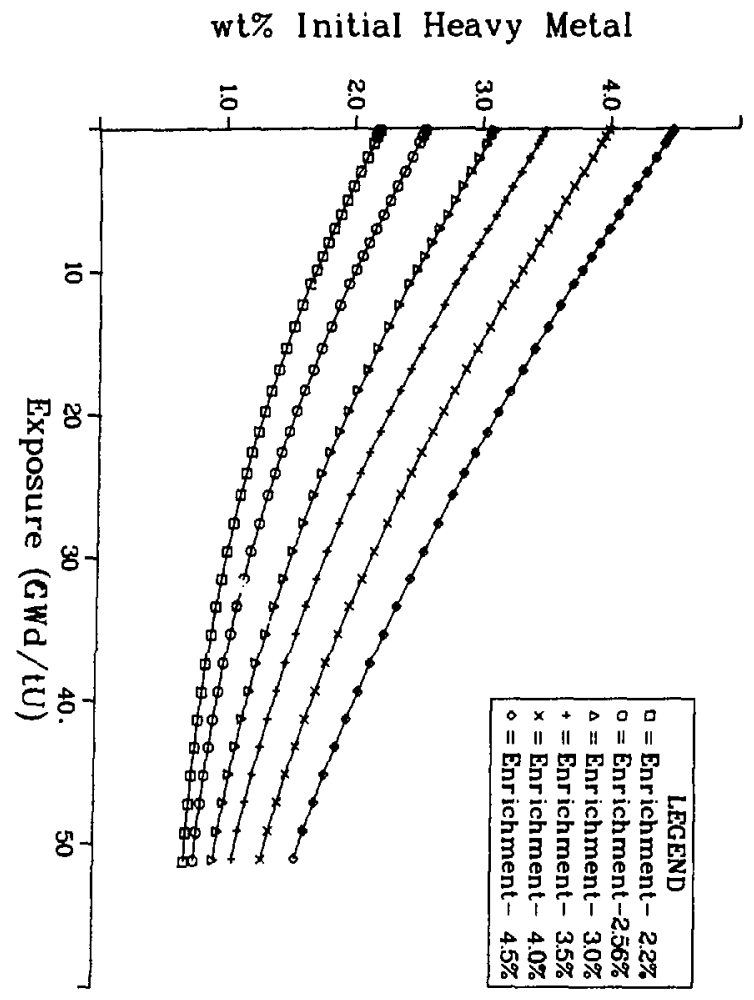

苗

英

wt\% Initial Heavy Metal
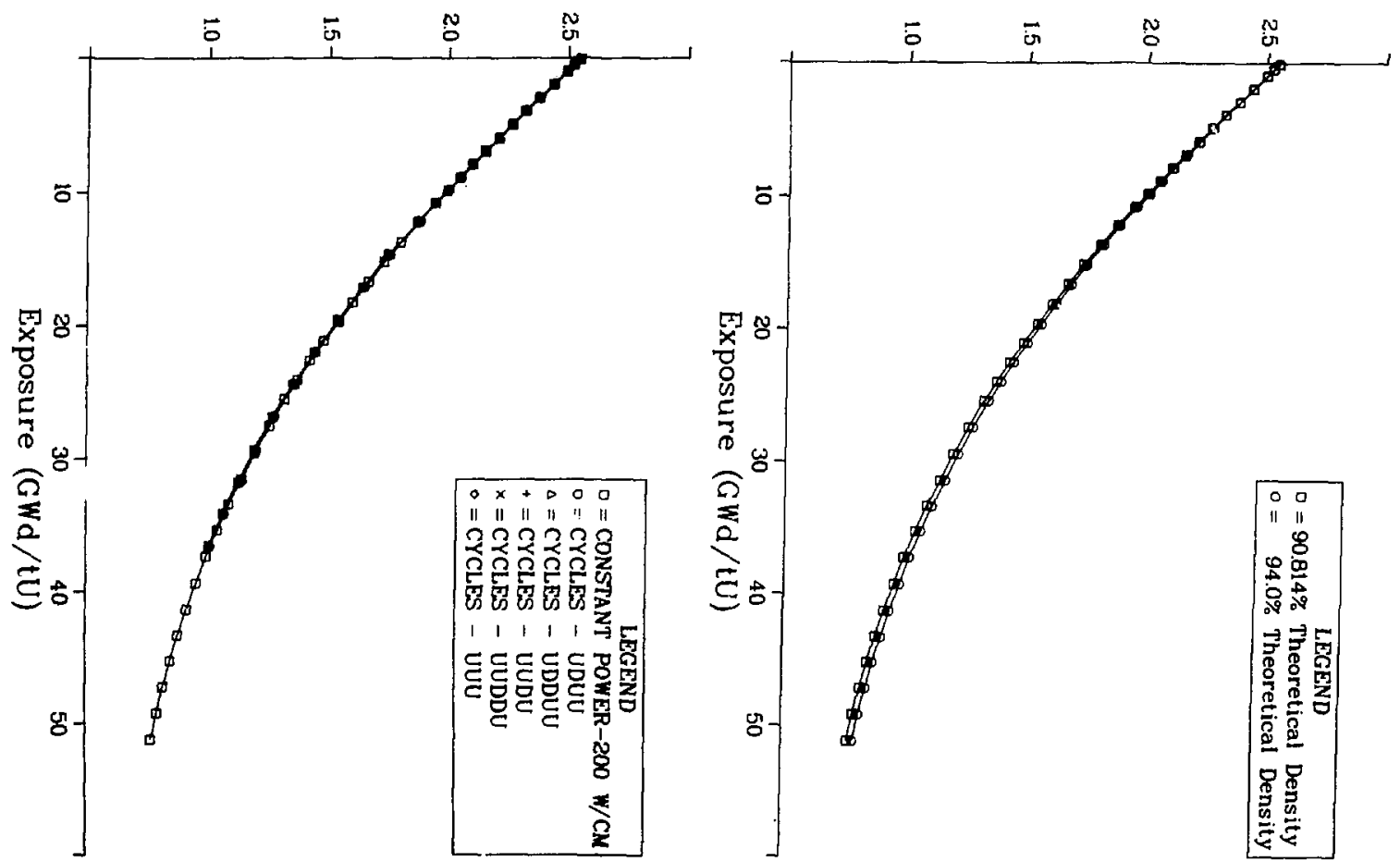

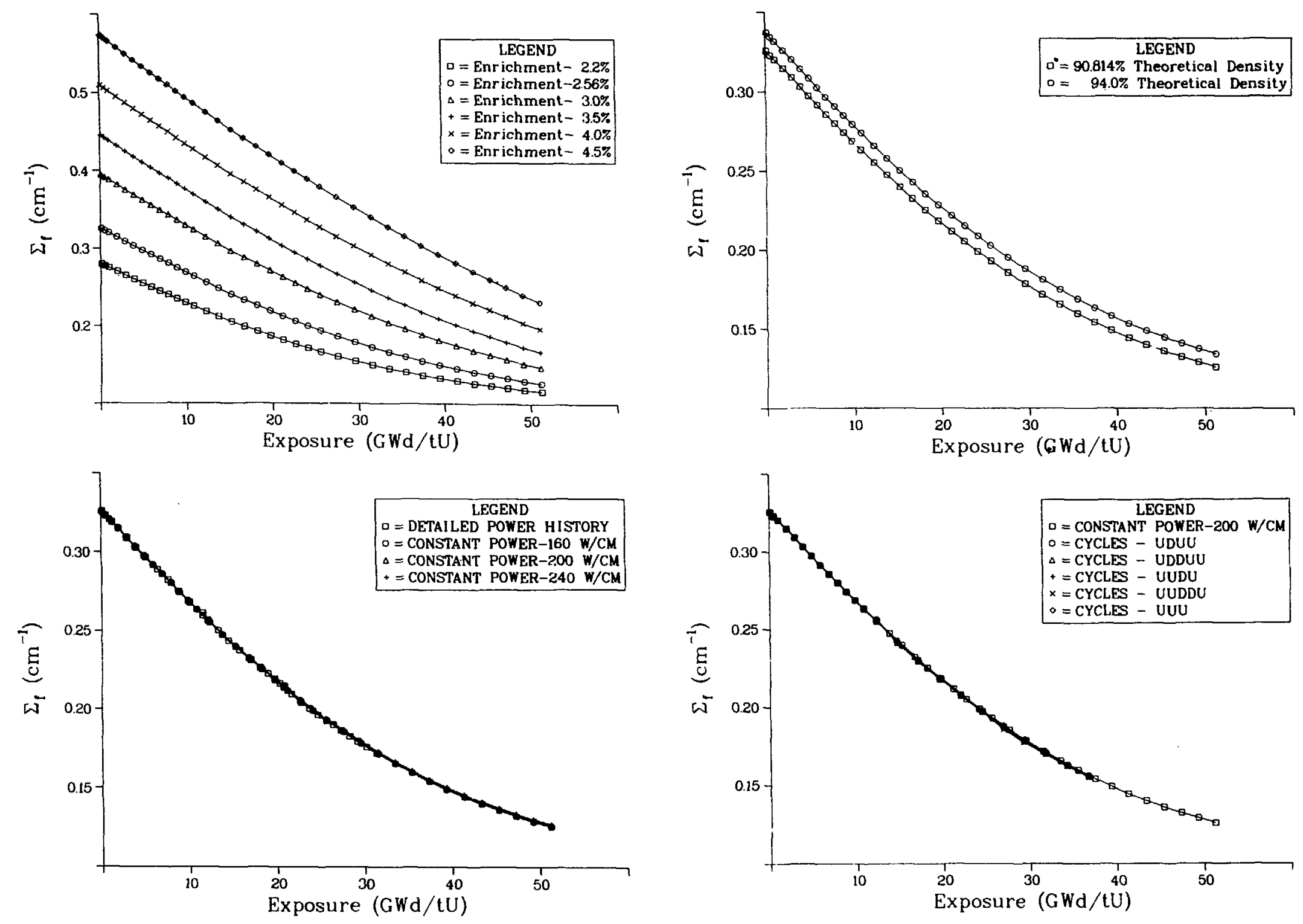

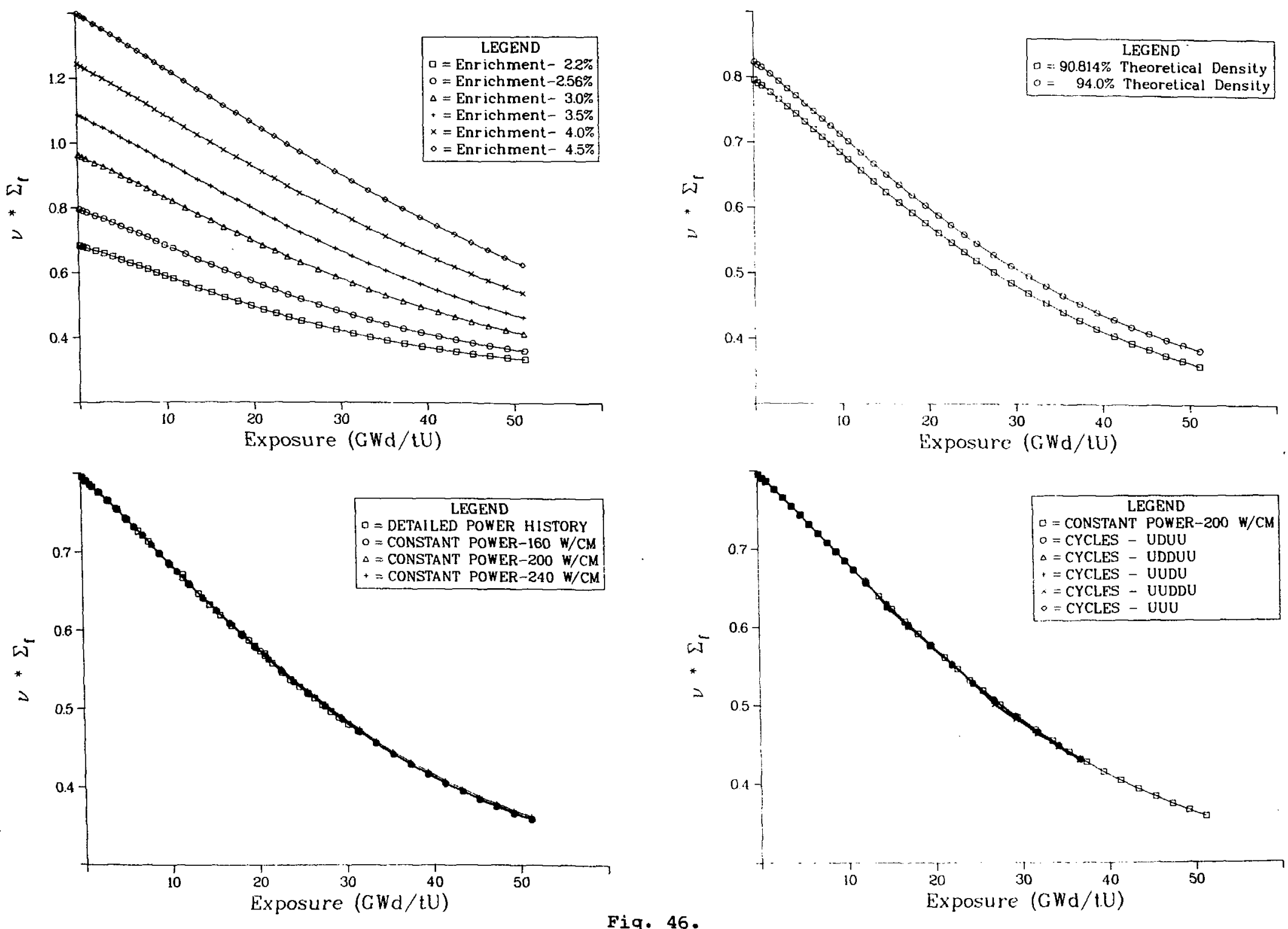

Sensitivity of the average induced-fission neutro function of exposure. 
neutron yield on increasing exposure. Multiplication of neutrons from various actinide isotopes depends on the fissile content of the fuel. As exposure increases, less multiplication occurs. As a result, the slope of a measured count rate vs exposure curve is less than the source rate vs exposure curve.

As shown in Table IV, the curium isotopes have the largest neutron yields of the principal neutron producers existing in irradiated fuel materials. Figure 47 compares the build-ups of ${ }^{242} \mathrm{Cm}$ and ${ }^{244} \mathrm{Cm}$ as a function of exposure and irradiation/cooling time. As explained in Sec. III, for exposures above $10 \mathrm{GWd} / \mathrm{tU}$, the curium isotopes become the dominant neutron producers. From Fig. 47 we see that the relative concentrations of ${ }^{242} \mathrm{~cm}$ and ${ }^{244} \mathrm{Cm}$ are similar for exposures up to $25 \mathrm{GWd} / \mathrm{tU}$, but above that level $244 \mathrm{~cm}$ builds up much more rapidly. By $40 \mathrm{GWd} / \mathrm{tU},{ }^{244} \mathrm{~cm}$ is the dominant neutron producer. In all LWR-irradiated fuel materials with exposures above $15 \mathrm{GWd} / \mathrm{tU},{ }^{244} \mathrm{Cm}$ will dominate when cooling time periods are long enough for ${ }^{242} \mathrm{~cm}$ (162.9-day half-life) to decay. The neutron source rate dependence on ${ }^{244} \mathrm{Cm}$ is important because of correlations between ${ }^{244} \mathrm{Cm}$ and fuel parameters such as fissile content and plutonium. To use these correlations with experimental measurements, the ${ }^{244} \mathrm{Cm}$ contribution to the count rate must be determined. If the neutrons being detected are principally from ${ }^{244} \mathrm{Cm}$, the ${ }^{244} \mathrm{Cm}$ concentration is directly proportional to the count rate. Where other isotopes such as ${ }^{242} \mathrm{Cm}$ are present and also contributing to the count rate, a correction must be applied to determine that portion of the count rate from ${ }^{244} \mathrm{~cm}$. Such corrections for ${ }^{242} \mathrm{Cm}$ can be difficult because of its dependence on power level and operating history. To produce accurate corrections for ${ }^{242} \mathrm{~cm}$, some knowledge of reactor operating conditions is necessary. By examining fuel with long cooling times compared to the ${ }^{242} \mathrm{Cm}$ half-life or fuel with very high exposures, no corrections would be needed.

For reprocessed plutonium materials, higher atomic number actinide isotopes, including the curiums, are removed. In these samples, which are typical of materials that International Atomic Energy Agency (IAEA) inspectors monitor, the principal neutron sources are the even-numbered plutonium isotopes ${ }^{238}{ }_{\text {Pu }}$, $240 \mathrm{Pu}$, and ${ }^{242} \mathrm{Pu}$. The relative yields of these isotopes are shown in Table IV. Typical dependence of the even-numbered isotopes is shown in Fig. 48 as weight

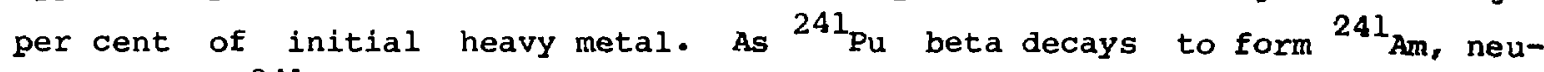

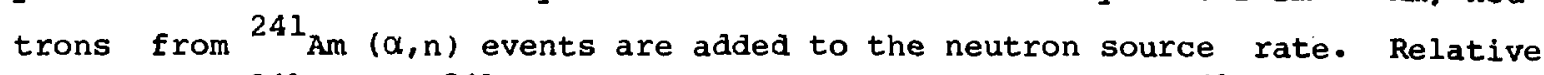
amounts of ${ }^{241} \mathrm{Pu}$ and ${ }^{241} \mathrm{Am}$ are shown in Fig. 49, where the ${ }^{241}$ Am concentration 

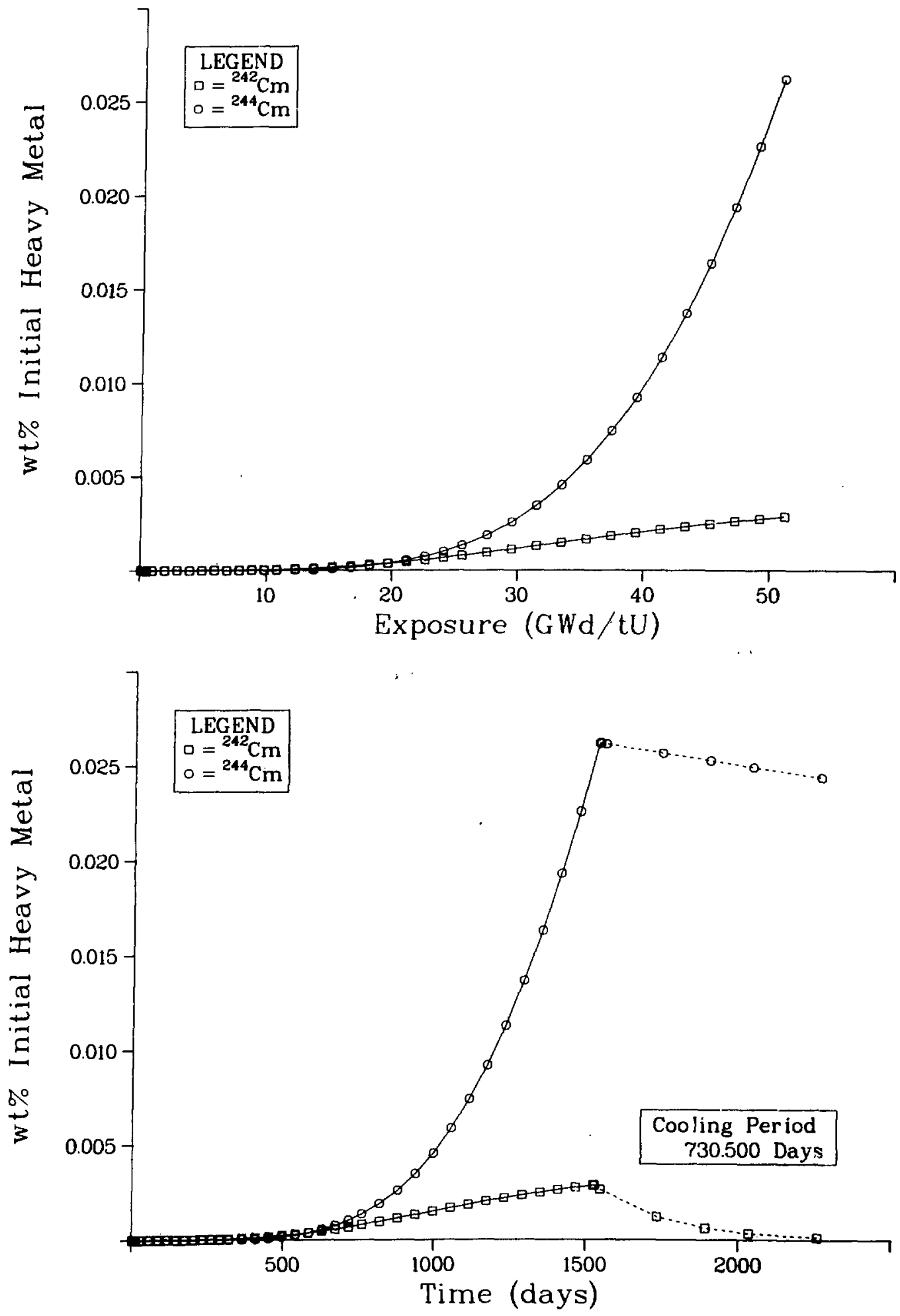

Fig. 47.

Concentrations of $242 \mathrm{~cm}$ and $244 \mathrm{Cm}$ as a function of exposure and irradiation/cooling time. 

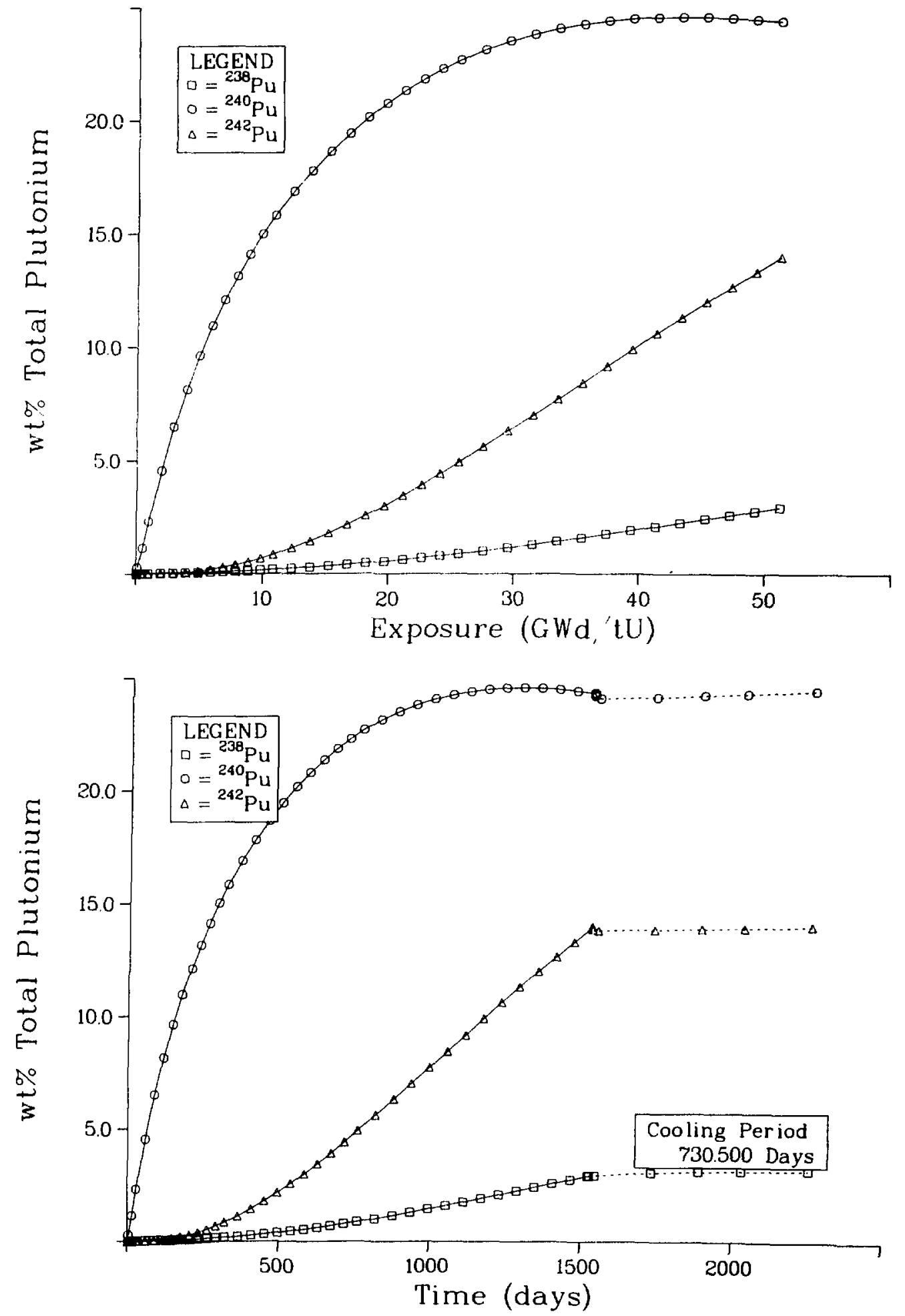

Fig. 48.

Concentrations of $238 \mathrm{Pu}, 240 \mathrm{Pu}$, and $242 \mathrm{Pu}$ as a function of exposure and irradiation/cooling time. Results expressed as wto of the initial heavy metal. 

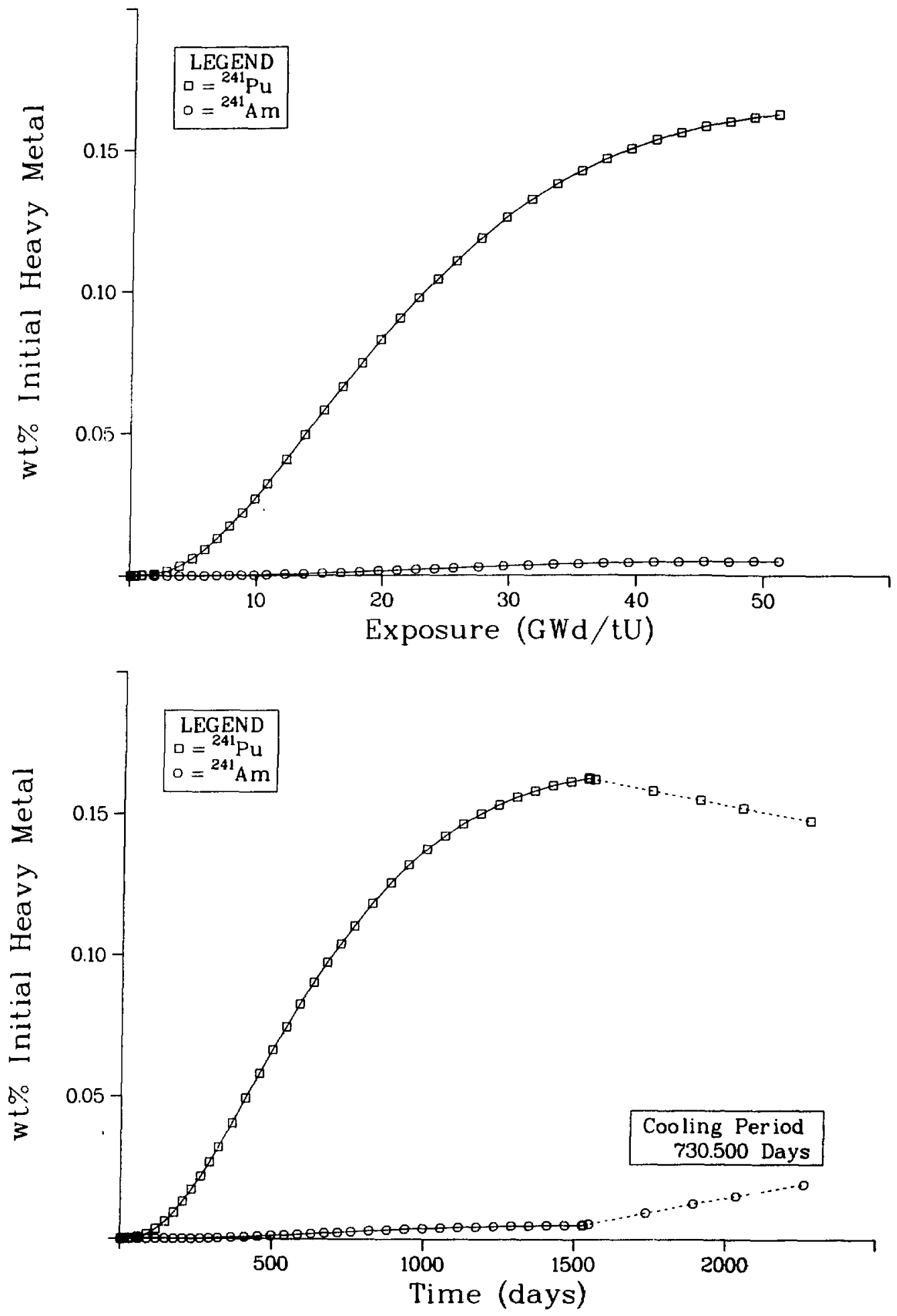

Fig. 49.

Concentrations of $24 I_{\mathrm{Pu}}$ and $24 \mathrm{I}_{\mathrm{Am}}$ as a function of exposure and irradiation/cooling time. Results expressed as wto of the initial heavy metal. 
is for a continuously operating reactor. In reality, ${ }^{241} \mathrm{Am}$ existing in the fuel before reprocessing is removed, and any ${ }^{241} \mathrm{Am}$ in the fuel after reprocess-

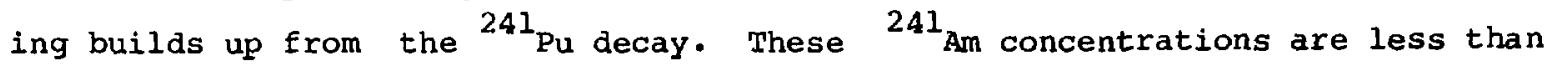
what would have existed if no ${ }^{241}$ Am were removed during reprocessing.

In Fig. 50, the even-numbered plutonium isotopes are shown as weight per cent of total plutonium. Although ${ }^{238} \mathrm{Pu}$ and ${ }^{242} \mathrm{Pu}$ have higher neutron yields than does $240_{\mathrm{Pu}}$, the ${ }^{240} \mathrm{Pu}$ concentration is higher for all exposures. Because all plutonium isotopes contribute some neutrons, coincidence counting or other neutron measurement techniques can only determine a response that is proportional to the abundance of all three plutonium isotopes. Because ${ }^{240} \mathrm{Pu}_{\text {is }}$ the dominant isotope, an effective ${ }^{240} \mathrm{Pu}$ mass is defined. For coiricidence counting, ${ }^{240}{ }_{\text {Pu }}$ eff is defined as

$$
{ }^{240} \mathrm{Pu}_{\mathrm{eff}}=2.49\left({ }^{238} \mathrm{Pu}\right)+\left({ }^{240} \mathrm{Pu}\right)+1.57\left({ }^{242} \mathrm{Pu}\right)
$$

The factors included with ${ }^{238} \mathrm{Pu}$ and ${ }^{242} \mathrm{Pu}$ take into account differences in the coincidence response resulting from the higher neutron yields of these isotopes. Most samples measured to date using coincidence detectors have had exposures less than $30 \mathrm{GWd} / \mathrm{tU}$, giving ${ }^{240} \mathrm{Pu}$ concentrations that are larger than the ${ }^{238} \mathrm{Pu}$ and ${ }^{242} \mathrm{Pu}$ concentrations. If samples with exposures as large as $50 \mathrm{GWd} / \mathrm{tU}$ are measured, then contributions from ${ }^{240} \mathrm{Pu}$ and ${ }^{242} \mathrm{Pu}$ will be similar.

V. CORRELATIONS

When gamma-ray signals from irradiated fuel materials are measured with high-resolution gamma spectroscopy systems, we can obtain qualitative information about the fission-product content of the material. The unique, discrete energies of emitted gamma rays are resolved by gamma-ray detectors and electronics. Neutrons do not have any similar unique signatures that are resolvable in detectors. Instead of unique, discrete energies, neutrons are emitted with a spectrum of energies. Even if discrete energies existed, most neutron detectors are incapable of resolving them. Typically, a detector such as a 

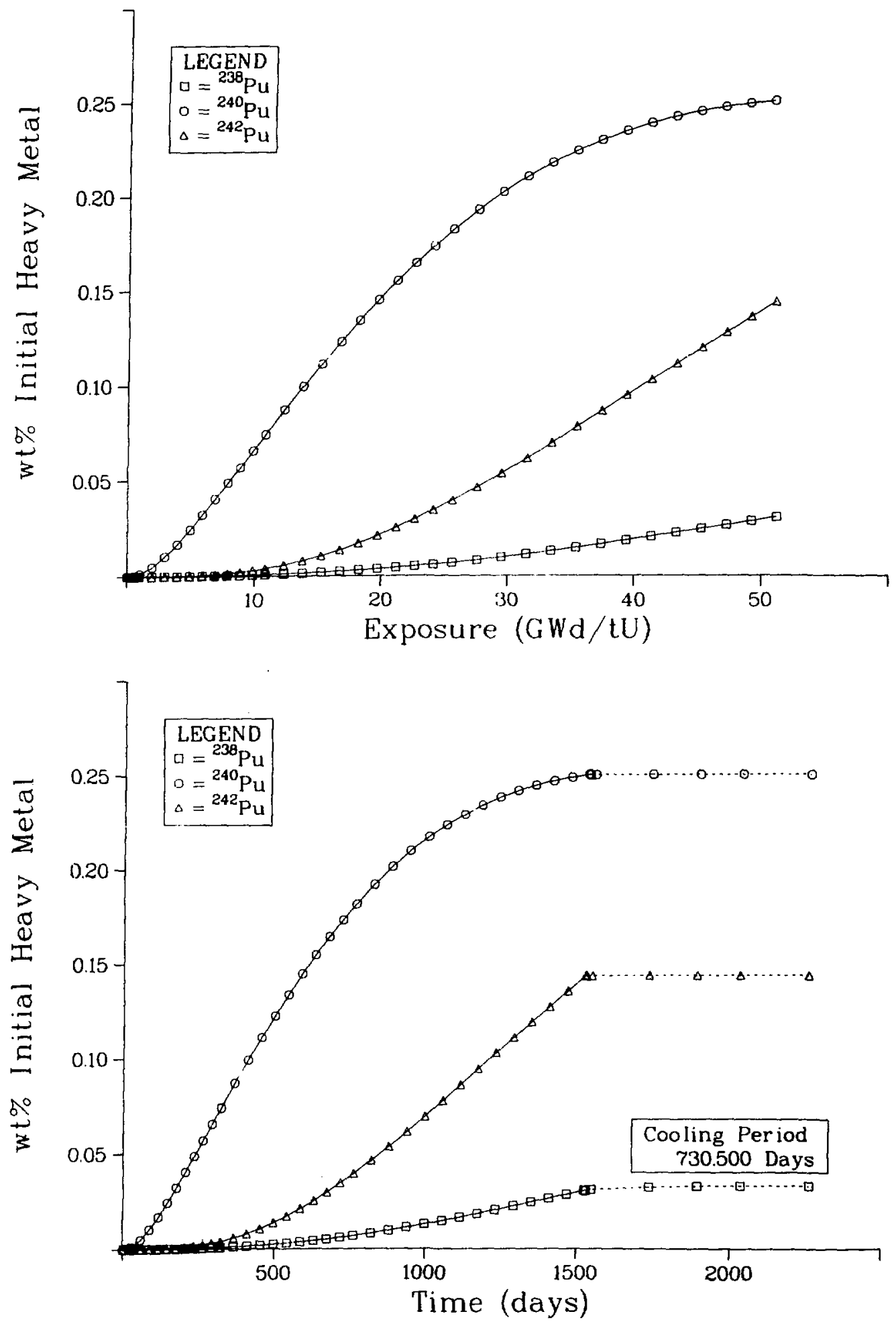

Fig. 50.

Concentrations of $238 \mathrm{Pu}, 240 \mathrm{Pu}$, and $242 \mathrm{Am}$ as a function of exposure and irradiation/cooling time. Results expressed as wto of total plutonium. 
fission chamber is based on a thermal neutron reaction that requires moderating the source neutrons before the reaction will occur. Such moderation further o'literates any possibility of energy resolution. As a result, neutron counting generally can be used to examine only gross effects such as total neutron count rate. Additional information about spontaneous or induced-fission activity is available from neutron coincidence counting. However, any quantitative information about the fuel material being examined can be obtained only from correlations between the count rates and knowledge of the initial fuel parameters.

A basic correlation relates the count rate to the exposure of the fuel assembly through a power function relationship of the form

$$
\text { neutron count rate }=\alpha *(\text { exposure })^{\beta} \text {. }
$$

where $\alpha$ is a normalization constant and $\beta$ is the functional power. With such a relationship, an assembly exposure can be predicted once $\alpha$ and $\beta$ are known. Both experimental and calculational techniques can be developed for estimating $\alpha$ and $\beta$ values.

Another type of correlation originally proposed by schulze et al. ${ }^{2}$ relates ${ }^{244} \mathrm{~cm}$ to total plutonium and to $\triangle \mathrm{Pu}=$ total plutonium - ${ }^{239} \mathrm{Pu}$. These correlations are shown in Figs. 51 and 52. As described in Secs. III and IV, neutron sources in fuel assemblies with long cooling times and exposures above $10 \mathrm{GWd} / \mathrm{tU}$ emanate principally from ${ }^{244} \mathrm{Cm}$, and, as a result, the detected neutron count rate is directly proportional to the ${ }^{244} \mathrm{Cm}$ concentration. With proper normalization, the neutron count rate can then be correlated to ${ }^{244} \mathrm{~cm}$ concentration and then from relationships shown in Figs. 51 and 52 to the actual plutonium content. For materials in which ${ }^{244} \mathrm{~cm}$ is not the dominant source, corrections must be made to determine that the precise proportion of the count rate is from ${ }^{244} \mathrm{~cm}$ neutrons. The corrected count rate is used to determine plutonium content.

Another correlation in Fig. 53 relates ${ }^{244} \mathrm{Cm}$ to the total fissile concentration of the assembly. Total fissile inventory is defined as the sum of $235_{\mathrm{U},} 239 \mathrm{Pu}$, and ${ }^{241} \mathrm{pu}$ atoms. 


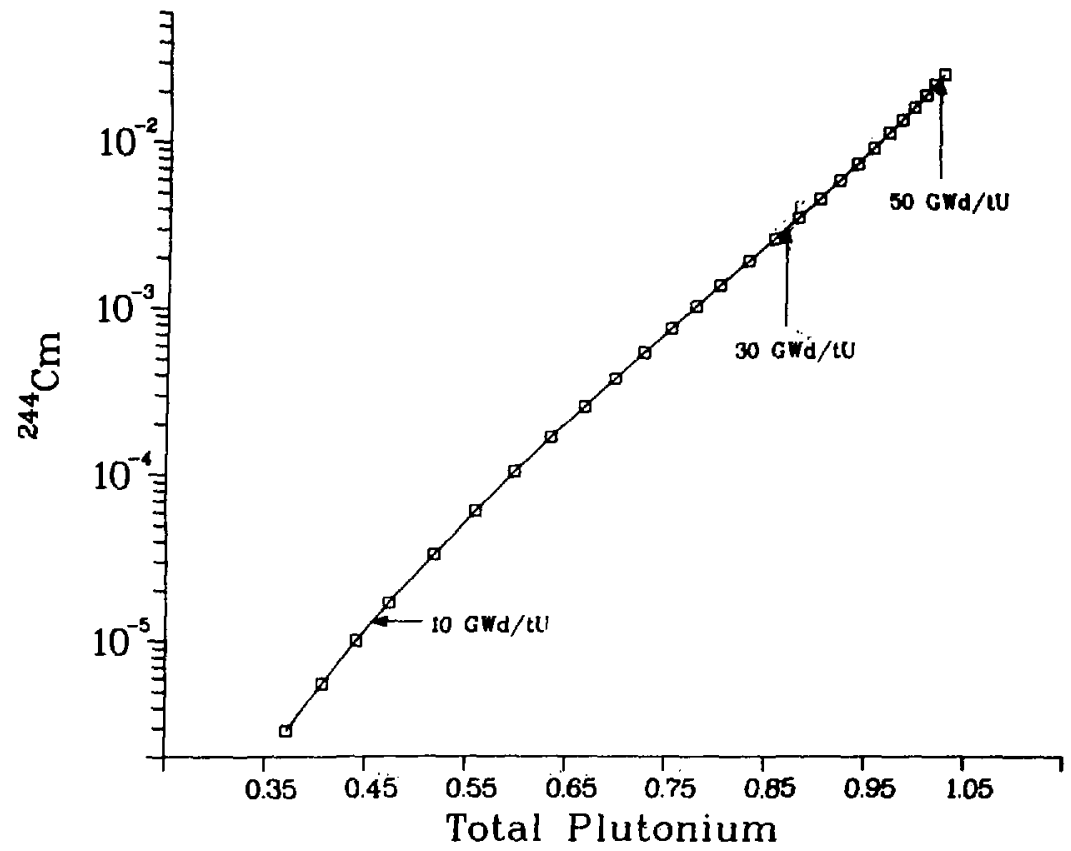

Fig. 51 .
Correlation between $244 \mathrm{Cm}$ and the total plutonium concentration.

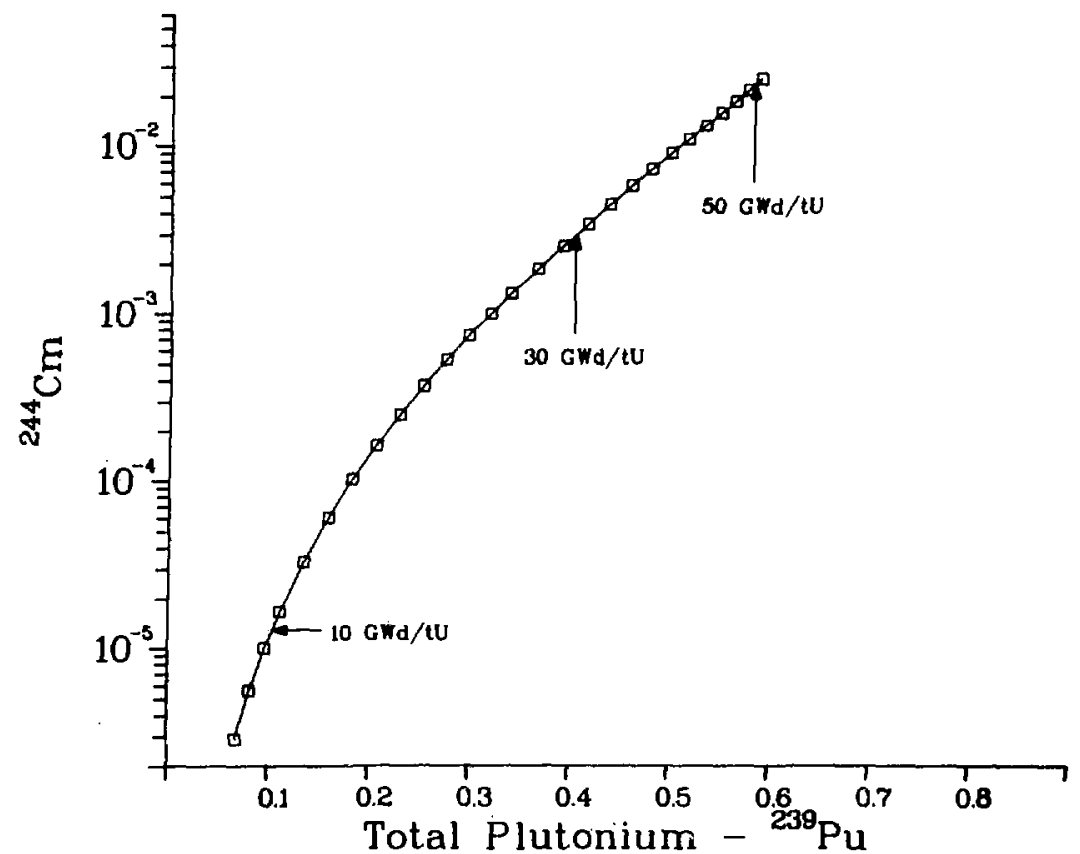

Fig. 52.

Correlation between $244 \mathrm{~cm}$ and the total plutonium minus $239 \mathrm{Pu}$ concentration. 


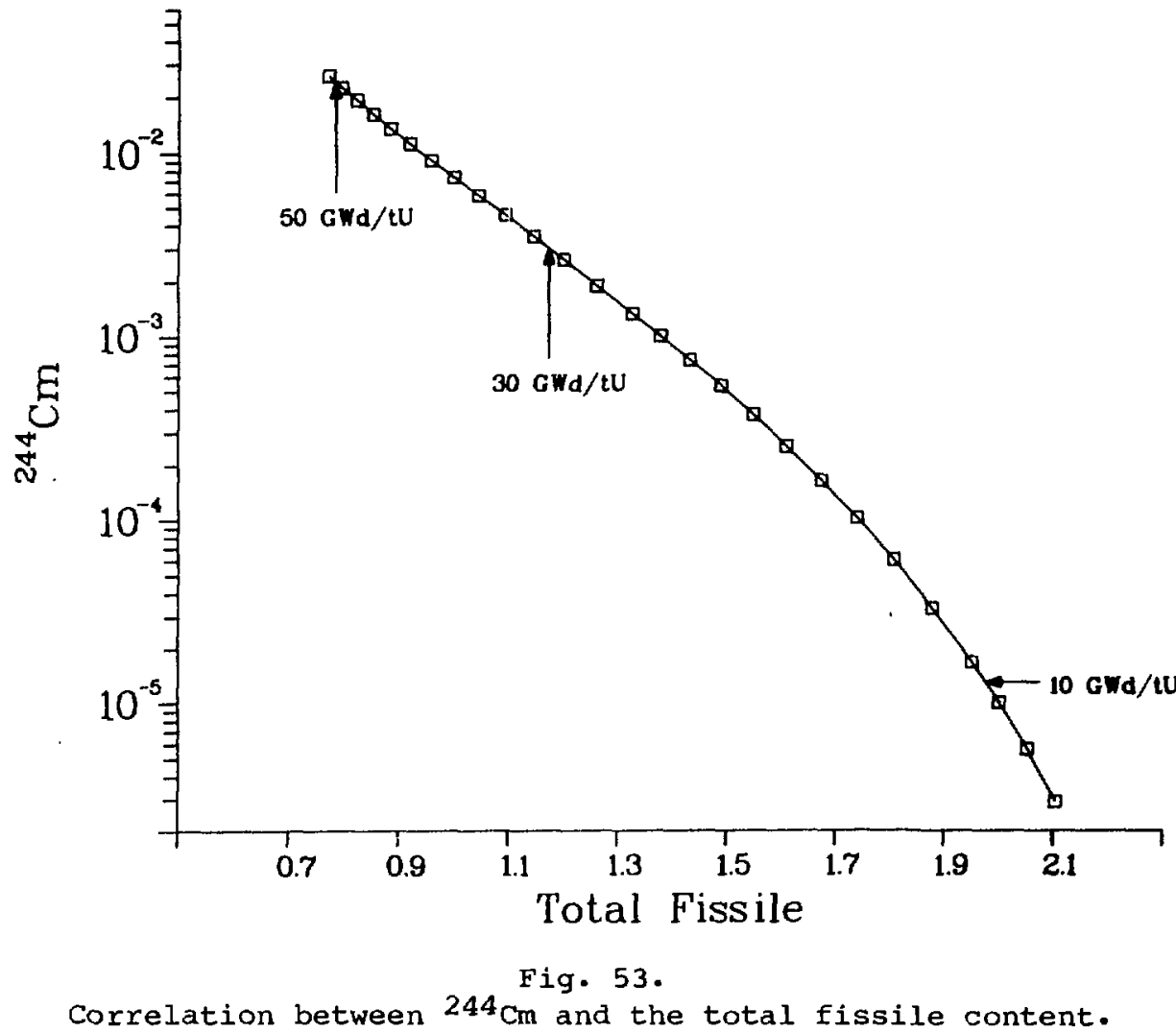

Sensitivity of the ${ }^{244} \mathrm{Cm}$ correlations is shown in Figs. 54 to 56 . The ${ }^{244} \mathrm{Cm}$ to total plutonium correlation is independent of all parameters except initial ${ }^{235} \mathrm{U}$ enrichment where there is a slight dependence (Fig. 54). The $\triangle \mathrm{Pu}$ correlation (Fig. 55) is very good because it exhibits little or no dependence on any sensitivity parameter. Thus, with only a correction for initial ${ }^{235} \mathrm{u}$ enrichment in the ${ }^{244} \mathrm{Cm}$ to total plutonium correlation, these two correlations may be used to obtain a value for ${ }^{239} \mathrm{Pu}$. The accuracy of such a ${ }^{239} \mathrm{Pu}$ value depends partly on how well the neutron count rate was correlated to ${ }^{244} \mathrm{~cm}$ concentration.

The total fissile correlation to ${ }^{244} \mathrm{Cm}$ is sensitive to initial ${ }^{235} \mathrm{U}$ enrichment but insensitive to other parameters (see Fig. 56). If such a correlation were used to determine total remaining fissile content, an accurate corrrection for initial ${ }^{235} \mathrm{U}$ enrichment would be required. 

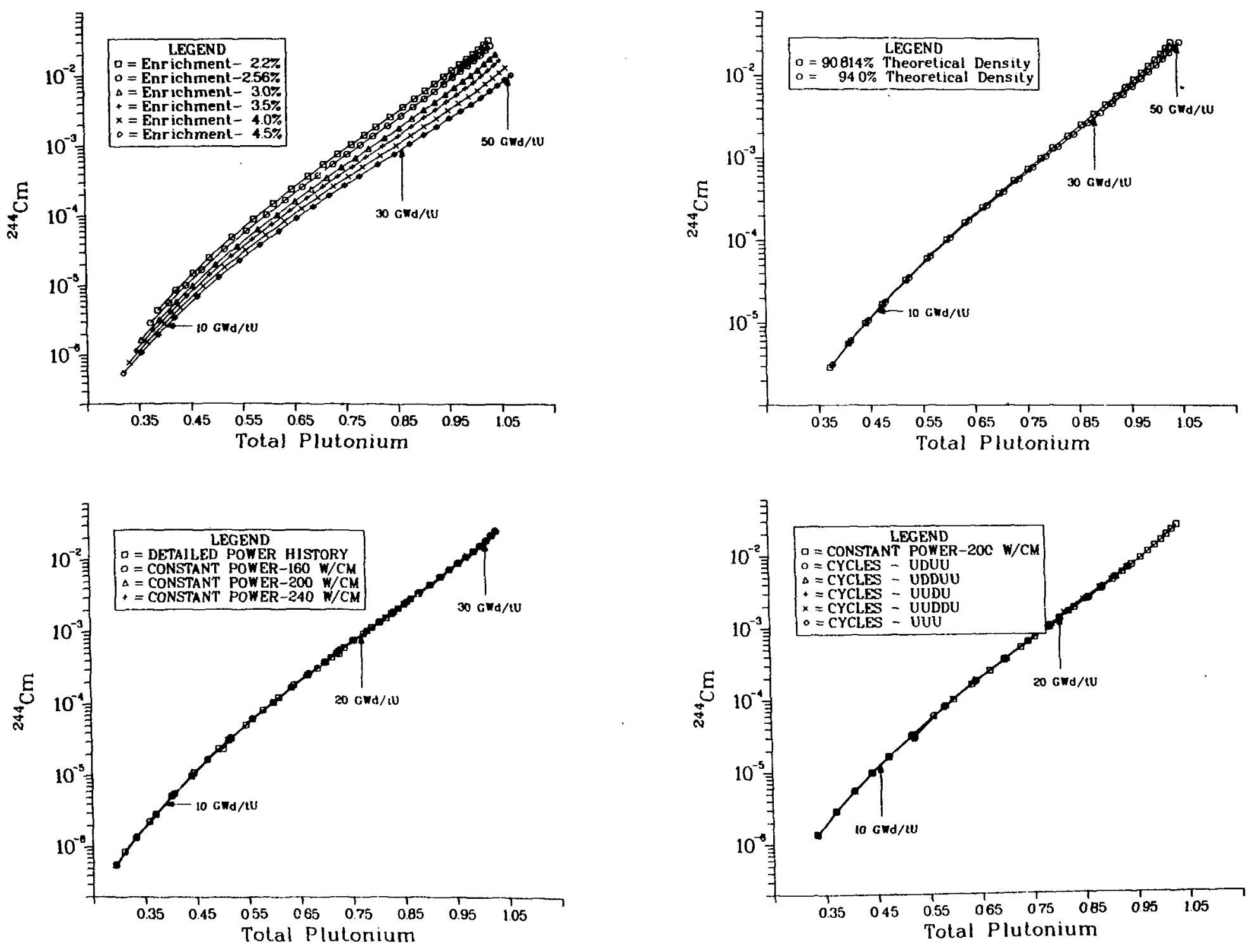

Fig. 54.

Dependence of the correlation between ${ }^{244} \mathrm{~cm}$ and total plutonium content on various reactor parameters. 

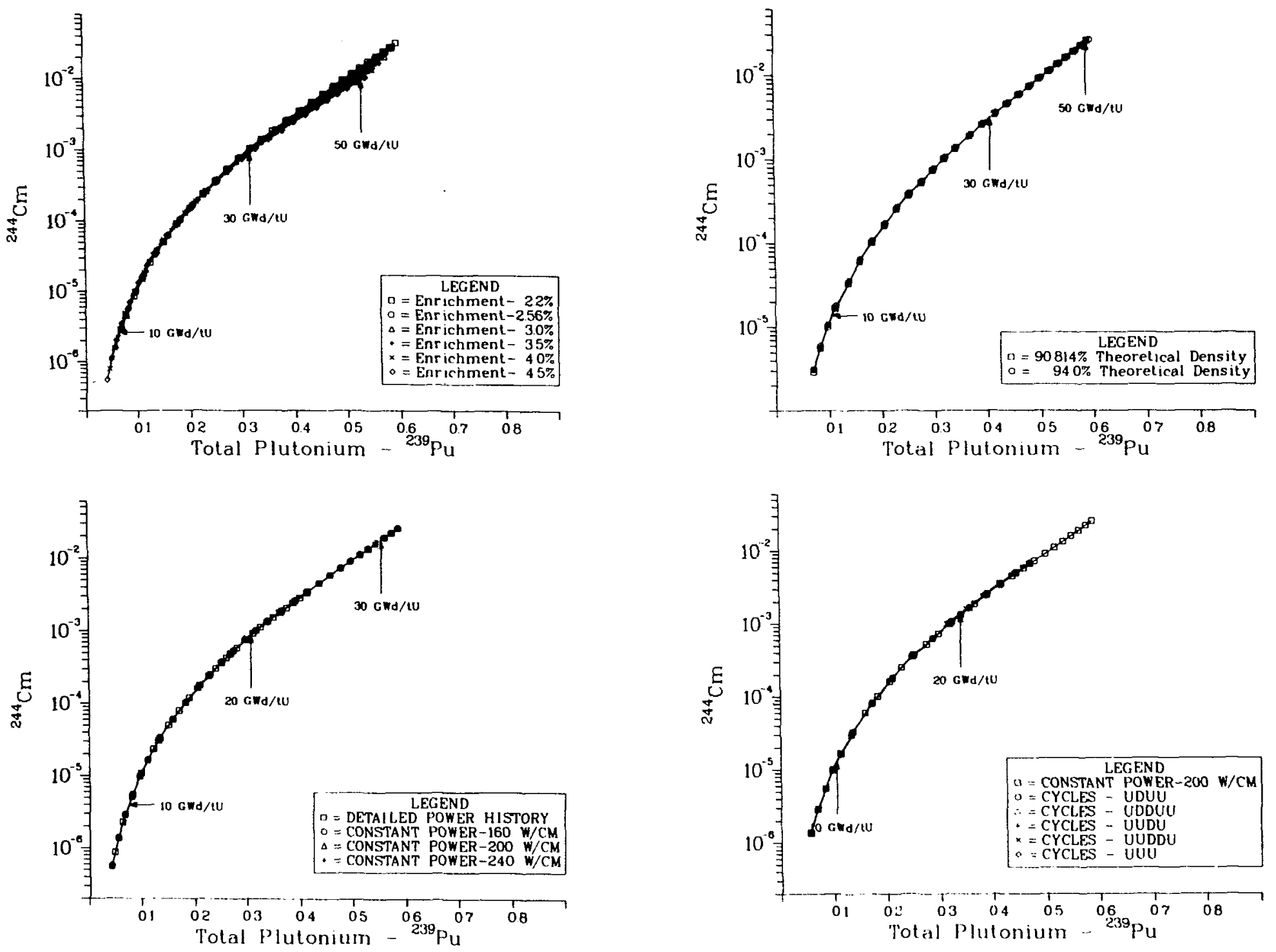

Fig. 55.

Dependence of the correlation between $244 \mathrm{Cm}$ and total plutonium- ${ }^{239} \mathrm{Pu}$ on various reactor parameters. 
wt\% Initial Heavy Metal

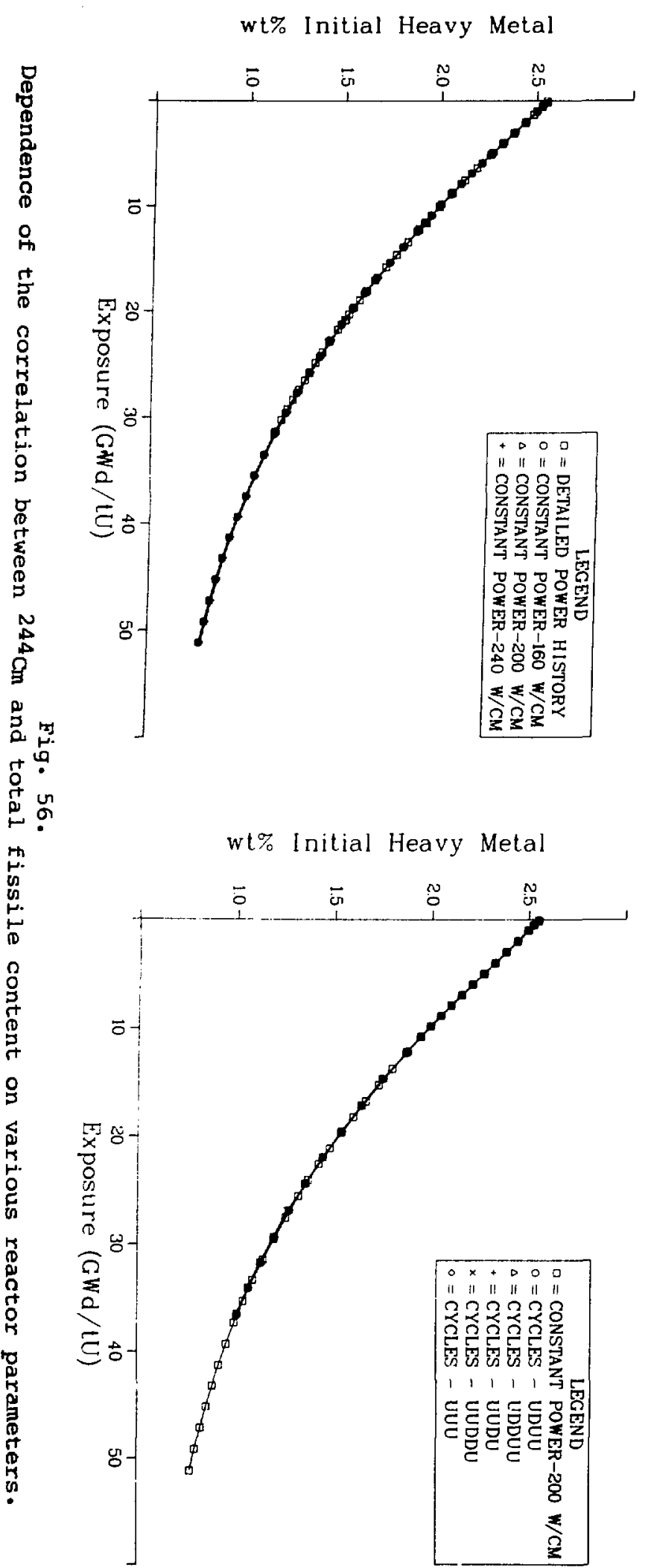

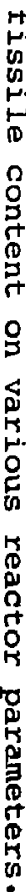
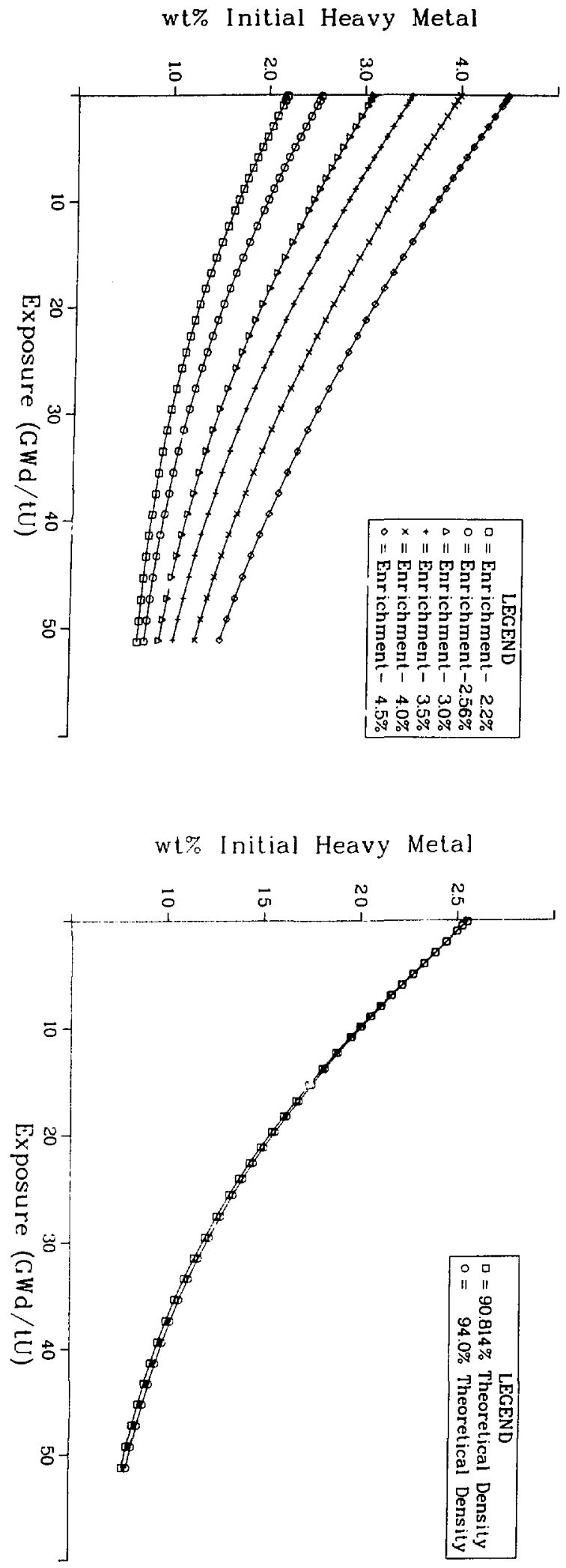
VI. SOURCES OF NEUTRONS IN IRRADIATED FUEL MATERIAL

For each 6-month time step in the basic actinide data library, atomic densities for each isotope are given for cooling times from 0 to 120 months. These atomic densities then were used to calculate the total source of neutrons from the $(\alpha, n)$ reaction and spontaneous fission factors in Table IV. Figure 57 gives the relative per cent contributions of the five most important nuclides to the total neutron source strength at 10-, 20-, 30-, and 50-GWd/tU exposures. As stated previously, ${ }^{242} \mathrm{Cm}$ contributes a significant portion of the source neutrons at time of discharge. Having a short half-life relative to the other neutron sources, the ${ }^{242} \mathrm{Cm}$ contributes an insignificant proportion of the source neutrons after 2 to $3 \mathrm{yr}$ of cooling time.

Curium-244, with an 18.1-yr half-life, is the major contributor to the source neutrons after ${ }^{242} \mathrm{~cm}$ decay for fuel materials with exposures greater than $15 \mathrm{GWd} / \mathrm{tU}$. For low exposures, less than $10 \mathrm{GWd} / \mathrm{tU},{ }^{240} \mathrm{Pu}$ and $244 \mathrm{~cm}$ are equal contributors following the ${ }^{242} \mathrm{Cm}$ decay. Relative neutron source strengths are given in Fig. 58 for the four exposure levels. In both the 10and $20-\mathrm{GWd} / \mathrm{tU}$ exposure plots, the ${ }^{241} \mathrm{Am}$ shows a build-up in its contribution, which results from the increase of ${ }^{241}$ Am from the beta decay of ${ }^{241}$ Pu produced during irradiation.

As shown in Table IV, neutrons can originate from both the $(\alpha, n)$ reactions and the spontaneous fission process. Figure 59 shows the relative contribution of both processes to the total neutron source strength as a function of exposure for four cooling times: 0 ; 12, 48, and 120 months. In all cases, the spontaneous fission process dominates for exposures above $10 \mathrm{GWd} / \mathrm{tU}$. For certain exposure regions, the different responses from $(\alpha, n)$ and spontaneous fission neutrons may be used to separate the plutonium (in particular, ${ }^{238}$ pu and ${ }^{240} \mathrm{Pu}$ ) neutrons from the ${ }^{244} \mathrm{~cm}$ neutrons by coincidence measurement techniques. The ratio of spontaneous fission neutrons $(\alpha, n)$ to reaction neutrons as a function of exposure for coolirig times of $0,12,48$, and 120 months is presented in Fig. 60 .

Figure 61 summarizes the calculated source neutron rates as a function of expos'ure for four cooling times. These results are similar to the experimental results in Fig. 62 for 38 PWR fuel assemblies. Both the calculational and experimental results exhibit a power function relationship between the neutron emission rate and exposure. The calculational results (Fig. 61) do not include 


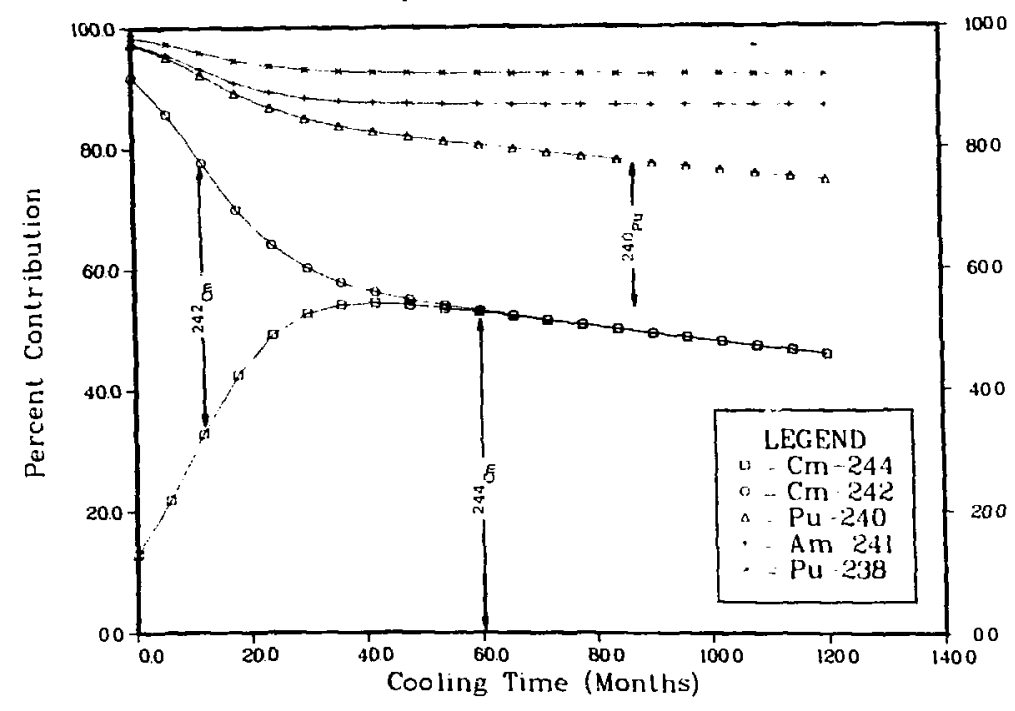

Exposure $=31505 \mathrm{GWd}: 111$

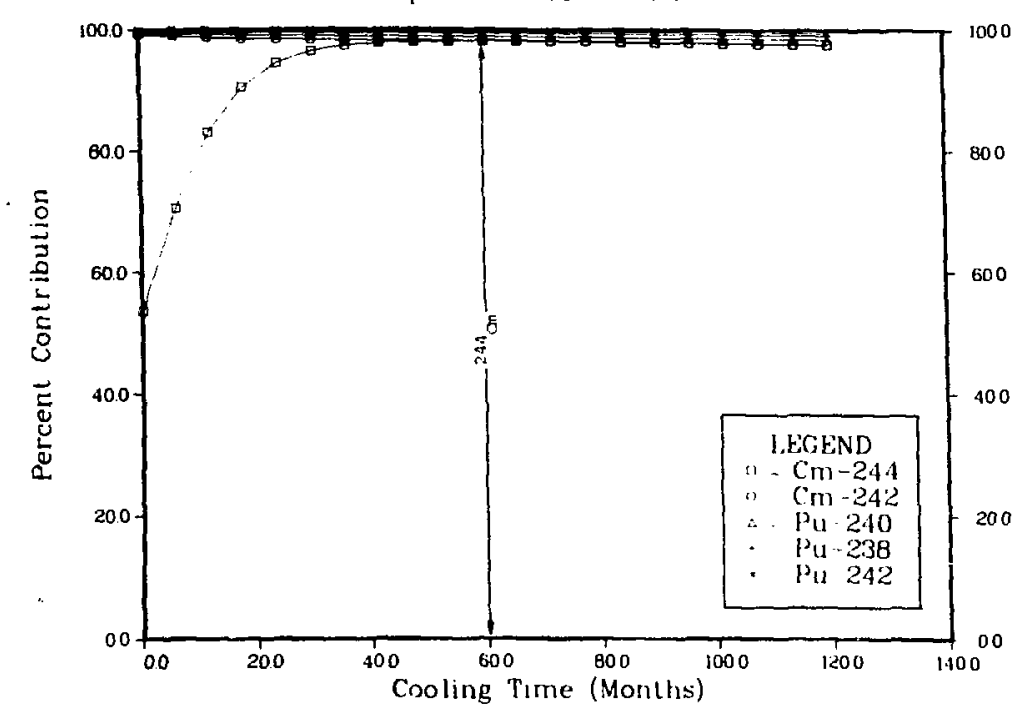

Exposure $=19717 \mathrm{GWd} / \mathrm{tU}$

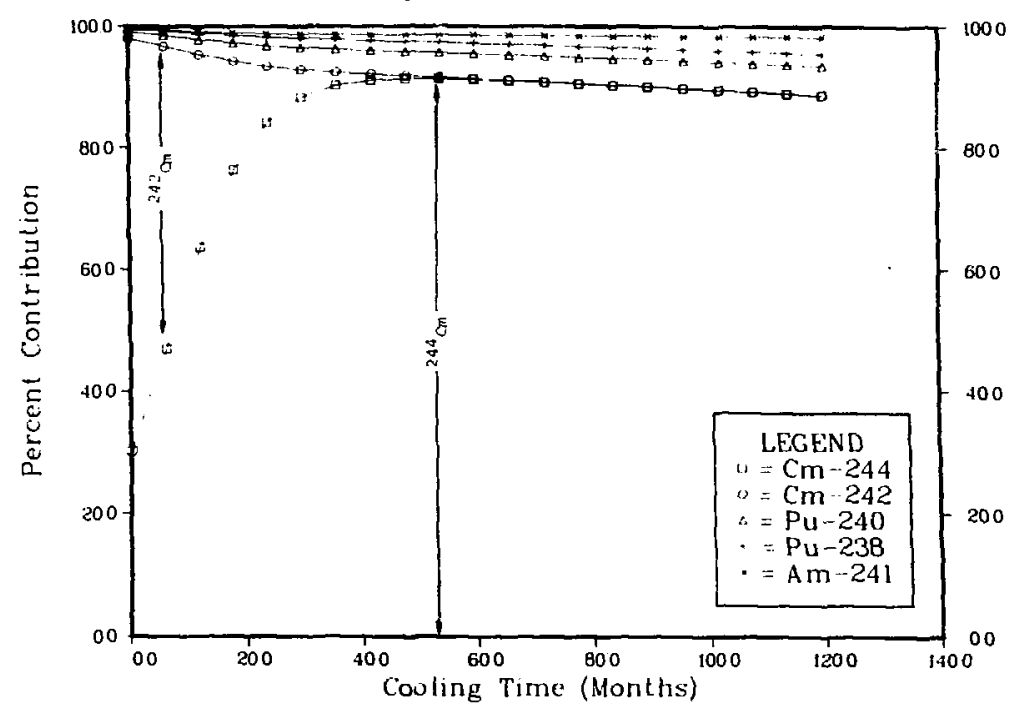

Exposure $=49223 \mathrm{cWd} / \mathrm{tU}$

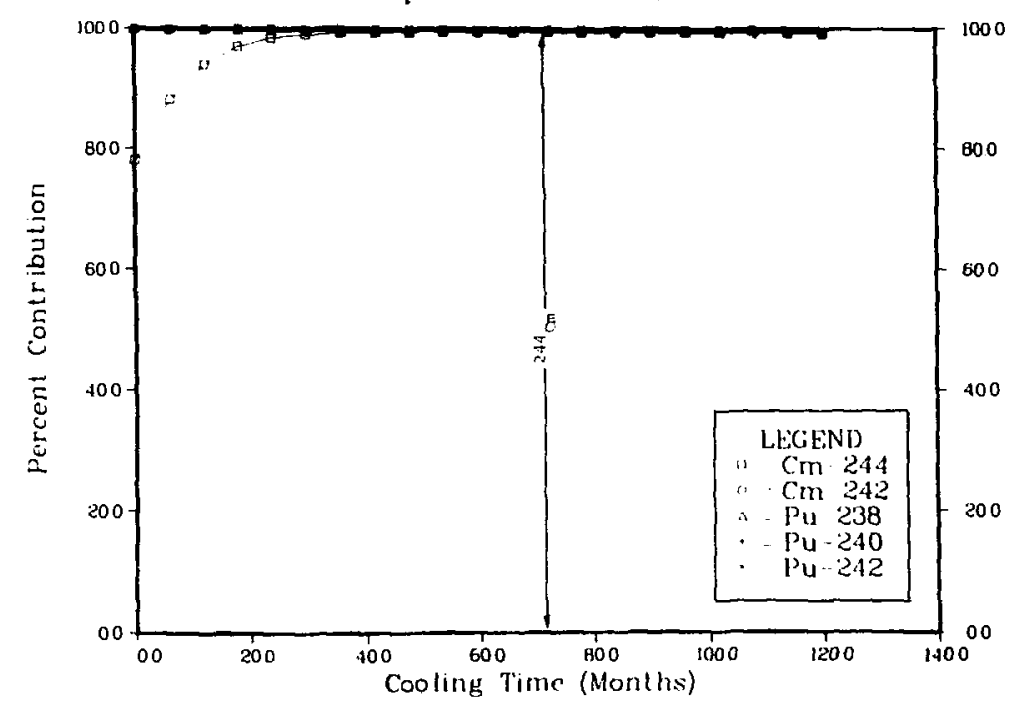

Fig. 57.

Per cent contribution of individual isotopes to the total neutron source strength as a function of cooling time. 

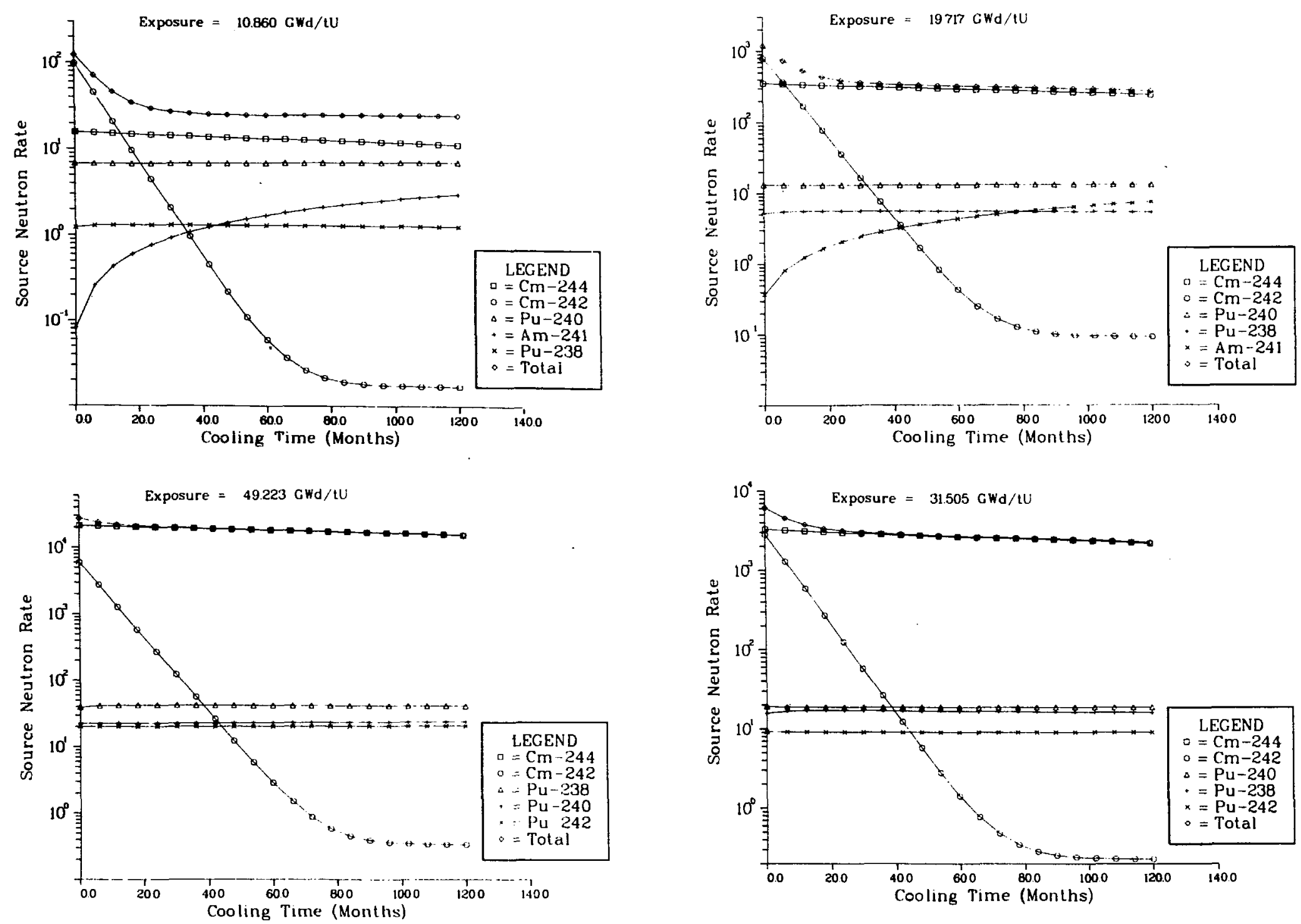

Fig. 58 .

Relative neutron source strengths for the five principal contributors. Curium-244 clearly is the dominant neutron source for exposures greater than $20 \mathrm{GWd} / \mathrm{tU}$ and cooling times greater than 36 months. 

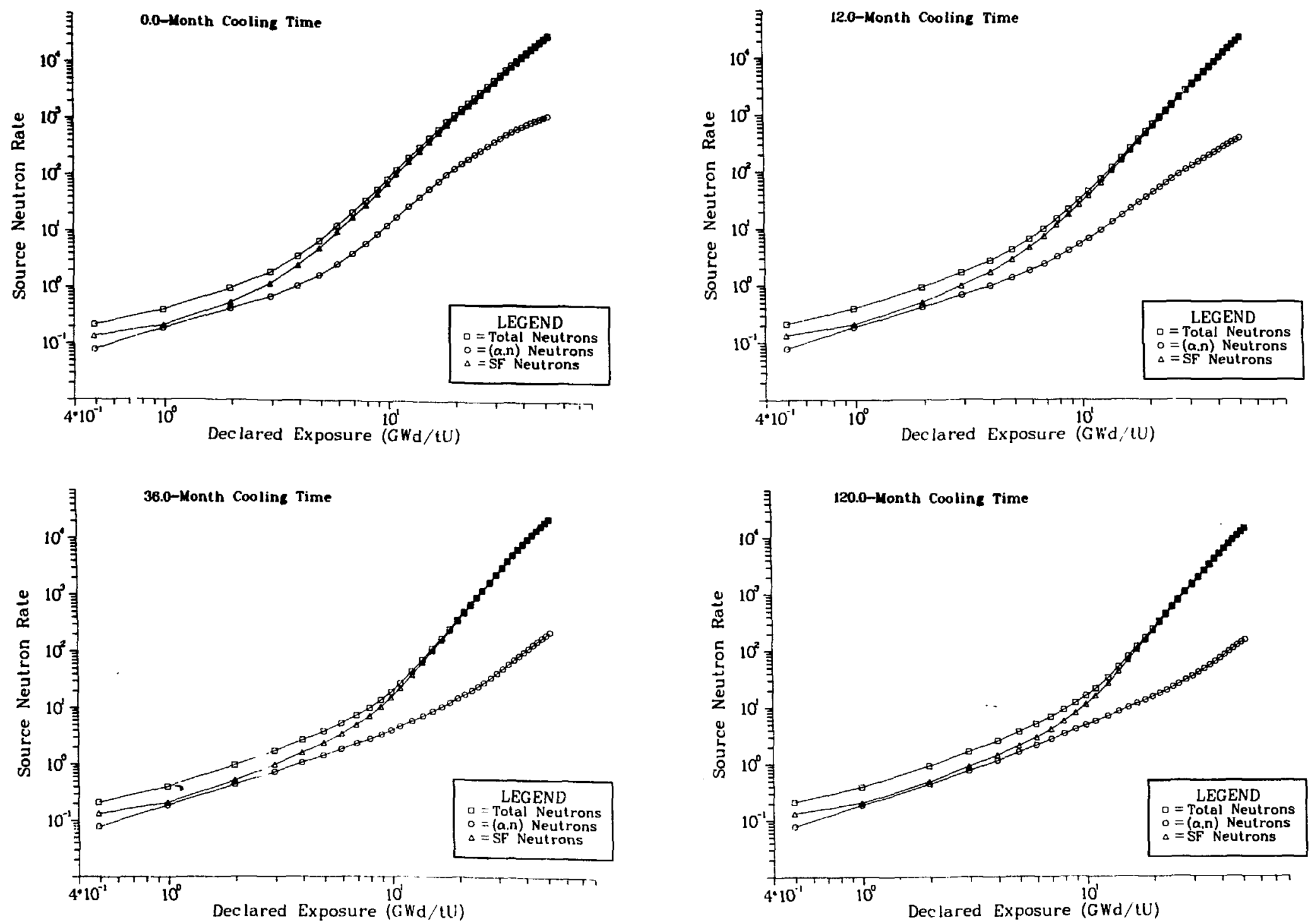

Fig. 59.

$(\alpha, n)$ and spontaneous fission sources of neutrons as a function of exposure for various cooling times. 


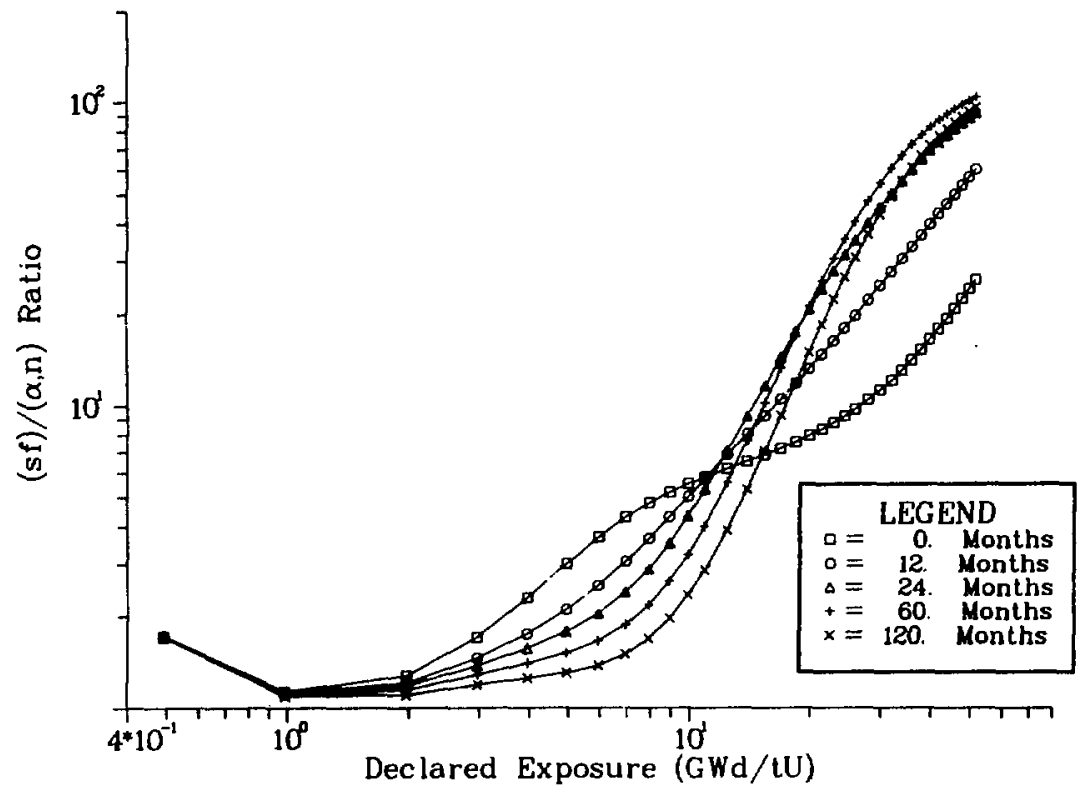

Fig. 60 .

(sf) $/(\alpha, n)$ neutron ratio as a function of declared exposure for cooling times up to 120 months.

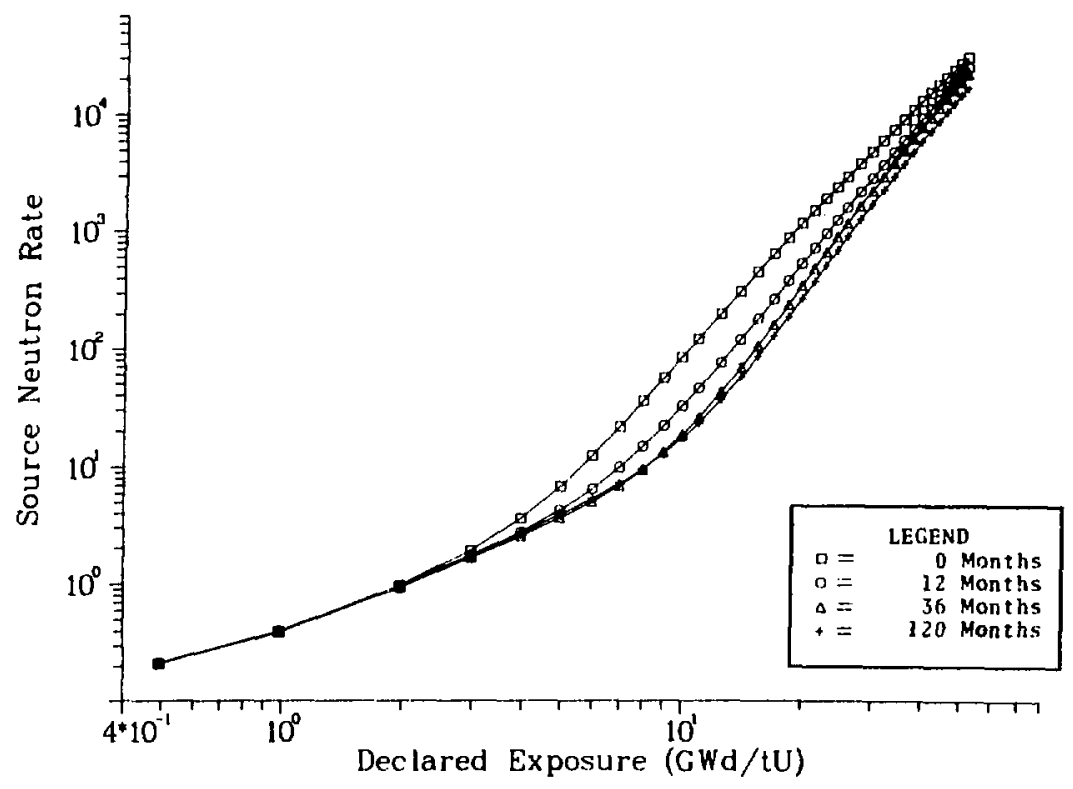

Fig. 61 .

Neutron source strength as a function of exposure up to $50 \mathrm{GWd} / \mathrm{tU}$ showing the power functional relationship: (Number of source neutrons) $=\alpha$ (exposure) $)^{\beta}$ where $\beta \sim 3$. 


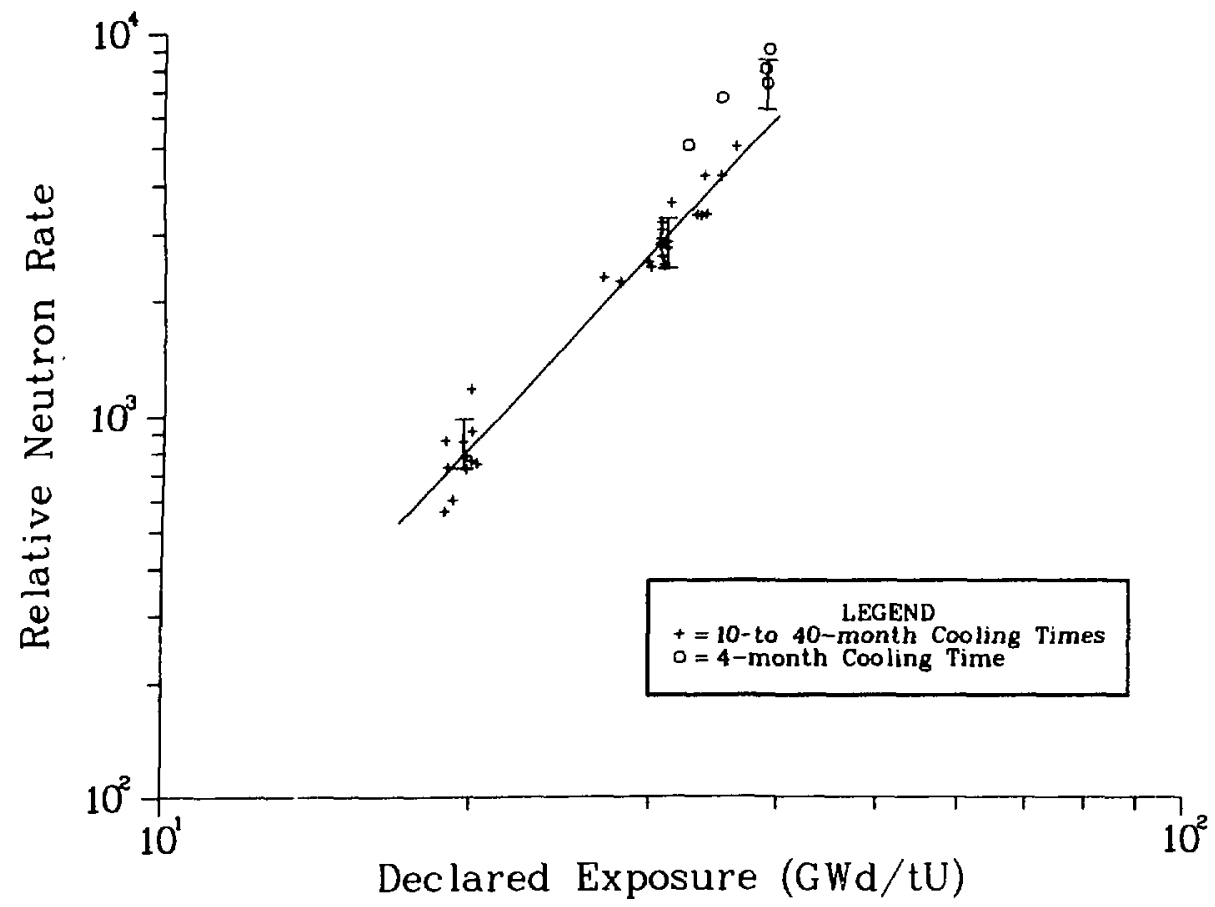

Fig. 62,

Experimental results for 38 PWR fuel assemblies with cooling times raiging from 40 to 4 months.

any source multiplication or transport factors unique to each fuel assembly. The experimental results have not been corrected for differences in cooling times that ranged from 4 to 40 months. In Fig. 62, the influence of the ${ }^{242} \mathrm{Cr}$ on the 4-month data is clearly evident because these data lie significantly above the fitted line.

VII. PARAMETERS AFEECTING NEUTRON SOURCES

We investigated various initial fuel and irradiation history parameters on the neutron sources in irradiated fuel material:

- constant power level,

- different theoretical fuel densities,

- changes in the per cent initial ${ }^{235} \mathrm{U}$ enrichment, and

- irradiation histories. 
Figure 63 compares the actual detailed power history of a specimen irradiated in the HBR-2 PWR and the constant power $(200 \mathrm{~W} / \mathrm{cm})$ history approximations after cooling times of $0,12,36$, and 120 months. For all cases, the two power histories are identical. Differences in specific power levels appear to have little effect on neutron sources after the first few months. If the enrichment and fuel density are constant, the neutron flux level must be adjusted to change the power level. Figure 64 shows the effect of irradiating fuel material of various power levels, 160,200 , and $240 \mathrm{~W} / \mathrm{cm}$. The three curves merge to the same form after a 12-month cooling time.

An increase in fuel density changes the neutron source rates only slightly as shown in Fig. 65, where the fuel density was changed from 90.8 to 94.08 TD. The difference between the two cases remains nearly constant for all the cooling times.

Per cent initial ${ }^{235} \mathrm{U}$ enrichment significantly affects the neutron source terms (Fig. 66). Initial fuel enrichments of 2.2 to 4.58 were selecteu for these comparisons because this range now is used in PWR fuels and these snrichments are projected (about 4.58) for high-exposure fuels to improve uranium utilization. The dependence of the source neutron rate on initial fuel enrichment continues throughout the cooling times investigated in this study (up to 120 months). Source neutron rates are higher for the lower enrichments $(2.2$ to 3.0 wtz) than for the higher enrichments (above 3 wtz) because of the higher flux levels required to maintain a constant power level. Another minor influence is the increased concentration level of the ${ }^{238_{U}}$ source material with lower enrichments.

If a relative neutron source rate of $10^{3}$ were measured for fuel material with a 36-month cooling time, the exposures would be $22 \mathrm{GWd} / \mathrm{tU}$ for the $2.20 \%$ initial ${ }^{235} \mathrm{U}$ enrichment material and $32 \mathrm{GWd} / \mathrm{tU}$ for the 4.58 initial ${ }^{235} \mathrm{U}$ enrichment. These two exposures represent the approximate exposure lavels for fuel material irradiated in a PWR for one and two cycles, respectively. Therefore, to interpret correctly the measured results, we must know the per cent initial ${ }^{235} \mathrm{U}$ enrichment.

Irradiation histories can also significantly influence the source neutron rate, as evidenced by the plots given in Fig. 67. The following historias are represented:

- constant power level through five cycles resulting in an exposure of $50 \mathrm{GWd} / \mathrm{tU}$, 


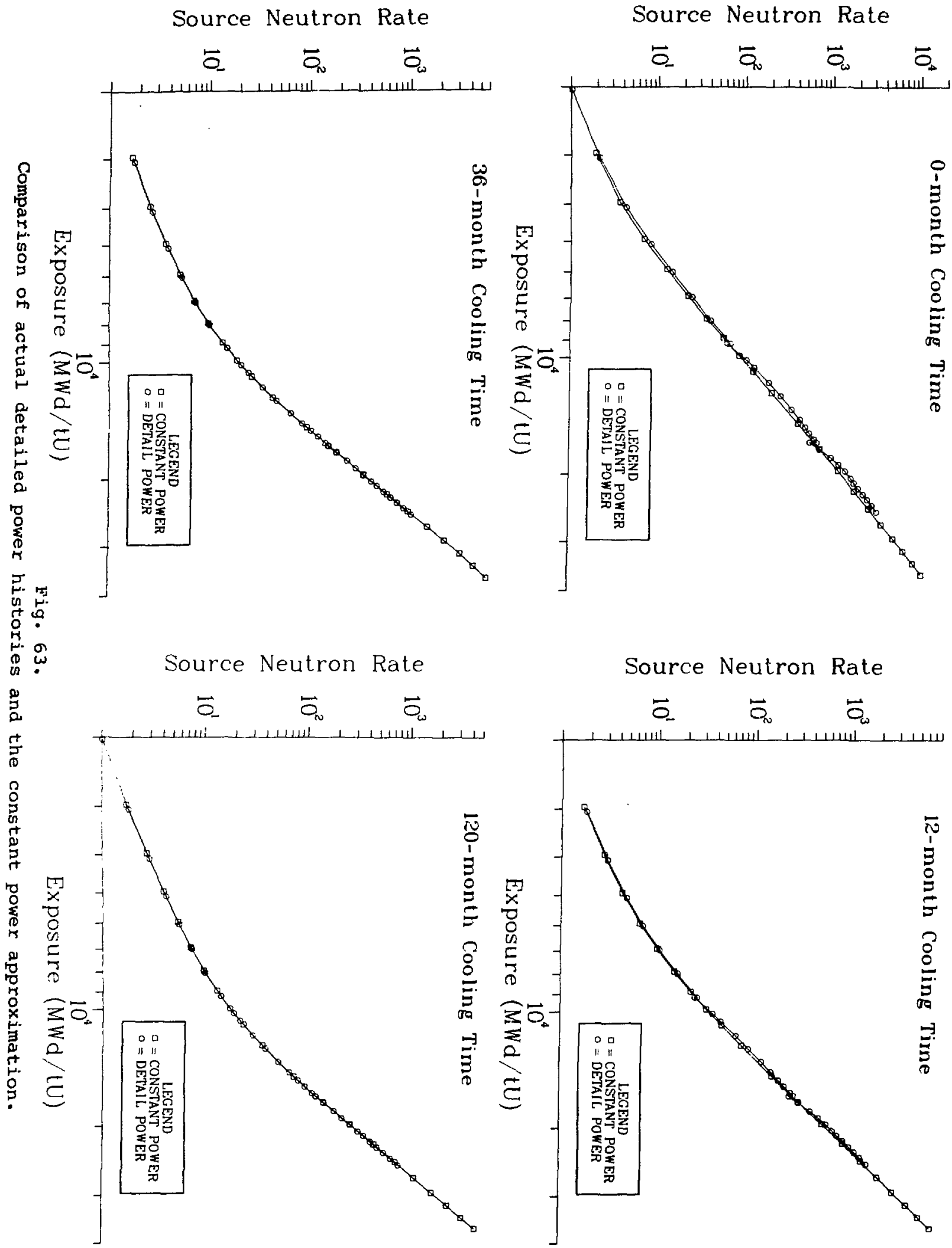




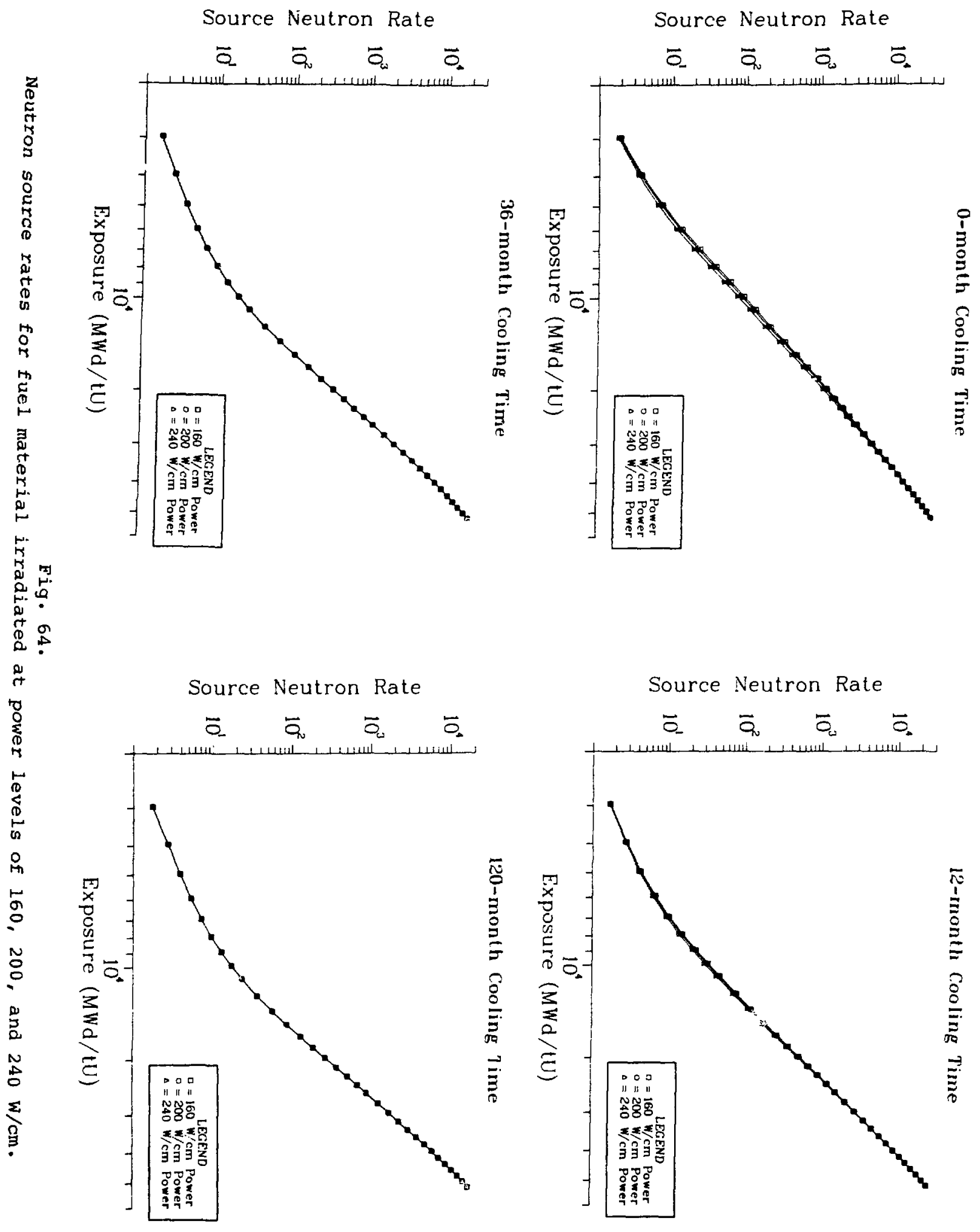


Source Neutron Rate
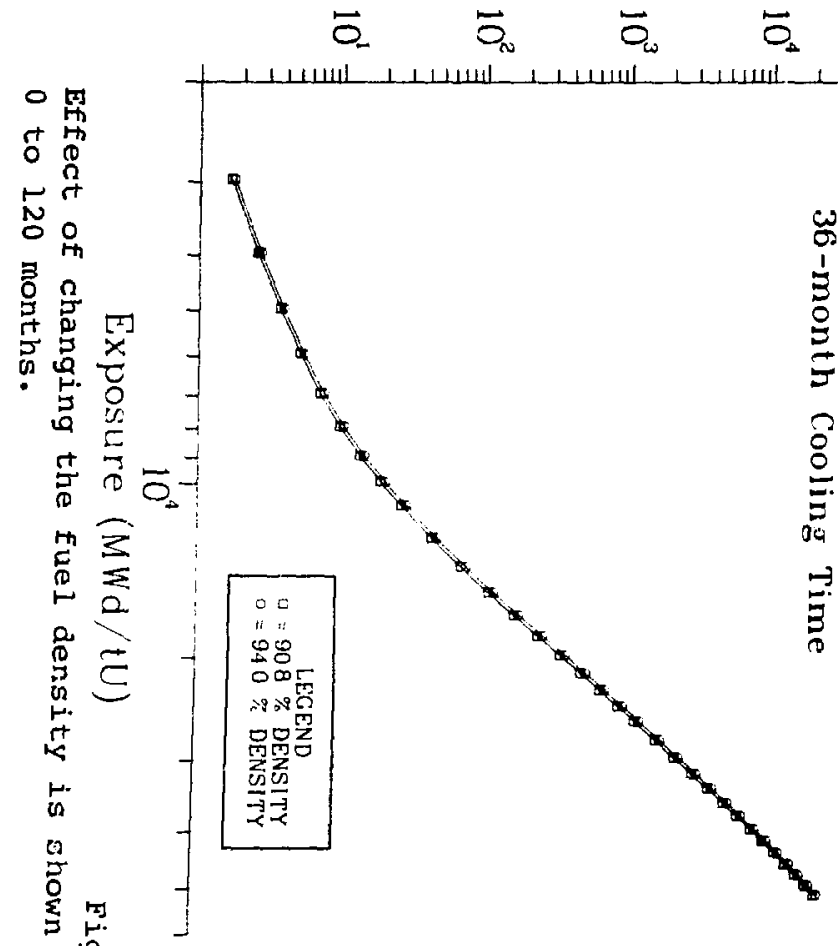

$+0^{\circ}$

ซั जิ

点

8
8
0
0
0
0
0

ก

$\stackrel{8}{\circ}$

:

$+\sum^{2}$

苟.

要

衶
Source Neutron Rate

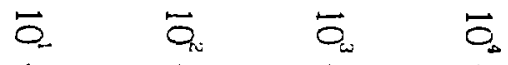

Source Neutron Rate

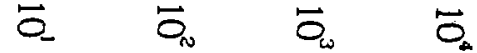

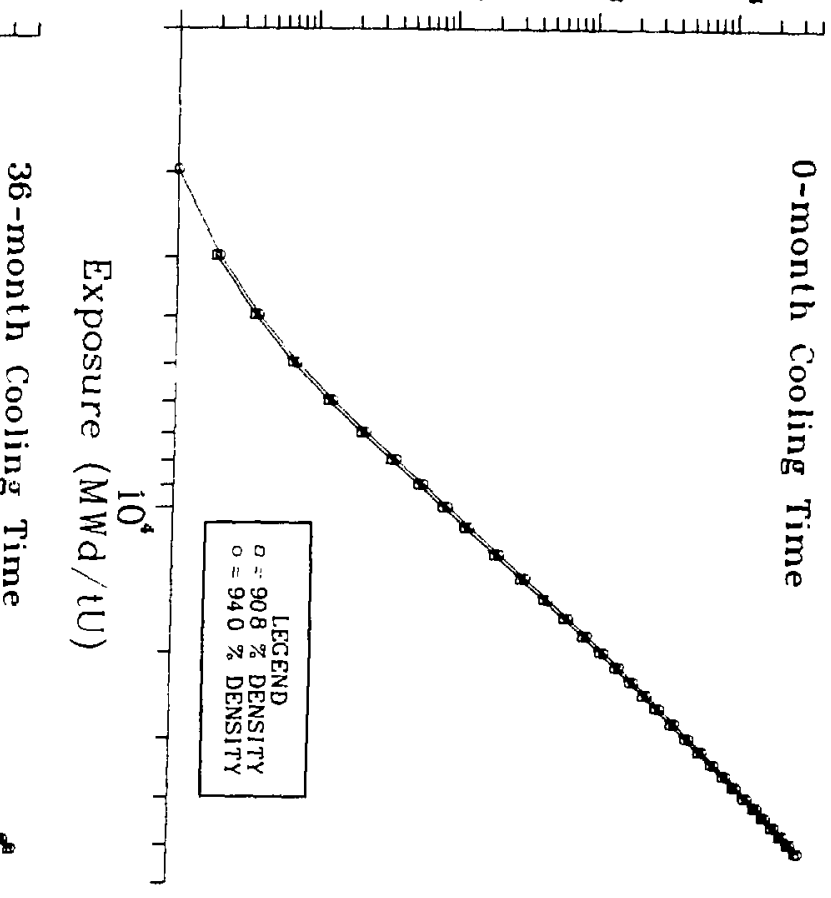

Source Neutron Rate

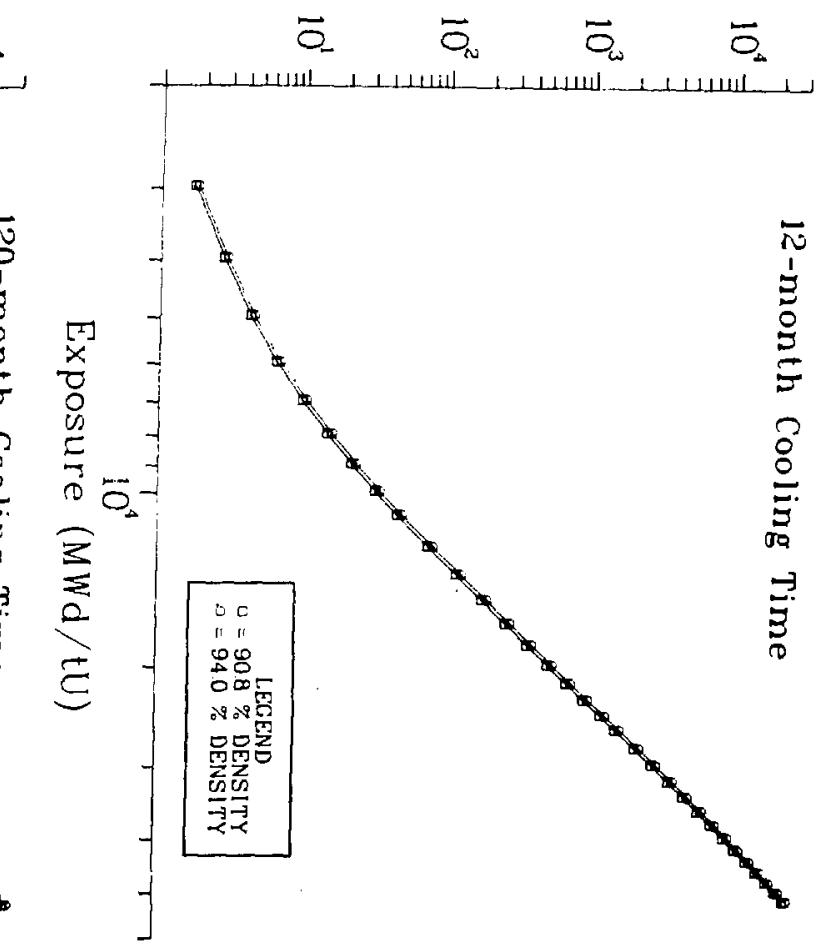



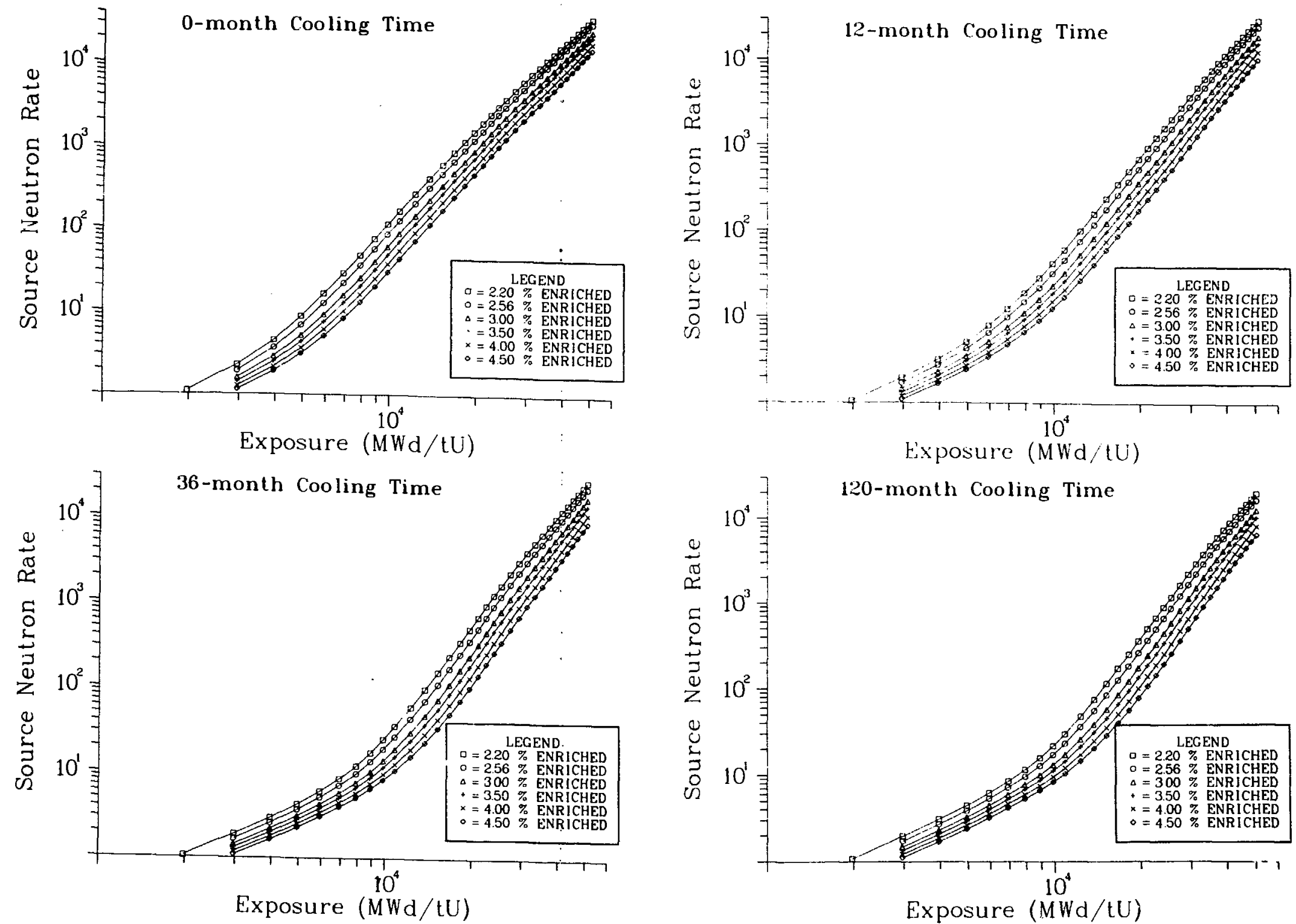

Initial $235 \mathrm{U}$ fuel enrichment effect on source neutron rates. Enrichments cover the range of values expected to occur in PWR fuel materials. 
$\nsubseteq$
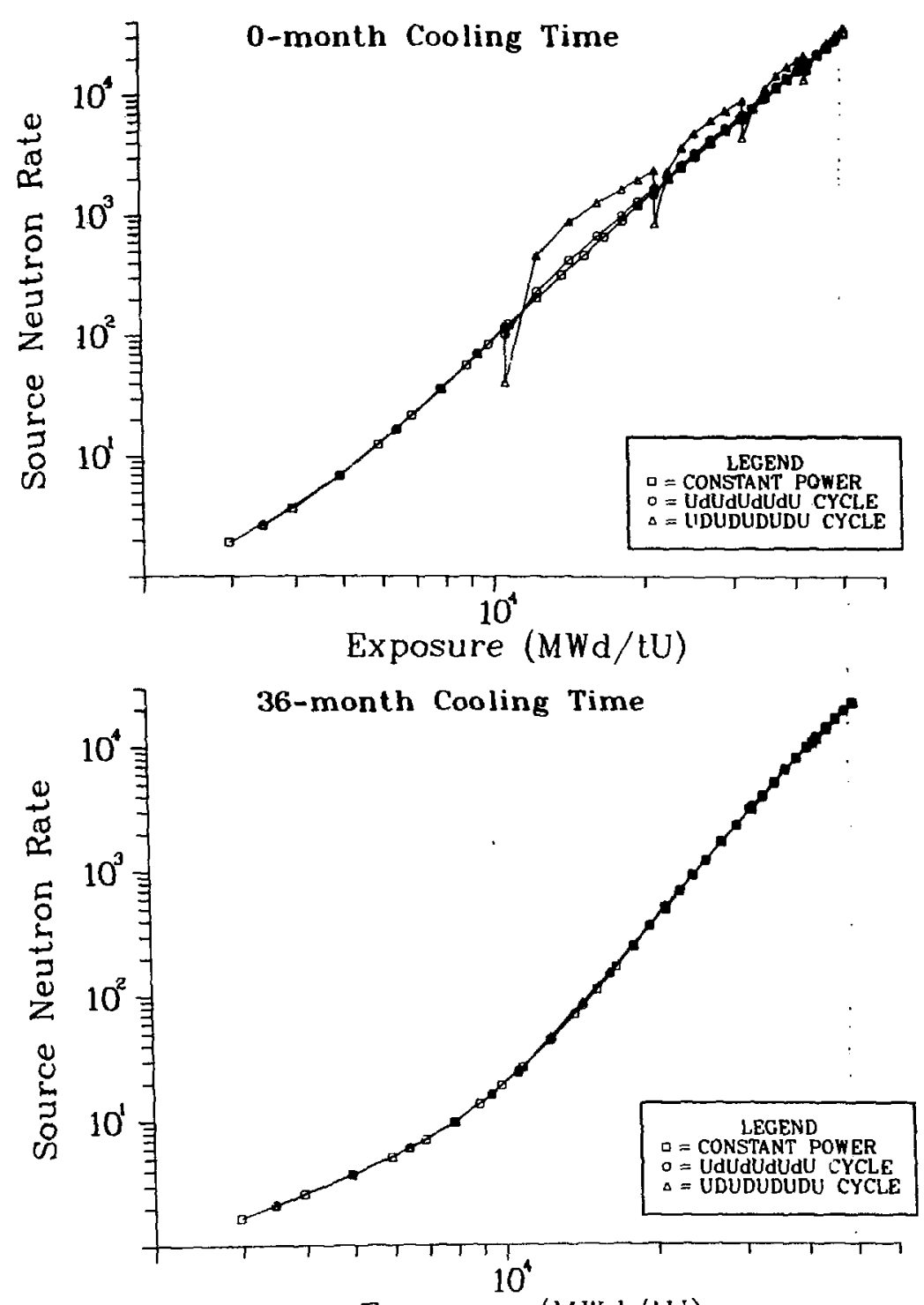

Exposure $(\mathrm{MWd} / \mathrm{tU})$
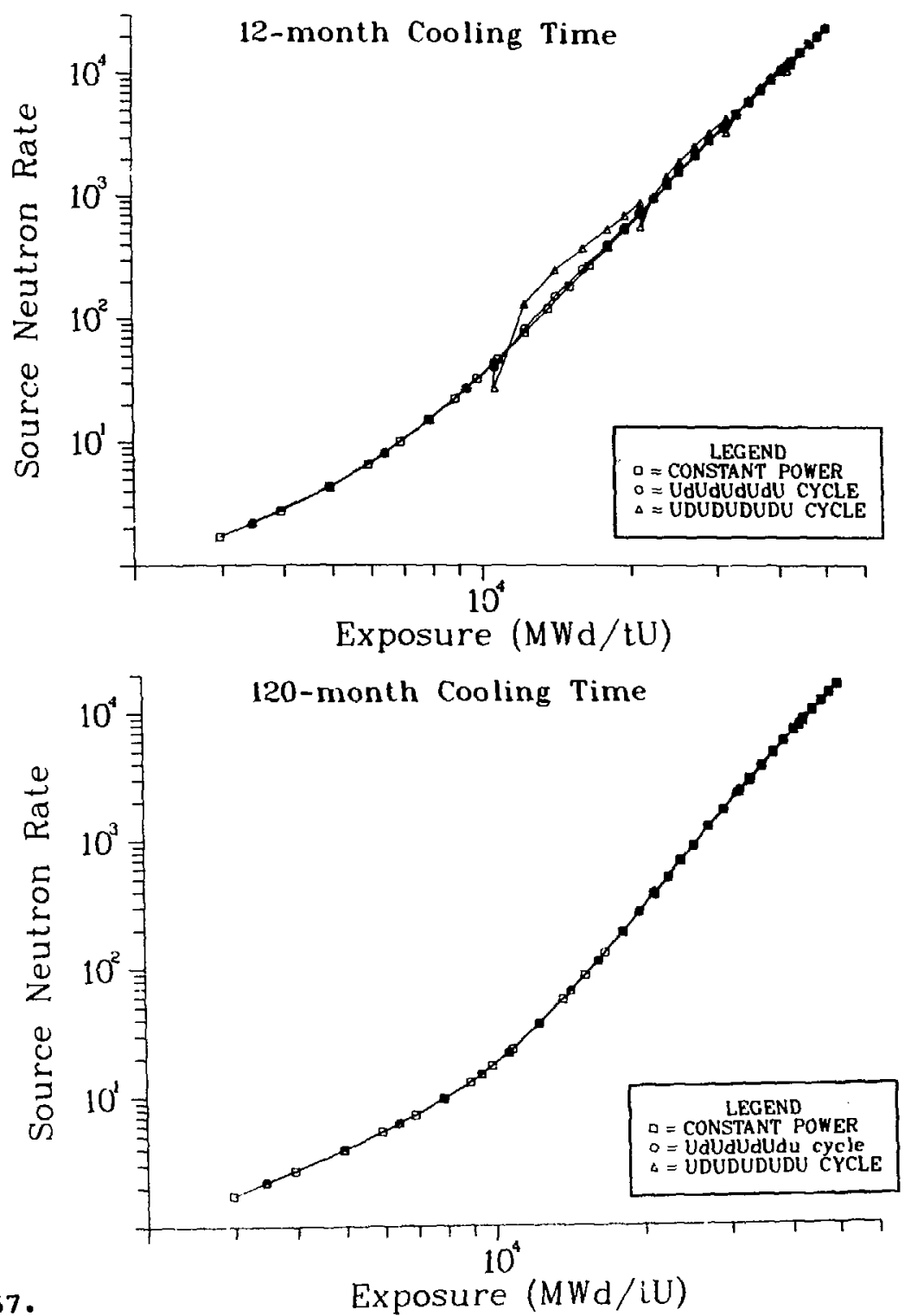

Comparison of a constant irradiation history with histories having downtimes between cycles of 48 days (d) and 414 days (D). This demonstrates the effect of the beta decay of $24 l_{\mathrm{Pu}}$ to $24 \mathrm{l}_{\mathrm{Am}}$, which is a precursor to the $242 \mathrm{Cm}$ isotope. 
- up-down history in which the up (U) times were 317 days followed by a downtime (d) equivalent to the time required to reload the reactor (48.25 days), and

- up-down history in which each up (U) cycle was 317 days and each (D) cycle was for 413.5 days.

After 36 months, all three irradiation histories merge to the same relationship between the source neutron rate and the exposure. However, for shorter cooling times there is an appreciable difference between the plots, with the history having 413.5-day downtimes (D) showing a significant increase in the neutron source rate after each downtime. This peculiar behavior is directly related to the build-up of ${ }^{242} \mathrm{~cm}$ within the fuel material. During the downtimes, ${ }^{241} \mathrm{Pu}$, with a half-life of $14.7 \mathrm{Y}$, beta decays to form ${ }^{241} \mathrm{Am}$ with a half-life of $432.2 \mathrm{yr}$. Americium-24I captures a neutron to produce ${ }^{242}$ Am that beta decays to ${ }^{242} \mathrm{Cm}$. The ${ }^{241} \mathrm{Am}$ concentration increases during the downtime, thereby providing more source material from which ${ }^{242} \mathrm{Cm}$ is produced. At higher exposures, the per cent contribution of neutrons from ${ }^{242} \mathrm{Cm}$ to the total source neutrons decreases (see Figs. 57 and 58); therefore, this influence is greatest at the beginning of the second cycle.

Figure 68 shows the results of five irradiation histories found in typical power reactors where the fuel assembly is removed for one or two cycles before being inserted into the reactor to corflete its designed exposure. As stated above, the greatest effect is observed when the fuel material is irradiated for one cycle and then cooled for one or two cycles before re-irradiation. For example, the same source neutron rates $\left(10^{3}\right)$ are obtained for fuel material with a UDDUU history $(15 \mathrm{GWd} / \mathrm{tU})$ and a constant UUU history of $20 \mathrm{GWd} / \mathrm{tU}$ if the fuel assembly was measured at discharge.

\section{CORRELATIONS BETWEEN SOURCE NEUTRON RATES AND FISSILE CONTENT}

The total source neutron rates compared to (1) the total fissile content $\left({ }^{235} \mathrm{v}+{ }^{239} \mathrm{pu}+{ }^{241} \mathrm{pu}\right),(2)$ total plutonium, (3) fissile plutonium, and (4) total plutonium minus ${ }^{239} \mathrm{Pu}$ for $0-, 12-, 48-$, and 120 -month cooling times are shown in Fig. 69. After a 36-month cooling time, this relation between the logarithm (neutron source rate) and total fissile content of the fuel material approximates a linear relationship. Likewise, the relationship of source 


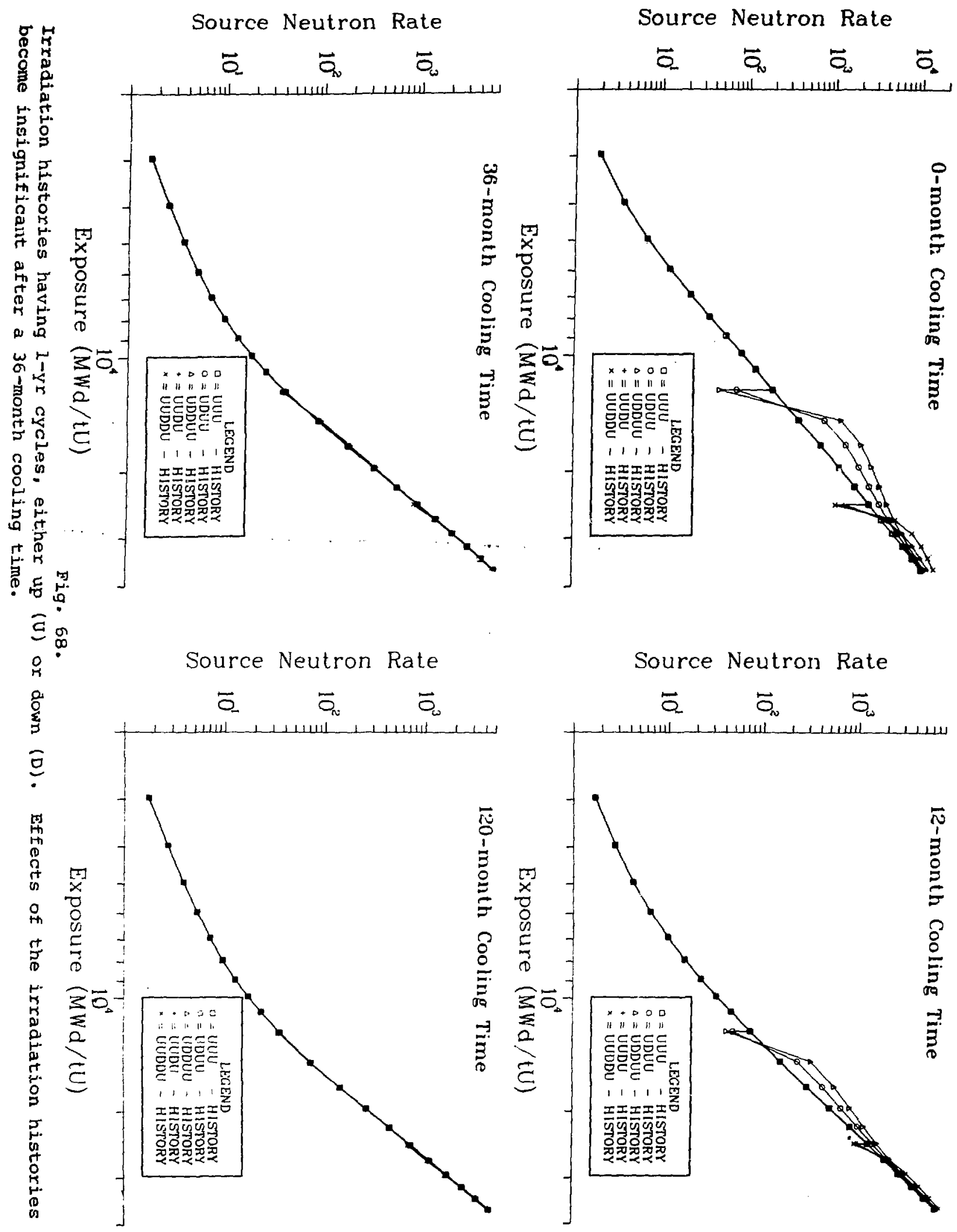



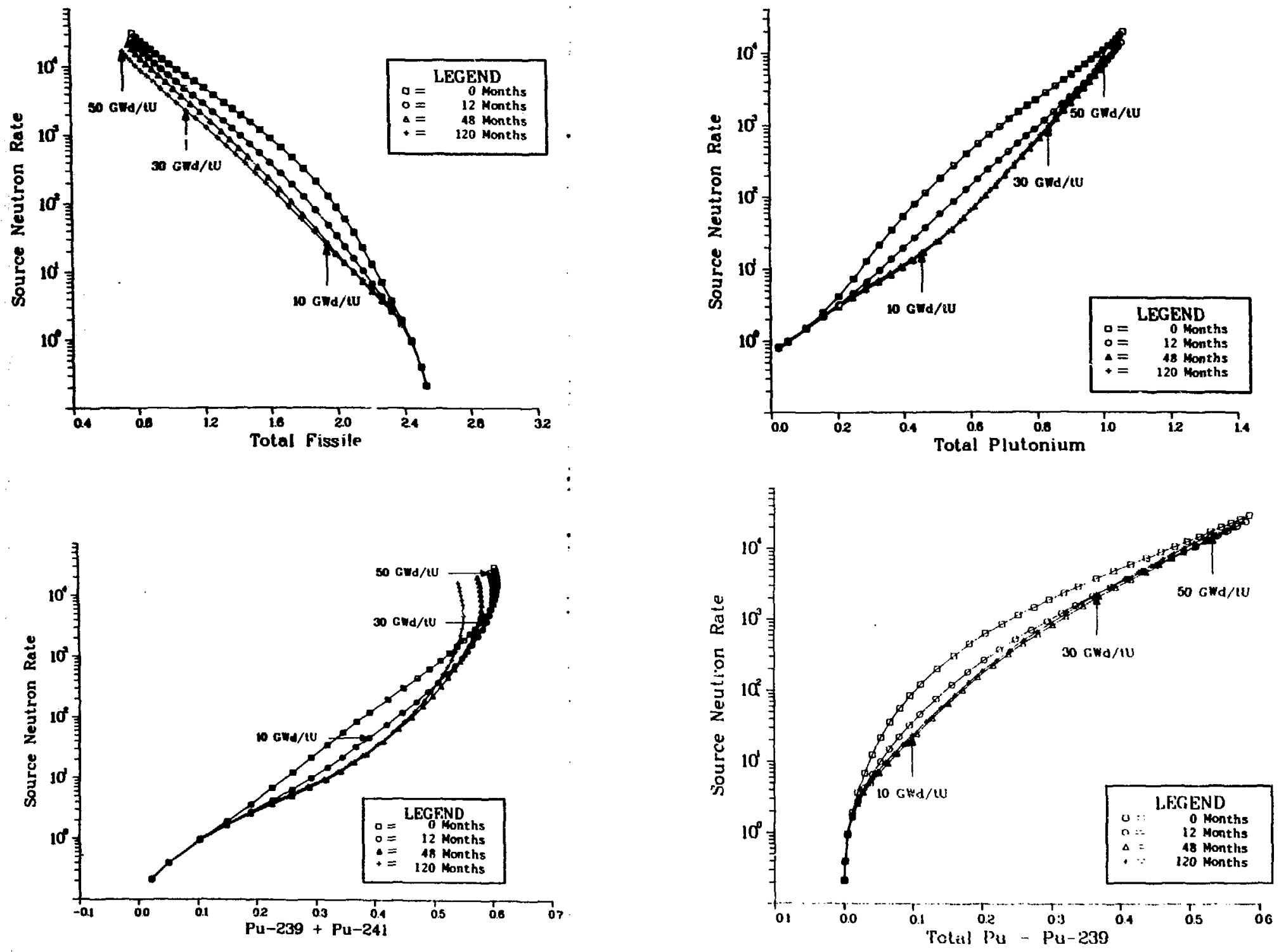

Fig. 69.

Correlations of the source neutron rate with total fissile, total plutonium, fissile plutonium, and total plutonium minus $239 \mathrm{pu}$. 
neutrons to total plutonium approaches a linear relationship. The neutron plot vs fissile plutonium bends upward as the ${ }^{239} \mathrm{Pu}$ and ${ }^{241} \mathrm{Pu}$ burn out more quickly than they are produced. Remember, in these cases the power level is maintained at a constant value; therefore, at higner exposures there is iess ${ }^{235} \mathrm{U}$ available for fissioning. The plots for total plutonium minus ${ }^{239} \mathrm{Pu}$ also converge to a common linear relationship with respect to the logarithm (neutron source rate).

\section{CONCLUSIONS}

Actinide isotopes in spent-fuel assemblies are important sources of neutrons. Because of the nature of neutron emission, multiplication, and detection, relating individual neutron signals to specific actinide isotopes is impossible. As a result, the neutron signal's intensity is the only pertinent data that are monitored and used to obtain qualitative information about spentfuel assemblies. Correlations between the calculated neutron signal's declared exposure, fissile: content, and plutonium content are determined. The calculations we describe validate these correlations and establish applicable ranges. Sensitivity studies examining various initial fuel parameters and reactor operating conditions demonstrate. that initial ${ }^{235} \mathrm{U}$. exrichment and irradiation history have the largest effects on spent-fuel assembly neutron emission rates. Knowing this dependence on certain reactor parameters, we can establish correction factors to improve the accuracy of the correlations.

If calculationally determined correction factors are to be used to adjust experimental data, the validity of the calculations must be known. Therefore, an ongoing data evaluation program is needed. As either destructive or neutron measurement data become available, calculational results should be verified. Experimental data from past exercises thus far have supported our calculations. In the future, experiuents should be designed to specifically complement calculational predictions.

Calculations of the type described in this report provide atom density and neutron source information for transport calculations. These calculations, which simulate fuel assembly and detector geometries, are used to optimize detectór configurations and to study varlous detection concepts. From such studies; techniques may be developed for accurately determining spent-fuel characteristics. 


\section{APPENDIX}

DEVELOPMENT AND VALIDATION OF CALCULATIONAL TECHNIQUES

The CINDER codes ${ }^{4,13-15}$ and libraries of processed nuclear data $5,16-18$ have been used in many calculations of irradiated fuel inventory (nuclide densities) and aggregate absorption properties. These calculations use initial fuel inventory, a neutron flux history, and basic nuclear data to determine inventory during and following irradiation. The original CINDER code ${ }^{13}$ was developed to calculate aggregate fission-product neutron absorption and decay heating in thermal reactor fuel. ${ }^{17}$ The original data library, ${ }^{16}$ using data from all available sources, represented the most complete collection of fission-product data in the early sixties.

A national data collection, the ENDF, has since been developed by the Cross Section Evaluation Working Group (CSEWG); versions of the evaluated file ENDF/B are distributed by the National Nuclear Data renter (NNDC) at Brookhaven National Isaboratory (BNL). Version four (ENDF/B-IV), released by NNDC in 1976, was the first to contain a special file of fission-product data; ${ }^{19}$ the crosssection and decay data of this file were processed and included in a data library for thermal reactor applications. ${ }^{5}$ The cross-section and decay properties of higher actinides were not well described until the 1978 release of the preliminary ENDF/B-V actinide data file. Cross sections and decay data from this file were included in an actinide data library, and the combined fissionproduct and actinide data library has been used in several recent calculations of thermal reactor inventory and decay power. $20-22$

Because of the high relative concentrations of uranium and plutonium nuclides in reactor fuel, the neutron flux shape is perturbed at neutron energies corresponding to the resonances of the uranium and plutonium nuclides. The effect of these flux perturbations on few-group cross sections, known as resonance self-shielding, is complicated by the changing mixture of nuclides in the fuel. Accurate inventory calculations depend on detailed description of the temporal actinide group cross sections and group fluxes. We used the EPRI-CELL code $e^{6,23}$ to provide these temporal data.

The EPRI-CELI code is designed to compute the space, energy, and burnup dependence of the neutron spectrum within cylindrical cells of LWR fuel rods. CELit, developed by Nuclear Associates International (NAI), uses the $B_{1}$ methor 
of $\mathrm{GAM}^{21}$ and the integral transport method of THERMOS ${ }^{25}$ to produce coarse-group neutron fluxes and cross sections for subsequent use in multidimensional diffusion theory depletion analysis. The behavior of heavy actinide and fission product nuclides is represented as a series of linearized chains consistent with the CINDER methodology.

Data libraries required by EPRI-CELL consist of infinitely dilute multigroup cross sections, composition- and energy-dependent resonance shielding factors, and energy-transfer matrices, including upscattering in the thermal range. For convenience, these library data are divided into three files labelled FASTLIB, for the modified GAM portion of the code; THRMLIB, for the modified THERMOS portion; and BURNLIB, for the modisied CINDER portion. Recently, new FASTLIB and THRMLIB data libraries have been generated 26,27 using ENDF/ $B-V^{10}$ and the NJOY nuclear data processing system. ${ }^{28}$ This has necessitated updating the CELL portion of EPRI-CELL to properly use the more extensive data representations in ENDF/B-V, adding, for example, "an epithermal disadvantage factor" for representing flux depression in the fuel. 27

The CINDER portion of the EPRI-CELL code, however, has not been upgraded to handle the more extensive actinide and fission product data in ENDF/B-V. Consequently, EPRI-CELL is not used alone, but collapsed flux and cross-section data from EPRI-CELL are used in CINDER-2, ${ }^{15}$ a new Los Alamos version of EPRICINDER: ${ }^{4}$ A small code, PHAZE, was written to link EPRI-CELL and CINDER-2.

The EPRI-CELL model Eor representing an HBR-2 fuel rod (Fig. A-1) consists of a cylindrical fuel region surrounded by a clad region, a moderator region, and an extra region that represents the fuel rod environment. Note that four space points are assigned to the fuel, one to the clad, seven to the moderator, and two to the extra region.

The detailed energy structure of the FASTLIB library consists of 62 neutron energy groups that range from $1.855 \mathrm{eV}$ to $10 \mathrm{MeV}$. The THRMLIB group. structure consists of 35 groups from 0.001012 to $1.855 \mathrm{eV}$. The group structure currently used in CINDER-2 consists of four groups (see Table A-I). Figure A-2 plots the FASTLIB and THRMLIB detailed fission cross section for ${ }^{235} \mathrm{U}$ at $300 \mathrm{~K}$, compared with the four-group cross section collapsed by the EPRI-CELL code. Figure A-3 shows a similar comparison of the thermal and fast fluxes in the fuel. Note that the detailed thermal flux is space dependent, with the greatest difference in the lowest energy groups. 


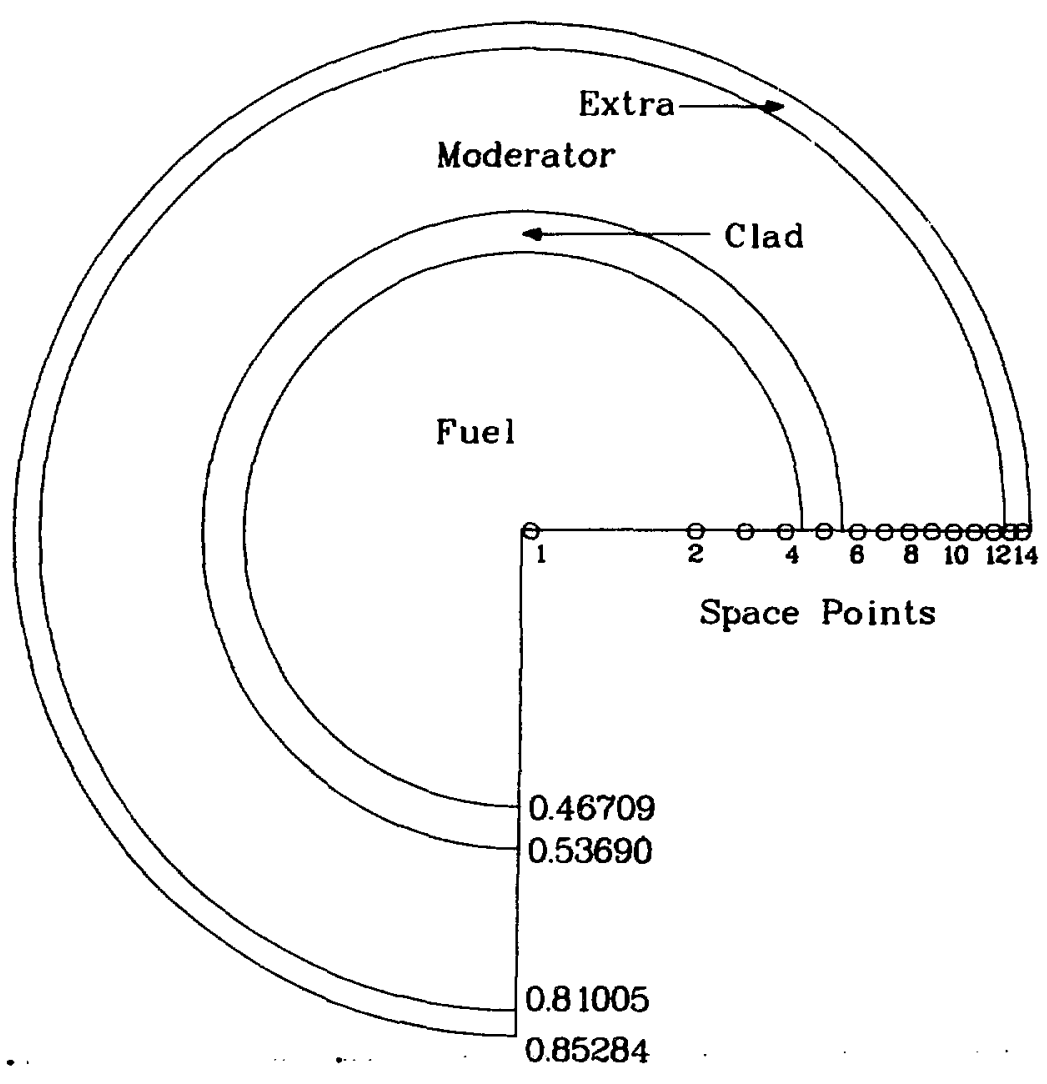

radii, cm.

$r$

Fig. A-1.

EPRI-CELI representation of HBR-2 fuel rod.

TABLE A-I

FOUR-GROUP ENERGY STRUCTURE

\begin{tabular}{lll}
$\begin{array}{l}\text { Group } \\
\text { No. }\end{array}$ & $\begin{array}{l}\text { Upper Limit } \\
(\mathrm{eV})\end{array}$ & \multicolumn{1}{c}{$\begin{array}{c}\text { Lower Limit } \\
(\mathrm{eV})\end{array}$} \\
1 & $10^{7}$ & $\frac{8.2085 \times 10^{5}}{2}$ \\
2 & $8.2085 \times 10^{5}$ & $5.53085 \times 10^{3}$ \\
3 & $5.53085 \times 10^{3}$ & $6.2506 \times 10^{-1}$ \\
4 & $6.2506 \times 10^{-1}$ & $10^{-5}$
\end{tabular}




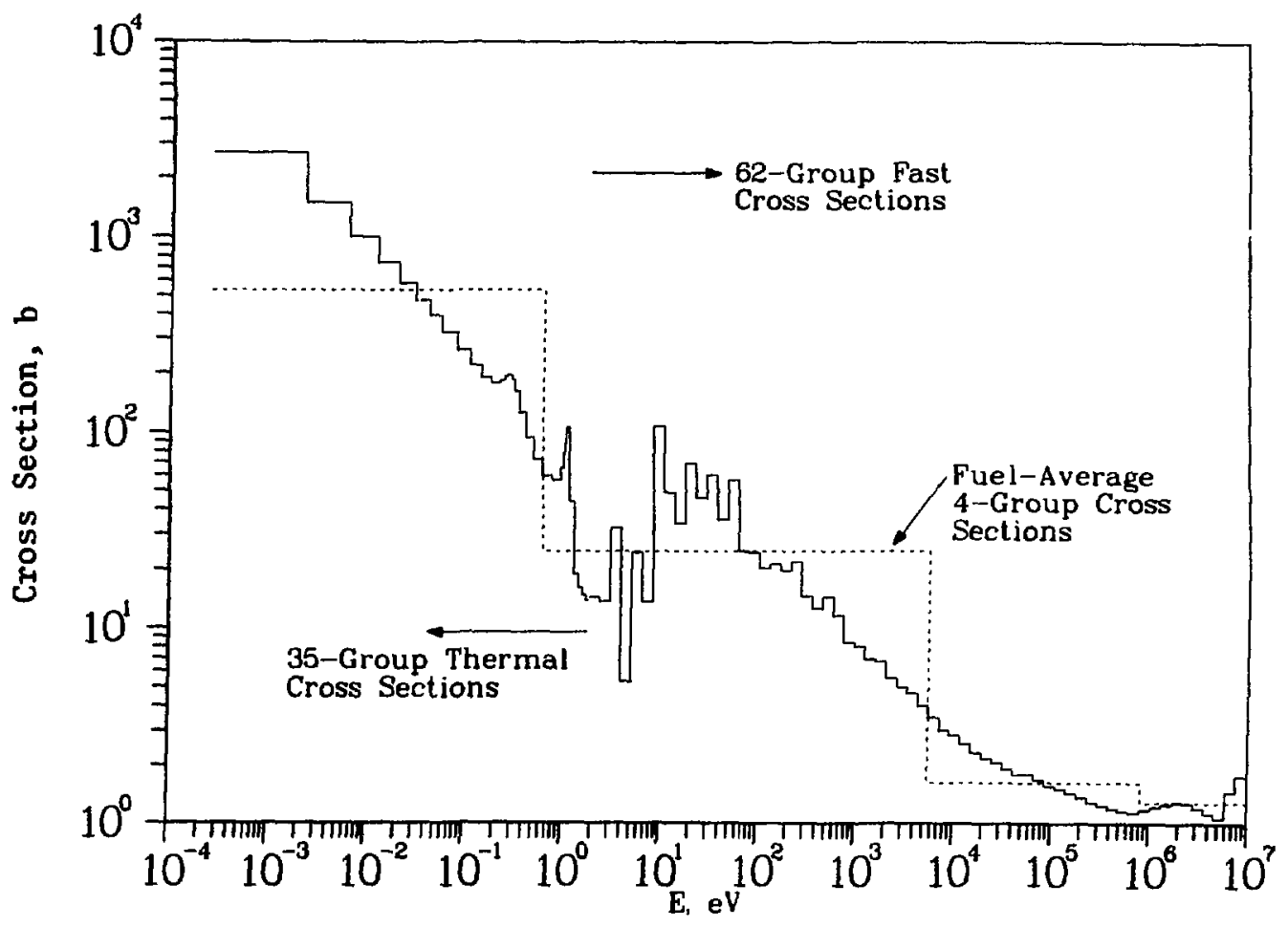

Fig. A-2.

Uranium-235 fission cross sections.

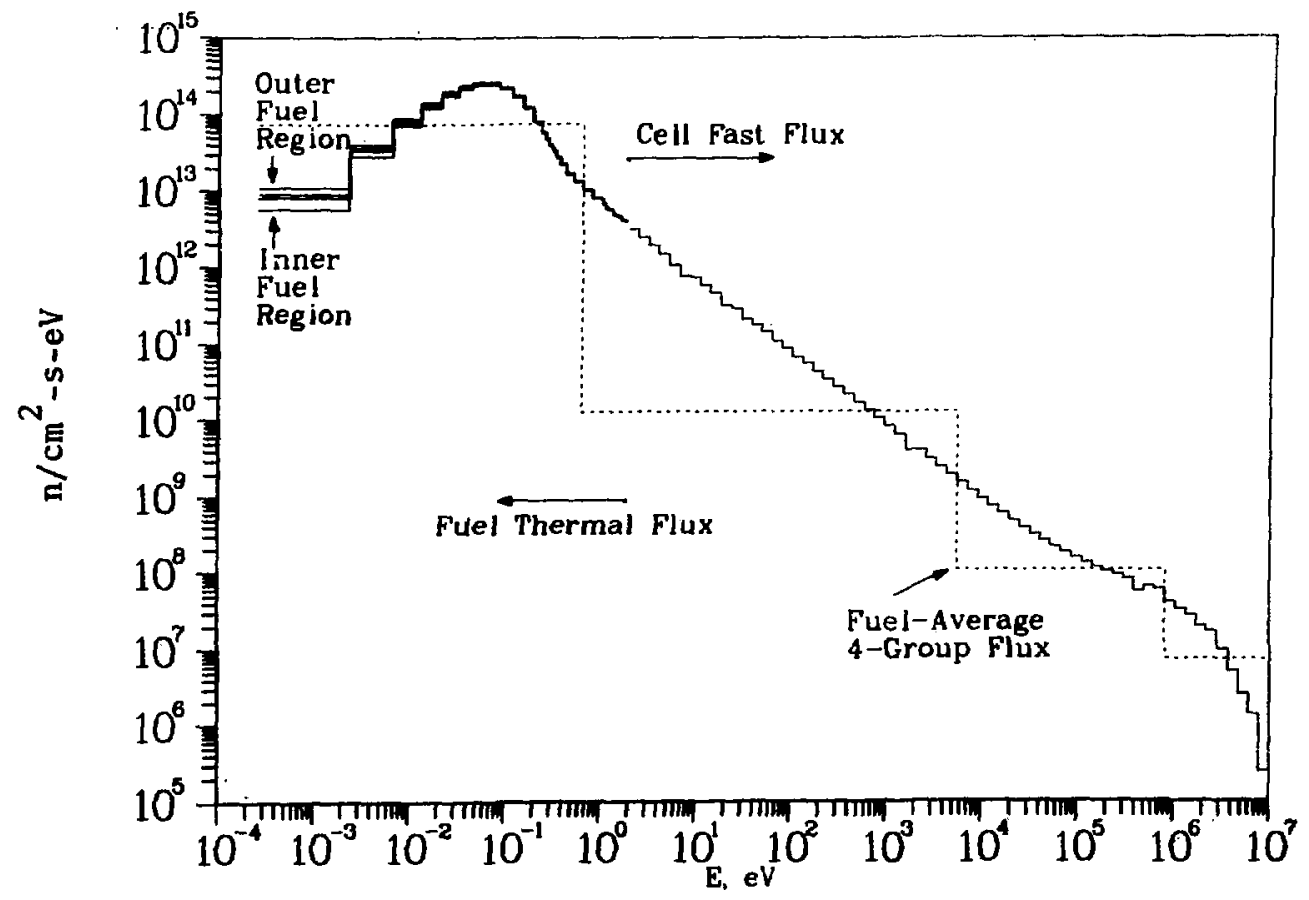

Fig. A-3.

Neutron flux in the fuel. 
EPRI-CELL has two distinct input types:

- general input, which is required to use the program's capability to handle a wide variety of problems; and

- engineering input, which describes fuel cell problems in familiar engineering units.

The engineering input is convenient for calculating nuclide inventory in spent reactor fuel, because the parameters required are more or less directly available from the Final Safety Analysis Report (FSAR) of the plant under consideration. Table A-II gives some of the engineering input parameters required and base values used for the $2.56 \%$-enriched HBR-2 fuel.

The HBR-2 fuel is one of the few actinide inventory benchmarks available. The power history of the HBR-2 fuel for cycles 1 and 2 is known, and fuel samples from rods of assembly B05 have been analyzed at Battelle columbus Laboratories (BCL) (rod P8, $)^{9}$ Idaho National Engineering Laboratory (rod E14), 29 Savannah River Laboratory (rods Al and 014 ), ${ }^{30}$ and Los Alamos National Iaboratory $^{31}$ (rod E14). Of these measurements, only those from BCL included procedures to determine fuel exposure (MWd/tU) or burnup (at.8 fission)--a key parameter required for correlating calculated and measured inventory values.

The burnup and select inventory values of three HBR-2 assembly B05 rod P8 samples were analyzed at BCL: the proximity of one sample to a spacer caused flux abnormalities and calculation uncertainties. The remaining two rod $p 8$ samples (P8A and P8B) were selected by EPRI as EPRI-CELI benchmark problems, 23 and the inventoxies of these samples have been routinely calculated. ${ }^{32}$ BCL measurements used the mass-spectrometric ${ }^{148}$ Nd method of buxnup analysis, 33 which relates the fission-product ${ }^{148}$ Nd content of the fuel to the fuel's cumulative fission history. This method assumes the following:

- Neodymium-148 yield fraction is independent of fissionable nuclide and is equal to $0.0168 \pm 0.003$ per fission.

- Exposure (MWd/tU) = burnup (at.8 fission) $\times 9600$. The ${ }^{148}$ Nd yield actually varies with fissionable nuclide, and the ENDF/B-V fission yield values for ${ }^{148}$ Nd from $235,238 \mathrm{U}$ and $239,241 \mathrm{Pu}$ fissions in a thermal reactor spectrum are as follows:

\begin{tabular}{lc}
$\begin{array}{l}\text { Fissionable } \\
\text { Nuclide }\end{array}$ & $\begin{array}{l}\text { Neodymium Fission } \\
\text { Yield Fraction }\end{array}$ \\
\hline${ }^{235_{\mathrm{U}}}$ & 0.01670038 \\
$238_{\mathrm{U}}$ & 0.02078896
\end{tabular}


TABLE A-II

EPRI-CELL ENGINEERING INPUT FOR HBR-2 FUEL-BASE CASEa

\section{Variable}

WF243

WF235

WF236

PPMB (I)

RHFUEL

VFMOD ( 5 )

VFXTR(2)

VEVTR( 5 )

CLAD

GRID

PRESS

NTS

TIMSTP (N)

POWR

BUCKI

SPECT

TRES (I)

TFUEL

TCLAD

TMOD

PELOR

CLADOR

CTAADIR

PITCH

XTRA

$\operatorname{DPITCH}(1,2)$

CERFAC $(1,2)$

P240

LIBR

DISAD
Definition

Weight fraction of ${ }^{234} \mathrm{v}$ in uranium Weight fraction of ${ }^{235} \mathrm{U}$ in uranium Weight fraction of ${ }^{236} \mathrm{U}$ in uranium Parts per million of natural boron by weight in moderator for time step I

Measured pellet density

Volume fraction of IN-718 in moderator

volume fraction of ${ }^{4} \mathrm{zr}$ in extra region

Volume fraction of IN-81B in extra region

2 for $4 \mathrm{Zr} c l a d$

2 for Inconel grid

System pressure in psia

Number of time steps

Duration of time steps

Power in watts/centimeter of height

Total buckling in square centimeters

1 for ${ }^{235} \mathrm{U}$ fission spectrum

Resonance temperature in ${ }^{\circ} \mathrm{F}$ for. time step I

Fuel temperature in ${ }^{\circ} \mathrm{F}$

Clad tempexature in ${ }^{\circ} \mathrm{F}$

Moderator temperature in ${ }^{\circ} \mathrm{F}$

Cold pellet radius in inches

Cold clad outer radius in inches

Cold clad inner radius in inches

Cold pitch in inches

Nonlattice fraction

Distance in inches for nonuniform

Dancoff calculation

Fractional contribution of Dancoff

for $\operatorname{DPITCH}(1,2)$

Multiplier on $\sigma_{\mathrm{a}} 3 / 4$ for $240_{\mathrm{Pu}}$ in CINDER library

2 for ENDF/B-V libraries

Fuel disadvantage factor
Value

0.00020

0.02561

0.00016

450 ppm for all time steps

0.90814

0.005836

0.084618

0.003261

2

2250.0

Varies with problem

Varies with problem

187.00269 (avexage)

0.0002705

1

1200.0 for all time steps

1200

620

572

0.18195

0.2110

0.1867

0.563

0.097826

$1.126,0.584$

$0.10294,0.073529$

0.973

2

$-1 \cdot 0$

${ }^{2}$ Only nonzero parameters are listed. 


\begin{tabular}{cc}
$\begin{array}{c}\text { Fissionable } \\
\text { Nuclide }\end{array}$ & $\begin{array}{c}\text { Neodymium Fission } \\
\text { Yield Fraction }\end{array}$ \\
\hline${ }^{238} \mathrm{Pu}$ & 0.01634225 \\
${ }^{241_{\mathrm{Pu}}}$ & 0.01989327
\end{tabular}

The constant relationship between exposure and burnup prescribed by this method implies a value of $Q$, the recoverable energy per fission, that is independent. of fissionable nuclide and irradiation history. Sher ${ }^{34}$ showed the components of $Q$ to be nuclide dependent, and Txapp ${ }^{35}$ investigated the effect of the composition of nuclides contributing to parasitic neutron absorption and subsequent decay energy of absorption products. EPRI-CELI calculates values of $Q$ for the mixture of fissionable nuclides and parasitic absorbers at each time interval; these are passed to CINDER-2 for detailed inventory calculations. Values of $Q$ increase in P8A calculations, for example, from 199.7 to $209.3 \mathrm{MeV} /$ fission. This increase is due both to an increase in ${ }^{239,241} \mathrm{Pu}$ fissions and to increased radionuclide decay energy associated with parasitic neutron absorption.

We have used iterative tandem EPRI-CELL/CINDER-2 calculations to match calculated sample burnup values with those reported in Ref. 9. These calculations used scaled histogram representations of the assembly BO5 power history in Ref. 36. Table A-III compares measured and calculated P8A and P8B sample inventory parameters following 1.32-yr decay; measured and calculated inventory values agree within 158. The largest differences occurred between the measured and calculated ${ }^{234} \mathrm{U}$ and ${ }^{238} \mathrm{Pu}$ values; these nuclides make small relative contributions to inventory and are produced both by $(n, 2 n)$ reactions and by $242 \mathrm{~cm}$ decay. The disagreements may result from uncertainty in the initial ${ }^{234} \mathrm{U}$ loading and in library data used in calculating the inventory of the nuclides. No uncertainties are given for the measured P8 sample values.

The BCL measurements were made for only a few nuclides, with results given as elemental fractions or nuclide rat:os; however, these are the only HBR-2 measurements known to have associated burnup or exposure values. Detailed absolute inventory measurements have been made for assembly BO5 samples, but, unfortunately, no sample burnup values are available. The results of a rod El4 sample analyzed at Ios Alamos are given in Table A-IV, where values calculated for the P8A and P3B samples are given at the longer 4.86-yr cooling time of the IOS Alamos measurements. The high measured concentrations of ${ }^{238} \mathrm{U}$ and ${ }^{239} \mathrm{Pu}$ suggest a small normalization problem between measurement and calculations. As 
COMPARISON OF MEASURED AND CALCULATED HBR-2 ISOTOPIC RATIOSa

\begin{tabular}{|c|c|c|c|c|c|c|}
\hline \multirow[b]{2}{*}{ quantity } & \multicolumn{3}{|c|}{ Sample P8A } & \multicolumn{3}{|c|}{ Sample P8B } \\
\hline & $\begin{array}{l}\text { Measured } \\
\text { Value }\end{array}$ & $\begin{array}{l}\text { Calculated } \\
\text { Value }\end{array}$ & $\begin{array}{l}\text { Per Cent } \\
\text { Difference }\end{array}$ & $\begin{array}{l}\text { Measured } \\
\text { Value }\end{array}$ & $\begin{array}{l}\text { Calculated } \\
\text { Value }\end{array}$ & $\begin{array}{l}\text { Per Cent } \\
\text { Difference }\end{array}$ \\
\hline $\begin{array}{l}\text { Burnup } \\
\text { at.8 fission }\end{array}$ & 2.559 & 2.560 & +0.04 & 3.221 & 3.221 & +0.01 \\
\hline Exposure & & & & & & \\
\hline MWd/tU & 24570 & 24660 & $+0 \cdot 37$ & 30920 & 31191 & +0.89 \\
\hline $234 \mathrm{U} / \mathrm{U}$ & 0.00016 & 0.00014 & -14.04 & 0.00014 & 0.00012 & -12.81 \\
\hline $235_{v / U}$ & 0.00816 & 0.00828 & +1.53 & 0.00612 & 0.00588 & -3.84 \\
\hline${ }^{236} \mathrm{U} / \mathrm{U}$ & 0.00326 & 0.00322 & -1.08 & 0.00352 & 0.00357 & +1.52 \\
\hline${ }^{238} \mathrm{u} / \mathrm{u}$ & $0.98 \quad 2$ & 0.98835 & -0.01 & 0.99022 & 0.99043 & +0.02 \\
\hline $1 / \mathrm{Py}$ & 0.01143 & 0.00979 & -14.35 & 0.01676 & 0.01452 & -13.35 \\
\hline $239 \mathrm{Pu} / \mathrm{Pu}$ & 0.59557 & 0.59365 & -0.32 & 0.54261 & 0.53966 & -0.54 \\
\hline${ }^{240} \mathrm{Pu} / \mathrm{Pu}$ & 0,23290 & 0.22766 & $-2 \cdot 25$ & 0.25101 & 0.24002 & $-4 \cdot 38$ \\
\hline${ }^{241} \mathrm{Pu} / \mathrm{Pu}$ & 0.11842 & 0.12385 & +4.58 & 0.12998 & 0.13772 & +5.95 \\
\hline${ }^{242} \mathrm{Pu} / \mathrm{Pu}$ & 0.04168 & 0.04506 & +8.10 & 0.05964 & 0.06807 & +11.41 \\
\hline${ }^{239} \mathrm{Pu} /{ }^{238} \mathrm{U}$ & 0.00494 & 0.00486 & -1.61 & 0.00518 & 0.00496 & $-4 \cdot 28$ \\
\hline${ }^{148} \mathrm{Nd} /{ }^{238} \mathrm{v}$ & 0.000450 & 0.000467 & +3.74 & 0.000570 & 0.000593 & +3.96 \\
\hline
\end{tabular}

aleasured isotopic ratios reported in BCL report BMI-1938, p. 16, (1975). Calculated values from March 1981 tandem CELL/CINDER-2 calculations using a detailed power history and 506.75-day cooling. 
COMPARISON OF HBR-2 ASSEMBLY BO5 SPENT-FUEL ISOTOPICS ${ }^{a}$

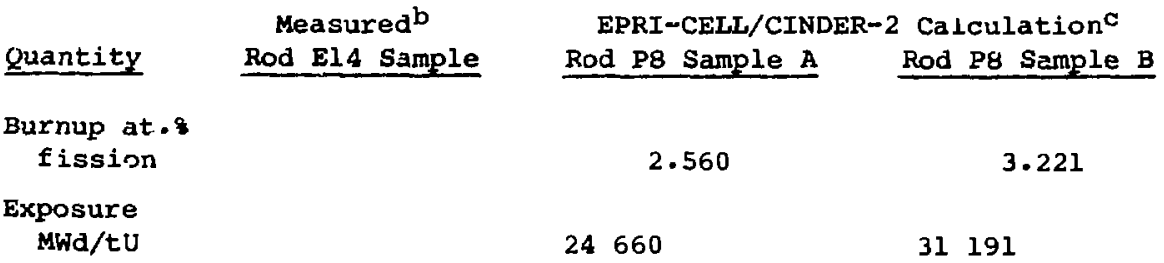

Nuclide densities, atoms/gram oxide at 4.86-yr cooling

\begin{tabular}{|c|c|c|c|}
\hline${ }^{90} \mathrm{Sr}$ & $2.73+18$ & $2.092+18$ & $2.493+18^{\mathrm{C}}$ \\
\hline${ }^{6} \mathrm{Ru}$ & $>1.71+16$ & $2.018+16$ & $2.866+16$ \\
\hline $\mathrm{sb}$ & $7.45+15$ & $7 \cdot 365+15$ & $9.825+15$ \\
\hline${ }^{34} \mathrm{Cs}$ & $7.61+16$ & $5.034+16$ & $7.943+16$ \\
\hline${ }^{37} \mathrm{Cs}$ & $3.75+18$ & $3.116+18$ & $3.935+18$ \\
\hline 14 & $1.41+16$ & $1.210+16$ & $1.486+16$ \\
\hline & $3.92+16$ & $5.638+16$ & $8.741+16^{\mathrm{a}}$ \\
\hline & $1 \cdot 28+16$ & $1.518+16$ & $2.301+16^{a}$ \\
\hline & $3.24+17$ & $2.941+17$ & $2.603+17^{d}$ \\
\hline & $1 \cdot 34+19$ & $1.759+19$ & $1.239+19$ \\
\hline & $7.6 B+18$ & $6.845+18$ & $7.497+18^{d}$ \\
\hline 238 & $2.15+21$ & $2.098+21$ & $2.086+21^{d}$ \\
\hline & $8.19+17$ & $6.278+17$ & $8.335+17$ \\
\hline & $3.25+17$ & $1.659+17$ & $2.744+17^{d}$ \\
\hline 23 & $1.08+19$ & $1.020+19$ & $1.034+19^{d}$ \\
\hline & $5.23+18$ & $3.909+18$ & $4.778+18^{a}$ \\
\hline & $2.18+18$ & $1.806+18$ & $2.241+18$ \\
\hline & $1.29+18$ & $7.739+17$ & $1.304 \div 18$ \\
\hline & $6.55+17$ & $5 \cdot 382+17$ & $6.589+17$ \\
\hline & $2.2+17 \pm 208$ & $1.193+17$ & $2.623+17$ \\
\hline $\begin{array}{l}242 \mathrm{~cm} \\
244 \mathrm{~cm}\end{array}$ & $\begin{array}{l}1.8+13 \\
5.10 \div 16 \pm 208\end{array}$ & $\begin{array}{l}1.306+13 \\
1.960+16\end{array}$ & $\begin{array}{l}1.982+13 \\
5.900+16\end{array}$ \\
\hline
\end{tabular}

a Measurements of Rod El4 sainple by Los Alamos CNC-11;

calculations of Rod P8 samples by Los Alamos T-2 .

bexperimental uncertainty \pm 5 \& unless otherwise indicated.

$c$ (Atoms/gram) from calculated (atoms/cubic centimeter) $/ 9.95 \mathrm{~g} / \mathrm{cm}^{3}$.

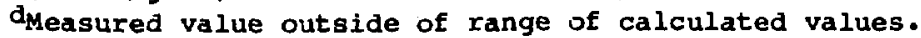


in the comparison of measured and calcilated $P 8$ sample values, the ${ }^{234} U$ and 238 $\mathrm{Pu}$ concentrations seem undercalculated. Most significant is the agreement of measured higher actinide nuclide densities with calculated values.

\section{REEERENCES}

1. J. R. Phillips, J. K. Halbig, D. M. Lee, S. E. Beach, T. R. Bement, E. Dırmendjiev, C. R. Hatcher, K. Kaieda, and E. G. Medina, "Application of Nondestructive Gamma-Ray and Neutron Techniques for the Safeguarding of Irradiated Fuel Materials," Los Alamos Scientific Laboratory reporc LA-8212 (ISPO-77) (May 1980).

2. G. Schulze, H. Würz, L. Koch, and R. Wellum, "Neutron Assay Plus Isotopic Correlation: A Method for Determining $P u$ and Burnup in Spent LWR Fuel Assemblies," Proceedings of the 2nd Annual ESARDA Symposium on Safeguards and Nuclear Materials Management, Edinburgh, Scotland, March 26-28, 1980 (European Safeguards Research and Development Association, Brussels, Belgium, 1980), p. 396.

3. E. Dermendjiev and H. Würz, "Calibration of IAEA NDA Equipment for Passive Neutron Assay of Irradiated Fuel Assemblies," International Atomic Energy Agency memorandum, October 1980.

4. T. R. England, W. B. Wilson, and M. G. Stamatelatos, "Fission Product Data for Thermal Reactors, Part 2: Users Manual for EPRI-CINDER Code and Data," Electric Power Research Institute report EPRI NP-356, Part 2 (December 1976). Also published as Los Alamos Scientific Laboratory report LA-6746-MS (December 1976).

5. T. R. England, W. B. Wilson, and M. G. Stamatelatos, "Fission Product Data for Thermal Reactors, Part 1: A Data set for EPRI-CINDER Using ENDF/ B-IV," Electric Power Research Institute report EPRI ND/356, Paxt 1 (December 1976). Also published as Los Alamos Scientific Laboratory report LA-6745-MS (December 1976).

6. W. R. Cobb and W. J. Eich, "A New Cell Depletion Code," Trans. Am. Nucl. Soc. 24, 442 (1976).

7. G. W. Eccleston, M. P. Baker, G. E. Bosler, and R. G. Schrandt, "Measurements and Calculations for PWR Fuel Assembly Assay," Trans. Am. Nucl. Soc. 39, 350 (1981).

8. Los Alamos Monte Carlo Group, "MCNP-A General Monte Carlo Code for Neutron and Photon Transport," Los Alamos Scientific Laboratory report LA-7396-M, Revised (November 1979).

9. A. A. Bauer, L. M. Lowry, and J. S. Perrin, "Progress on Evaluating strength and Ductility of Irradiated Zircaloy During July Through September, 1975," Battelle Memorial Institute report BMI-19.38 (September 1975), p. 16 . 
10. Evaluated Nuclear Data File (available from and maintained by the National Nuclear Data Center at Brookhaven National Laboratory). Spectral files in these compilations are based on data evaluated at Idaho Nuclear Engineering Laboratory.

11. R. T. Perry and W. B. Wilson, "Neutron Production from $(\alpha, n)$ Reactions and Spontaneous Fission in $\mathrm{ThO}_{2}, \mathrm{UO}_{2}$, and $(U, \mathrm{Pu}) \mathrm{O}_{2}$ Fuels," Los Alamos National Laboratory report LA-8869-MS (June 1981).

12. D. L. Johnson, "Evaluation of Neutron Yields from Spontanous Fission to Transuranic Isotopes," Trans. Am. Nucl. Soc. 22, 673 .(1975).

13. T. R. England, "CINDER - A One-Point Depletion and Fission Product Program," Westinghouse Electric Corp. report WAPD-TM-334 (1962, Rev. 1964).

14. T. R. England, R. Wi'lczynski, and N. L. Whittemore, "CINDER-7: An Interim Report for Users," Los Alamos Scientific Laboratory report LA-5885-MS (April 1975).

15. W. B. Wilson, T. R. England, R. J. LaBauve, M. E. Battat, D. E. Wessol, and R. T. Perry, "Status of CINDER and ENDF/B-V Based Libraries for Transmutation Calculations," Proc. International Conference on Nuclear waste Transmutation. Austin, Texas, July 22-24, 1980 (University of Texas at Austin, March 1981), p. 673.

16. T. R. England, "Time-Dependent Fission-Product Thermal and Resonance Absoxption Cross Sections (Data Revisions and Calculational Extensions)," Westinghouse Electric Corp. report WAPD-TM-333, Addendum No. 1 (1965).

17. T. R. England, "An Investigation of Fission Product Behavior and Decay Heating in Nuclear Reactors," Ph.D. Thesis, University of wisconsin, University Microfilm Order No. 70-12, 727 (1969).

18. T. R. England and M. G. Stamatelatos, "Multigroup Beta and Gamma Spectra of Inäividual ENDF/B-IV Fission-Product Nuclides," Los Alamos Scientific Laboratory report LA-NUREG-6622-MS (December 1976).

19. T. R. England and R. E. Schenter, "INDF/B-IV Fission-Product Files: Summary of Major Nuclide Data," Los Alamos Scientific Laboratory report LA-6116-MS (ENDF-223) (October 1975).

20. W. B. Wilson, T. R. England, O. Ozer, and D. E. Wessol, "Actinide Decay Power," Trans. Am. Nucl. Soc. 32, 737 (1979).

21. T. R. England and W. B. Wilson, "TMI-2 Decay Power: LASL Fission-Product and Actinide Decay Power Calculations for the President's Commission on the Accident at Three Mile Island," Los Alamos Scientific Laboratory report LA-8041-MS, Rev. (March 1980).

22. W. B. Wilson and T. R. England, "TMI-2 Radionuclide Inventory and Decay Properties," Trans. Am. Nucl. Soc. 34, 787 (1980). 
23. W. R. Cobb, w. J. Eich, and P. E. Tivel, "ARMP: Advanced Recycle Methodology Program," Electric Power Research Institute report CCM-3 (September 1977).

24. G. D. Joanow and J. S. Dujek, "GAM-I: A Consistent $P_{1}$ Multigroup Code for the Calculation of Fast Neutron Spectra Multigroup Constants," General Atomics report GA-1850 (June 1961).

25. H. C. Honeck, "Thermos, A Thermalization Transport Theory Code for Reactor Lattice Calculations," Brookhaven National Laboratory report BNL-5826 (September 1961).

26. O. Ozer, R. E. MacFarlane, and M. L. Williams, "Implementation of ENDF/ B-IV and $-V$ Data in LWR Design Codes: EPRI-CELL and EPRI-CPM," Trans. Am. Nucl. Soc. 33,820 (1979).

27. R. E. MacFarlane, "ENDF/B-IV and -V Cross Section Libraries for Thermal Power Reactor Analysis," Proc. International Conference on Nuclear Cross Sections for Technology, Knoxville, Tennessee, October 22-26, 1979 (National Bureau of Standards NBS-Spec. Publ.-594, Colorado, September 1980), p. 217 .

28. R. E. MacFarlane, R. J. Barrett, D. W. Muir, and R. M. Boicourt, "The NJOY Nuclear Data Processing System: User's Manual," Los Alamos Scientific Laboratory report LA-7584-M (ENDF-272) (December 1978).

29. L. D. McIsaac, T. D. Baker, J. F. Krupa, R. E. La Pointe, D. H. Meikrantz, and N. C. Schroeder, "Study of Bidentate Compounds for Separation of Actinides from Commercial LWR Reprocessing Wastes," Idaho National Engineering Laboratory report ICP-1180 (February 1979).

30. D. R. Johnson and J. A. Stone, "Light Water Reactor Fuel Reprocessing: Dissolution Studies of Voloxidized and Nonvoloxidized Fuel," Savannah River Laboratory report DP-i520 (April 1980).

31. A. E. Norris, "H. B. Robinson-2 Spent-Fuel Isotopics," Los Alamos National Laboratory memorandum CNC-7-81-304 to W. B. Wilson, November 19, 1981 .

32. T. C. Gorrell, "Transmutation of Waste Actinides in Thermal Reactors," Savannah River Laboratory report DP-1496 (November 1978).

33. American Society for Testing and Materials, "Standard Test Method for Atom Percent Fission in Uranium and Plutonium Fuel (Neodymium-148 Method)," 1974 Annual Book of ASTM Standards (American Society for Testing and Materials, Philadelphia, Pennsylvania, 1974), p. 721.

34. R. Sher and C. Beck, "Fission Energy Release for 16 Fissioning Nuclides," Electric Power Research Institute report NP-1771 (March 1981).

35. T. J. Trapp, Jr., "The Effects of the Depletion and Buildup of Fissile Nuclides and of $238_{\mathrm{U}}$ Fast Fisgions on Fission Product Decay Power," Ph.D. Thesis, Oregon State University, Oregon State University report OSU-NE7806 (July 1978). 
36. S. J. Dagbjartsson, B. A. Murdock, D. E. Owen, and P. E. MacDonald, "Axial Gas Flow in Irradiated PWR Fuel Rods," Idaho National Engineering Laboratory report TREE-NUREG-1158 (September 1977), as amended by the authors to include the omitted table. 